Geosci. Model Dev. Discuss., 4, 65-136, 2011

www.geosci-model-dev-discuss.net/4/65/2011/

doi:10.5194/gmdd-4-65-2011

(c) Author(s) 2011. CC Attribution 3.0 License.

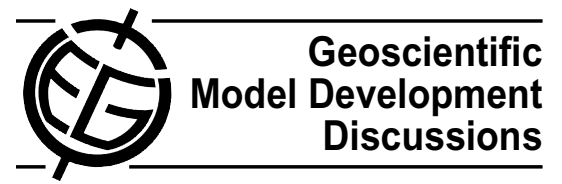

GMDD

4, 65-136, 2011

\title{
A two-layer flow model to represent ice-ocean interactions beneath Antarctic ice shelves
}

V. Lee ${ }^{1}$, A. J. Payne ${ }^{1}$, and J. M. Gregory ${ }^{2}$

${ }^{1}$ Bristol Glaciology Centre, School of Geographical Science, University of Bristol, University Road, Bristol, BS8 1SS, UK

${ }^{2}$ Department of Meterology, University of Reading, P.O. Box 243, Earley Gate, Reading, RG6 6BB, UK

Received: 17 December 2010 - Accepted: 2 January 2011 - Published: 14 January 2011

Correspondence to: V. Lee (v.lee@ bristol.ac.uk)

Published by Copernicus Publications on behalf of the European Geosciences Union.

A two-layer flow model to represent ice-ocean interactions

V. Lee et al.

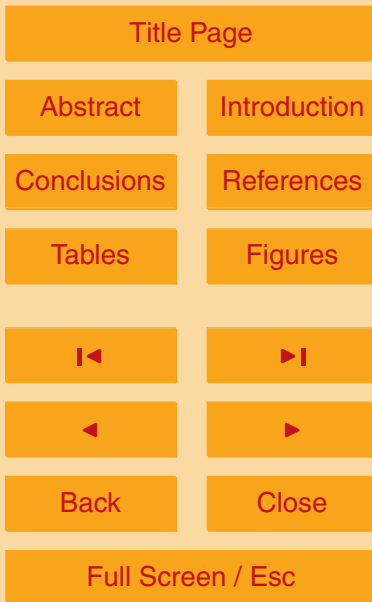

Printer-friendly Version

Interactive Discussion 


\section{Abstract}

We develop a two-dimensional two-layer flow model that can calculate melt rates beneath ice shelves from ocean temperature and salinity fields at the shelf front. The cavity motion is split into two layers where the upper plume layer represents buoy5 ant meltwater-rich water rising along the underside of the ice to the shelf front, while the lower layer represents the ambient water connected to the open ocean circulating beneath the plume. Conservation of momentum has been reduced to a frictional geostrophic balance, which when linearized provides algebraic equations for the plume velocity. The turbulent exchange of heat and salt between the two layers is modelled through an entrainment rate which is directed into the faster flowing layer.

The numerical model is tested using an idealized geometry based on the dimensions of Pine Island Ice Shelf. We find that the spatial distribution of melt rates is fairly robust. The rates are at least 2.5 times higher than the mean in fast flowing regions corresponding to the steepest section of the underside of the ice shelf close to the grounding line and to the converged geostrophic flow along the rigid lateral boundary. Precise values depend on a combination of entrainment and plume drag coefficients. The flow of the ambient is slow and the spread of ocean scalar properties is dominated by diffusion.

\section{Introduction}

20 Observations during the 1990s suggest that the margins of Antarctic Ice Sheet, where grounded ice streams and glaciers terminating in the oceans form floating ice shelves, are the key to understanding sea level rise contributions (Zwally et al., 2005). Analysis of satellite data show that the ice shelves in the Amundsen Sea sector of West Antarctica are thinning due to basal melting (Shepherd et al., 2004) and the ice streams that feed these shelves are also thinning (Shepherd et al., 2002). The largest of the ice streams, Pine Island Glacier, is also accelerating (Joughin et al., 2003), its grounding

\section{GMDD}

4, 65-136, 2011

\section{A two-layer flow model to represent ice-ocean interactions}

V. Lee et al.

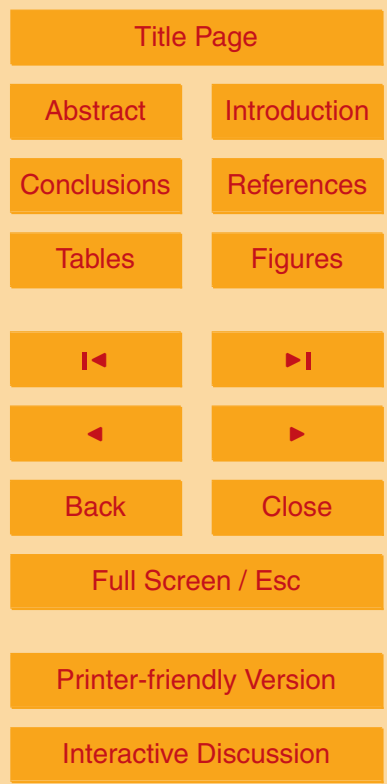


line, where grounded and floating ice meet, is retreating inland (Rignot, 1998; Rignot et al., 2002) and thinning is accelerating and spreading into its tributaries (Wingham et al., 2009). It is believed that relatively warm ocean water, probably Circumpolar Deep Water (CDW), enters the cavity beneath the ice shelves and increases basal 5 melting. Unsteady changes in melt rates, which are not balanced by discharge from inland, thin the shelves. This weakens the contact between the ice and bedrock near the grounding line altering the dynamics of ice stream. The ice stream experiences local acceleration across the grounding line which is transmitted far inland. This hypothesis is supported by both model results (Payne et al., 2004) and recent ground-based ob10 servations of Pine Island Glacier (Scott et al., 2009). Observed thinning is not confined to the Amundsen Sea sector but also includes other glaciers that feed ice shelves in West Antarctica, Antarctic Peninsula and East Antarctica, which supports the idea of a common external source (Pritchard et al., 2009).

The extent to which this dynamic thinning caused by ocean driven melting could drain 15 the Antarctic Ice Sheet is unknown. Most of the bedrock beneath the West Antarctic Ice Sheet (WAIS) is below sea level which may mean that it is susceptible to marine ice sheet instability where the bedrock slopes upward towards the margin. Theory suggests that if the grounding line were to retreat slightly, due to rapid thinning of an adjacent ice shelf, say, then the outward flux of ice across the grounding line would increase (Weertman, 1974; Mercer, 1978; Schoof, 2007). If the bedrock is sloping upward towards the ocean then the retreat would continue irreversibly as outward flux increases with water depth until the bedrock is reversed or stabilized by other ice dynamics. Bamber et al. (2009) estimated that collapse of WAIS due to this instability would lead to a global, eustatic sea level rise contribution of about $3.3 \mathrm{~m}$. While total collapse is contentious, Jenkins et al. (2010) have speculated that Pine Island Glacier may have experienced unstable retreat based on their observations of bedrock beneath the ice shelf.

Uncertainty also exists about the size and duration of ocean forcing required to generate high basal melt rates capable of triggering and sustaining thinning of grounded

\section{GMDD}

4, 65-136, 2011

\section{A two-layer flow model to represent ice-ocean interactions}

V. Lee et al.

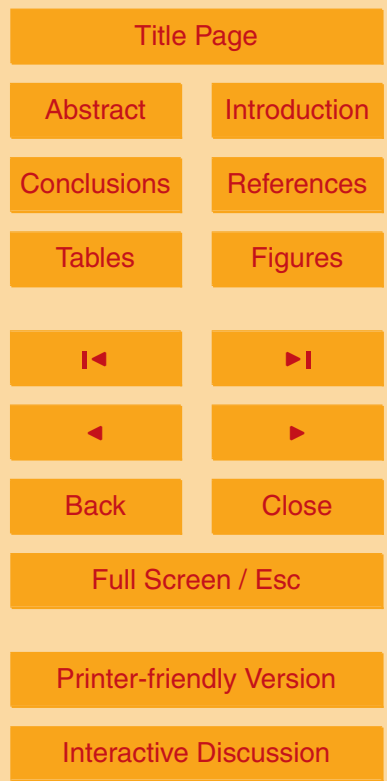


ice streams. Regional ocean modelling of the Amundsen Sea by Thoma et al. (2008) showed that changes in the circulation due to changes in wind forcing in the late 1980s and early 1990s caused warm CDW to reach Pine Island Ice Shelf, which may have triggered the observed thinning in the 1990s. It also showed that there were small 5 seasonal influxes of CDW onto the continental shelf which may be a source of more sustained warming if it could be linked to the general warming of the Southern Ocean away from the continental shelf (Gille, 2002).

Developing an ice sheet model for the whole of Antarctica that captures processes at its margins is crucial for the assessment of future sea level rise. Higher order 10 stress balance models are required to simulate ice streams, while grounding line migration requires high resolution around the line and other specialized treatment such as parametrization of its sub-grid scale position. Also, ocean forcing at the ice shelf front must be converted into basal melt rates, which are used as a boundary condition for the ice sheet model.

15 A number of models of varying levels of complexity can predict basal melt rates. Three-dimensional oceanic general circulation models (OGCM), which have been modified for use beneath floating ice shelves, have modelled ice shelf-ocean interactions using detailed circulation in cavities both with idealized geometries (Determann and Gerdes, 1994; Holland and Jenkins, 2001; Holland et al., 2008; Losch, 2008; Little et al., 2009) and with more realistic geometries (Grosfeld et al., 1997; Gerdes et al., 1999; Williams et al., 1998, 2001). OGCMs have been successfully coupled to ice shelf models to represent interactions beneath individual shelves (Grosfeld and Sandhäger, 2004; Lange et al., 2005). However, three-dimensional ocean models are presently computationally too expensive to model several ice shelves simultaneously. Losch (2008) did attempt a global run of his model, but found that melt rates were overestimated due to the parametrization behaving poorly on the coarse grid. At the other end of the complexity spectrum are parametrizations (Beckmann and Goosse, 2003; Hattermann and Levermann, 2010) and a box model (Olbers and Hellmer, 2010), which can be easily incorporated into coupled global OGCMs and ice sheet models. They are

GMDD

4, 65-136, 2011

\section{A two-layer flow model to represent ice-ocean interactions}

V. Lee et al.

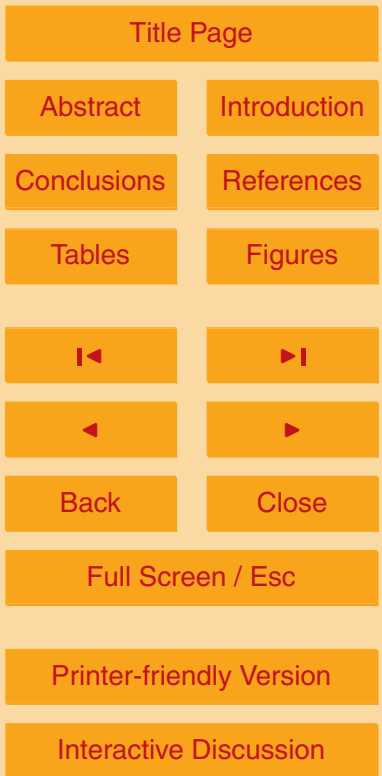

Interactive Discussion 
useful particularly for simulating the freshening of surface waters and the formation of high salinity shelf water around shelves, but cannot provide a spatial pattern for melting and freezing.

This leaves two-dimensional models; those that use a vertical slice along the main 5 axis of flow (Hellmer and Olbers, 1989) or reduced-gravity plume models, which calculate variation in the horizontal directions (Holland and Feltham, 2006; Payne et al., 2007), both of which predict high melt rates near the grounding line as observed by Rignot (1998) for Pine Island. The former can capture the overturning circulation and when coupled to a one-dimensional ice shelf model reveal strong feedback between the ice 10 shelf topography and melt rates (Walker and Holland, 2007). The latter includes Coriolis force and captures lateral effects of undulations in topography. However, plume models assume that the ocean water beneath the melt water at the base of the ice shelf is stationary so that the passage of warm ocean water towards the grounding line cannot be simulated properly.

15 We have developed a two-layer cavity model based on the reduced-gravity models. The upper layer represents the buoyant, meltwater-rich plume and the other represents the circulating ambient ocean water. The active ambient layer allows open ocean properties in front of the ice shelf to be advected around the cavity. The flow within the cavity is governed by a system of vertically integrated equations where Boussinesq and hydrostatic approximations have been applied. We employ the rigid lid streamfunction method to calculate a vertically averaged cavity velocity that satisfies continuity. Once the plume flow is known the ambient flow is simply the residual motion between that of the cavity and the plume. The transport of ocean properties around the cavity is described by advection-diffusion equations with Dirichlet boundary conditions beneath the ice shelf front expressing conservation of heat and salt in the ambient. Interactions between the layers are parametrized through an entrainment rate, which depends on the relative velocities, thicknesses and densities of the layers and can be positive or negative. The main advantage of this model is that it provides spatial patterns of basal melt rates that includes both the effects of the geometry of the cavity beneath an ice

\section{GMDD}

4, 65-136, 2011

\section{A two-layer flow model to represent ice-ocean interactions}

V. Lee et al.

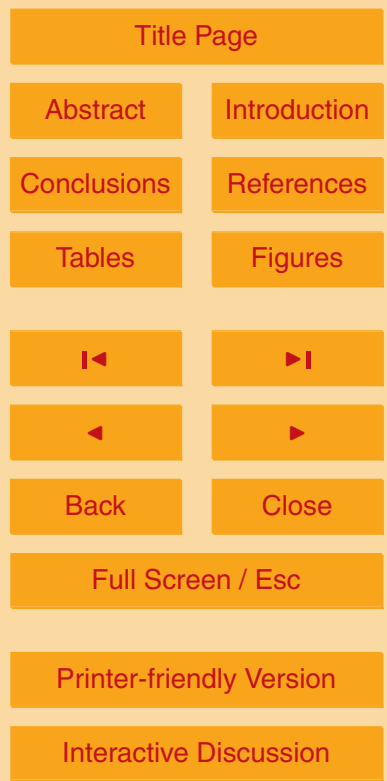


shelf and changes in surrounding ocean properties at lower computational cost than OGCMs. Potential disadvantages are that it may struggle to calculate flow over steep topography and will break down if the plume separates from the underside of the shelf.

Details of the model description are given in Sect. 2 followed by the numerical imple5 mentation in Sect. 3. Section 4 sets up a test case using an idealized geometry based on Pine Island Bay. Results, in Sect. 5, of a standard model run are compared with a reduce-gravity plume model followed by sensitivity analysis of poorly constrained flow parameters. Finally, we draw some conclusions and discuss the implications of using our model to represent ice-shelf ocean interactions at the margins of an Antarctica Ice 10 Sheet model.

\section{Model description}

We describe the flow within the cavity beneath an ice-shelf using a simple two-layer model. The model set up is shown in Fig. 1 as a vertical slice along the shelf's direction of flow. A cavity of thickness $H$ is bounded by the Cartesian surfaces $z=-B(x, y)$ and $15 Z=-h(x, y)$ denoting the underside of the shelf and the bedrock, respectively, where $z$ points up and $z=0$ is sea level. Meltwater produced beneath grounded ice streams enters the cavity across the grounding line to form buoyant plumes. These plumes travel upwards along the underside of the shelf entraining ambient ocean water and melting or freezing the base of the shelf at rates of $\dot{e}$ and $\dot{m}$, respectively, as they head towards the front. They are represented as a single layer, referred to as the plume, which is separated from a layer of ambient ocean water by a movable interface located at $z=-I(x, y, t)$.

\subsection{Cavity equations}

The two-dimensional governing equations for the layers are derived from threedimensional equations for the whole cavity. The motion of the cavity is described by

\section{GMDD}

4, 65-136, 2011

\section{A two-layer flow model to represent ice-ocean interactions}

V. Lee et al.

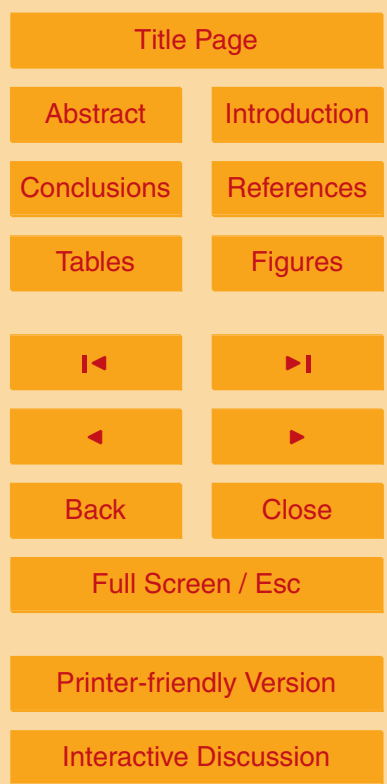


the following Boussinesq equations for the conservation of horizontal momentum, hydrostatic pressure, continuity, conservation of heat and salt, and an equation of state:

$f \boldsymbol{k} \times \boldsymbol{u}=-\frac{1}{\rho_{0}} \nabla p-c_{\mathrm{D}} \boldsymbol{u}$,

$\frac{\partial p}{\partial z}=-g \rho$

${ }_{5} \nabla \cdot \boldsymbol{u}+\frac{\partial w}{\partial z}=0$

$\frac{\partial T}{\partial t}+\boldsymbol{u} \cdot \nabla T+w \frac{\partial T}{\partial z}=K_{\mathrm{h} T} \nabla^{2} T+K_{\mathrm{v} T} \frac{\partial^{2} T}{\partial z^{2}}$

$\frac{\partial S}{\partial t}+\boldsymbol{u} \cdot \nabla S+w \frac{\partial S}{\partial z}=K_{\mathrm{h} S} \nabla^{2} S+K_{\mathrm{v} S} \frac{\partial^{2} S}{\partial z^{2}}$

$\rho=\rho_{0}\left(1+\beta_{S}\left(S-S_{0}\right)-\beta_{\top}\left(T-T_{0}\right)\right)$,

where $\boldsymbol{k}$ is the unit vector in vertical direction and $\nabla$ is the horizontal gradient operator.

cavity variables are $u=(u, v)$ re velocity, $p$ as pressure, $\rho$ as density, $T$ as potential temperature and $S$ as salinity. The parameter $f$ is the Coriolis parameter, $\rho_{0}$ is the reference density of seawater, $c_{\mathrm{D}}$ is constant drag coefficient, $g$ is acceleration due to gravity and $K_{\mathrm{h}}$ and $K_{\mathrm{v}}$ are horizontal and vertical diffusivities. Also, we use a linearized equation of state where $\beta_{\mathrm{T}}$ and $\beta_{S}$ are the coefficients of temperature and salinity and $T_{0}$ and $S_{0}$ are the reference values. Along the solid boundaries of the cavity we impose a no-normal flow condition

$\boldsymbol{u} \cdot \boldsymbol{n}=0$,

and no-normal temperature and salinity gradients, $\partial T / \partial n=0$ and $\partial S / \partial n=0$, where $n$ is the normal to the boundary. Along a section of the grounding line where discharged
GMDD

4, 65-136, 2011

\section{A two-layer flow model to represent ice-ocean interactions}

V. Lee et al.

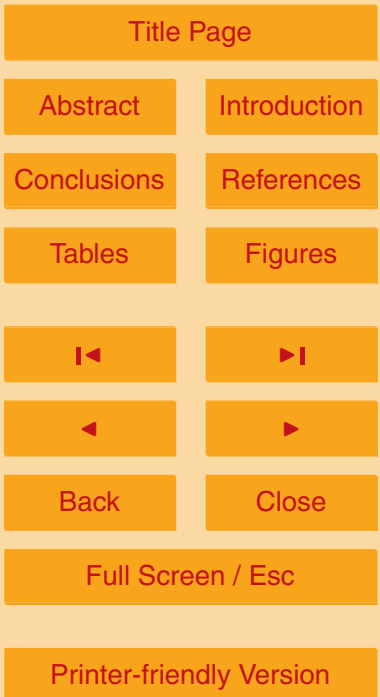

Interactive Discussion 
meltwater from beneath an ice stream enters the cavity we impose a Dirichlet boundary condition where temperature, salinity and meltwater depth are prescribed. We refer to this condition as the glacial inflow even though we assume that the discharge has negligible momentum flux and the no-normal flow condition is applied. On the boundary 5 beneath the ice shelf front open boundary conditions are applied.

We have assumed that conservation of horizontal momentum reduces to a frictional geostrophic balance, Eq. (1), where the material derivative, i.e. acceleration, has been neglected and friction is represented by a linear drag law with constant drag coefficient $c_{\mathrm{D}}$ (Rayleigh friction). The assumption of geostrophic balance is based on ob10 Ice Shelf using a reduced gravity model (Payne et al., 2007) and in idealized cavities
using a three-dimensional ocean circulation model (Holland et al., 2008). The inclusion of Rayleigh friction is necessary for the governing equations to be well posed with respect to the boundaries conditions (Samelson and Vallis, 1997; Salmon, 1998; Edwards et al., 1998). Without it imposing no-normal flow conditions results in pressure discontinuities and loss of differentiability at the lateral boundaries. Also, the choice of a linear drag law is convenient because it allows a relatively simple vorticity equation to be derived from which the streamfunction can be calculated. This would not be possible with a quadratic drag law. It should be noted that the linear drag law is just a first-order approximation for frictional forces and only really holds for non turbulent flow. While we would argue a posteriori that the cavity flow, averaged over its depth, is slow, we cannot justify its use for the flow of the meltwater along the underside of the shelf. A preliminary model which employed a linear drag law for meltwater flow produced basal melt rates that were relatively insensitive to flow parameters and were much too low compared to observations. The model presented here uses a linear drag law for vertically integrated cavity flow and a quadratic one for meltwater flow. The attraction of using a frictional geostrophic balance for the meltwater flow is that its components form two simultaneous equations for the unknown horizontal velocity which can be readily solved if the pressure field is known.

\section{GMDD}

4, 65-136, 2011

\section{A two-layer flow model to represent ice-ocean interactions}

V. Lee et al.

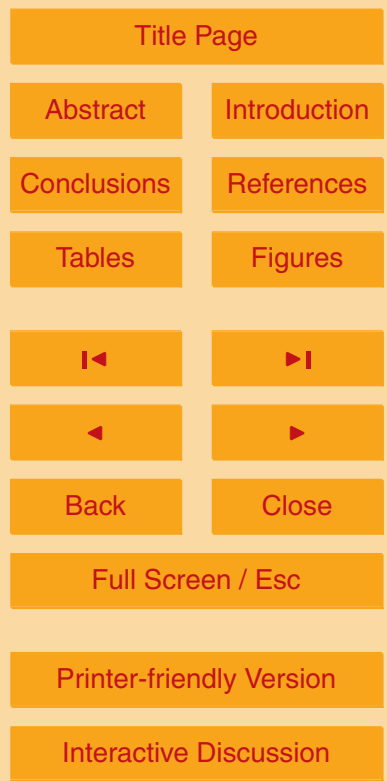


The cavity pressure could be obtained by integrating the hydrostatic Eq. (2) to give

$p=p_{\mathrm{B}}+p_{\mathrm{b}}$

where $p_{\mathrm{B}}=p(x, y,-B(x, y))$ is the pressure at the base of the ice shelf and $p_{\mathrm{b}}$ is the baroclinic pressure given by

${ }_{5} p_{\mathrm{b}}=g \int_{z}^{-B} \rho d z$.

However, $p_{\mathrm{B}}$ is unknown. In ocean modelling surface pressure is removed using the rigid lid streamfunction method which we employ here.

\subsection{Rigid lid streamfunction method}

In order to proceed we must make the assumption that the volume flux of meltwater across the base of the ice shelf can be neglected. This means that the plume layer can only grow by entraining ocean water and that the effects of melting and freezing can only be felt through the vertical heat and salt fluxes at the ice-cavity interface. This is justified for Pine Island, at least, because the mean entrainment rate calculated using a reduced gravity model where this assumption has not been made (Payne et al., 2007)

was just over 50 times larger than the mean melt rate. Now we can ensure that the vertically integrated cavity flow is non-divergent and the streamfunction can be defined.

The vertically averaged momentum equation is obtained by substituting the expression for pressure, Eq. (8), into Eq. (1) to give

$f \boldsymbol{k} \times \overline{\boldsymbol{u}}=-\frac{1}{\rho_{0}} \nabla p_{\mathrm{B}}-\frac{1}{\rho_{0}} \overline{\nabla p_{\mathrm{b}}}-c_{\mathrm{D}} \overline{\boldsymbol{u}}$,

\section{GMDD}

4, 65-136, 2011

\section{A two-layer flow model to represent ice-ocean interactions}

V. Lee et al.

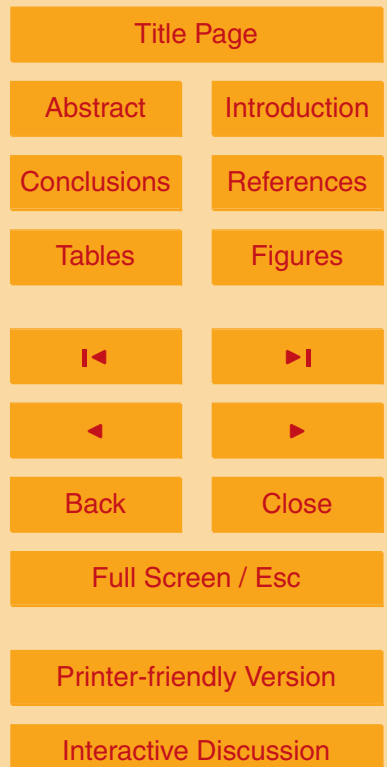

Interactive Discussion 
function, $\phi$,

$\bar{\phi}(x, y, t)=\frac{1}{H} \int_{-h}^{-B} \phi(x, y, z, t) d z$.

Note that the pressure at the base of the ice shelf is independent of depth.

Obtaining vertically integrated continuity from Eq. (3) requires some manipulation. 5 The Leibniz integral rule is used to interchange derivatives and the definite integration with variable limits. Then no-normal flow conditions at the base of the ice shelf and the bedrock in the following form

$w_{\mathrm{B}}=-\boldsymbol{u}_{\mathrm{B}} \cdot \nabla B \quad$ on $z=-B$,

$w_{\mathrm{h}}=-\boldsymbol{u}_{\mathrm{h}} \cdot \nabla h \quad$ on $z=-h$,

10 where the subscript denotes the surface on which the variable is evaluated, are applied. The resulting equation,

$\nabla \cdot(H \bar{u})=0$,

is non-divergent. It is possible to satisfy the above equation using a single arbitrary function. Let such a function, known as the streamfunction, be defined by

${ }_{15} \overline{\boldsymbol{u}}=\boldsymbol{k} \times \frac{1}{H} \nabla \psi$.

Clearly, from this definition the vertically averaged velocity can be determined once the streamfunction has been found. Its value is found by solving the streamfunctionvorticity equation which is derived next.

Let the vorticity, $\zeta=\zeta(x, y, t) k$, be defined as

\section{A two-layer flow model to represent ice-ocean interactions}

V. Lee et al.

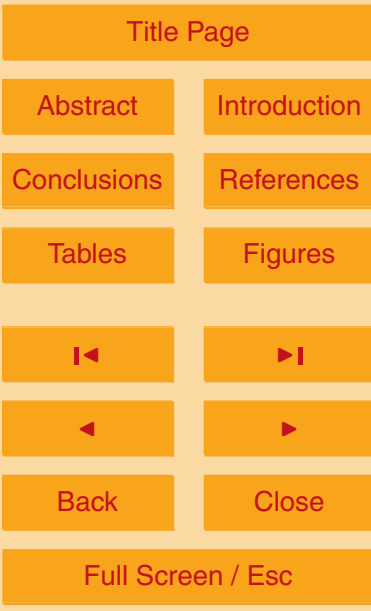

Printer-friendly Version 
Its governing equation is derived by taking the curl of the vertically averaged moment Eq. (10) and applying the vector calculus identity $\nabla \times(X \times Y)=X(\nabla . Y)-Y(\nabla . X)+(Y . \nabla) X-(X . \nabla) Y$ for any two vectors $X$ and $Y$. At this point the term involving the pressure at the base of the ice shelf conveniently 5 drops out because the curl of the gradient of a scalar is zero. The resulting vorticity equation is as follows

$\zeta=-\frac{f}{c_{\mathrm{D}}} \nabla \cdot \overline{\boldsymbol{u}}-\frac{1}{\rho_{0} c_{\mathrm{D}}} \boldsymbol{k} \cdot \nabla \times \overline{\nabla p_{\mathrm{b}}}$

A relationship between the streamfunction and the vorticity is found by substituting Eq. (15) into Eq. (16) to give

$10 \quad \nabla \cdot\left(\frac{1}{H} \nabla \psi\right)=\zeta$.

Substituting the above expression and the streamfunction definition, Eq. (15), into the vorticity Eq. (17) we obtain the streamfunction-vorticity equation

$\nabla \cdot\left(\frac{1}{H} \nabla \psi\right)-\frac{f}{c_{\mathrm{D}}} \mathcal{J}\left(\frac{1}{H}, \psi\right)=-\frac{1}{\rho_{0} c_{\mathrm{D}}} k \cdot \nabla \times \overline{\nabla p_{\mathrm{b}}}$,

where $\mathcal{J}$ is the determinant of the Jacobian given by

$15 \mathcal{J}(X, Y)=\frac{\partial X}{\partial x} \frac{\partial Y}{\partial y}-\frac{\partial X}{\partial y} \frac{\partial Y}{\partial x}$.

The accompanying boundary condition for $\psi$ on the solid lateral boundaries is found by substituting Eq. (15) into the no-normal flow condition. Rearranging the order of the dot and vector products and multiplying through by $H$, the condition becomes

$\nabla \psi \cdot t=0$,

20 where $\boldsymbol{t}=\boldsymbol{n} \times \boldsymbol{k}$ is the unit vector tangential to the boundary. We obtain a simple boundary condition for $\psi$ by integrating the above along the boundary to give

$\psi=\psi_{g}$

GMDD

4, 65-136, 2011

\section{A two-layer flow model to represent ice-ocean interactions}

V. Lee et al.

\section{Title Page}

\section{Abstract}

Introduction

Conclusions

Tables

References

Figures

14

4

Back

Full Screen / Esc

Printer-friendly Version

Interactive Discussion 
where $\psi_{g}$ is a constant. If the cavity is simply connected, i.e. free of islands, than $\psi_{g}$ can take any value. The streamfunction-vorticity equation can be solved to give the streamfunction once the baroclinic pressure field, $\rho_{\mathrm{b}}$, has been determined.

\subsection{Two-layer flow}

5 We have assumed that the cavity beneath the ice shelf can be divided into two layers; the plume at the top consisting of relatively fresh water with density $\rho_{\mathrm{p}}$ and depth $D_{\mathrm{p}}$ and the other the ambient with density $\rho_{\mathrm{a}}$ and depth $D_{\mathrm{a}}$. We also assume that pressure is continuous across the interface between the layers and that density within each layer is independent of depth. This allows us to vertically integrate the cavity's density field and the vertically averaged baroclinic pressure gradient $\overline{\nabla p_{\mathrm{b}}}$ can be written as

$\overline{\nabla p_{\mathrm{b}}}=\frac{g}{H} \int_{-h}^{-B} \nabla \int_{z}^{-B} \rho d z d z=\frac{g}{H} \int_{-l}^{-B} \nabla\left(\rho_{\mathrm{p}} \int_{z}^{-B} d z\right) d z+\frac{g}{H} \int_{-h}^{-l}\left[\nabla\left(\rho_{\mathrm{p}} \int_{-l}^{-B} d z\right)+\nabla\left(\rho_{\mathrm{a}} \int_{z}^{-l} d z\right)\right] d z \overline{\nabla p_{\mathrm{b}}}$

$-g \rho_{\mathrm{p}} \nabla B+\frac{g}{H}\left(\frac{D_{\mathrm{p}}^{2}}{2} \nabla \rho_{\mathrm{p}}+D_{\mathrm{p}} D_{\mathrm{a}} \nabla \rho_{\mathrm{p}}-D_{\mathrm{a}}\left(\rho_{\mathrm{a}}-\rho_{\mathrm{p}}\right) \nabla I+\frac{D_{\mathrm{a}}^{2}}{2} \nabla \rho_{\mathrm{a}}\right)$,

using $D_{\mathrm{p}}=-B+l$ and $D_{\mathrm{a}}=-l+h$. The first term on the right hand side of Eq. (23) is a force due to the slope of the underside of the ice shelf. It appears because the

upper limit of the integration is a function of horizontal position. The baroclinic torque in Eqs. (17) and (19) can be expressed as

$\boldsymbol{k} \cdot \nabla \times \overline{\nabla p_{\mathrm{b}}}=-g \mathcal{J}\left(\rho_{\mathrm{p}}, B\right)+\frac{g D_{\mathrm{p}}}{2}\left(D_{\mathrm{p}}+2 D_{\mathrm{a}}\right) \mathcal{J}\left(\frac{1}{H}, \rho_{\mathrm{p}}\right)-g D_{\mathrm{a}}\left(\rho_{\mathrm{a}}-\rho_{\mathrm{p}}\right) \mathcal{J}\left(\frac{1}{H}, I\right)+\frac{g}{H}\left[D_{\mathrm{p}} \mathcal{J}\left(H, \rho_{\mathrm{p}}\right)\right.$

$\left.+\frac{g D_{\mathrm{a}}^{2}}{2} \mathcal{J}\left(\frac{1}{H}, \rho_{\mathrm{a}}\right)+D_{\mathrm{a}} \mathcal{J}\left(D_{\mathrm{p}}, \rho_{\mathrm{p}}\right)-\left(\rho_{\mathrm{a}}-\rho_{\mathrm{p}}\right) \mathcal{J}\left(D_{\mathrm{a}}, I\right)+D_{\mathrm{a}} \mathcal{J}\left(I, \rho_{\mathrm{a}}-\rho_{\mathrm{p}}\right)+D_{\mathrm{a}} \mathcal{J}\left(D_{\mathrm{a}}, \rho_{\mathrm{a}}\right)\right]$,

4, 65-136, 2011

\section{A two-layer flow model to represent ice-ocean interactions}

V. Lee et al.

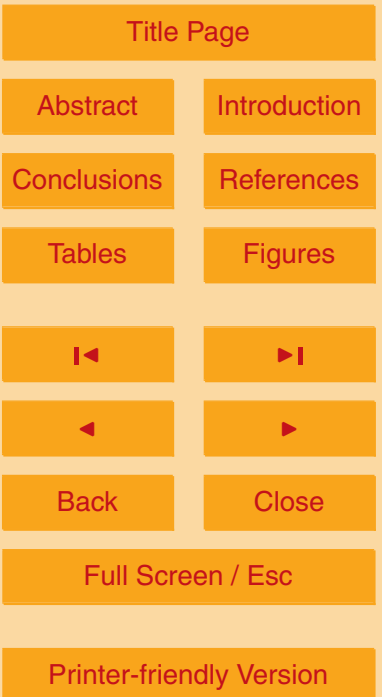

where $\mathcal{J}$ is defined by Eq. (20).

Next we turn our attention to the motion in the individual layers. 


\subsubsection{The plume}

We assume that the plume is the most active part of the cavity while occupying only a small proportion of the cavity's total thickness. Plume velocities, even averaged over the layer, are unlikely to be small, which means that we cannot justify the use of a linear

5 drag law for the plume. We use a quadratic drag law instead, which is more appropriate for fast flows. A momentum equation for the plume is readily obtained by substituting Eq. (8) into Eq. (1), vertically averaging from the plume-ambient interface to the underside of the ice shelf and replacing the linear drag term with a quadratic one to give

$f \boldsymbol{k} \times \overline{\boldsymbol{u}}_{\mathrm{p}}=-\frac{1}{\rho_{0}} \nabla p_{\mathrm{B}}+\frac{g \rho_{\mathrm{p}}}{\rho_{0}} \nabla B-\frac{g D_{\mathrm{p}}}{2 \rho_{0}} \nabla \rho_{\mathrm{p}}-\frac{c_{\mathrm{p}}\left|\overline{\boldsymbol{u}}_{\mathrm{p}}\right|}{D_{\mathrm{p}}} \overline{\boldsymbol{u}}_{\mathrm{p}}$

10 where $c_{\mathrm{p}}$ is a dimensionless drag coefficient and the plume velocity, $\overline{\boldsymbol{u}}_{\mathrm{p}}$, is defined as

$\bar{u}_{\mathrm{p}}(x, y, t)=\frac{1}{D_{\mathrm{p}}} \int_{-1}^{-B} \boldsymbol{u}(x, y, z, t) d z$.

The advantage of the quadratic law is that the drag term is an inverse function of plume thickness, which better represents turbulent drag exerted by the rough underside of the ice shelf than the constant coefficient of the linear law.

The pressure gradient on the underside of the ice shelf is replaced by an expression in terms of vertically averaged cavity velocity found by rearranging Eq. (10) and using Eq. (23). The plume momentum equation is written as

$f \boldsymbol{k} \times \overline{\boldsymbol{u}}_{\mathrm{p}}+\frac{c_{\mathrm{p}}\left|\overline{\boldsymbol{u}}_{\mathrm{p}}\right|}{D_{\mathrm{p}}} \overline{\boldsymbol{u}}_{\mathrm{p}}=f \boldsymbol{k} \times \overline{\boldsymbol{u}}+c_{\mathrm{D}} \overline{\boldsymbol{u}}+\frac{g D_{\mathrm{a}}}{\rho_{0} H}\left[\frac{D_{\mathrm{p}}}{2} \nabla \rho_{\mathrm{p}}-\left(\rho_{\mathrm{a}}-\rho_{\mathrm{p}}\right) \nabla /+\frac{D_{\mathrm{a}}}{2} \nabla \rho_{\mathrm{a}}\right]$.

The first two terms on the right hand side are the barotropic forcing and the terms in the square brackets are the forcing due to lateral plume density gradients, buoyancy across the interface and forcing due to lateral ambient density gradients.

GMDD

4, 65-136, 2011

\section{A two-layer flow model to represent ice-ocean interactions}

V. Lee et al.

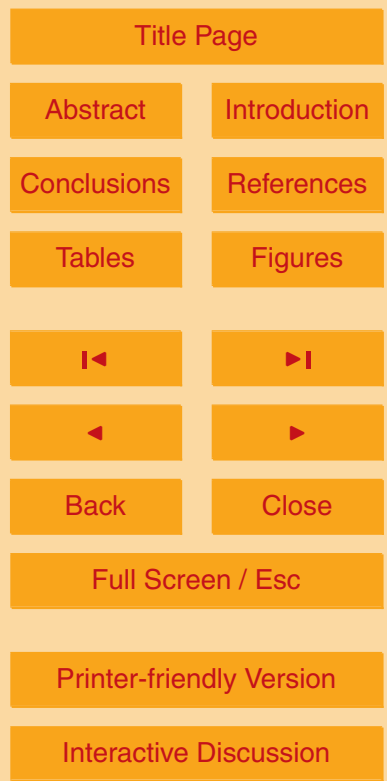

Interactive Discussion 
The nonlinear drag term in Eq. (27) is linearized using the Picard iterative scheme, which approximates the unknown plume speed, $\left|\bar{u}_{\mathrm{p}}\right|$, using the velocity field from the previous iteration. If the system tends to a steady state the error improves. The components of Eq. (27) form a pair of simultaneous equations for the plume velocity which 5 are readily solved to give

$\bar{u}_{\mathrm{p}}=D_{\mathrm{p}}\left(\frac{c_{\mathrm{p}}\left|\bar{u}_{\mathrm{p}}\right| P_{x}+D_{\mathrm{p}} f P_{y}}{D_{\mathrm{p}}^{2} f^{2}+c_{\mathrm{p}}^{2}\left|\bar{u}_{\mathrm{p}}\right|^{2}}\right), \quad \bar{v}_{\mathrm{p}}=-D_{\mathrm{p}}\left(\frac{D_{\mathrm{p}} f P_{x}-c_{\mathrm{p}}\left|\bar{u}_{\mathrm{p}}\right| P_{y}}{D_{\mathrm{p}}^{2} f^{2}+c_{\mathrm{p}}^{2}\left|\bar{u}_{\mathrm{p}}\right|^{2}}\right)$,

where $P=\left(P_{x}, P_{y}\right)$ represents the right hand side of Eq. (27).

The plume-ambient interface is not fixed; ocean water is entrained into the plume as the meltwater travels along the underside of the shelf. Here the time derivative of the interface following the motion of the water, $D(z+l) / D t=w_{l}+\partial I / \partial t+u_{l} . \nabla I$, is equal to the rate of entrainment, $\dot{e}$. This provides the kinematic boundary condition for vertical velocity on the interface

$w_{l}=-\frac{\partial I}{\partial t}-u_{l} \frac{\partial l}{\partial x}-v_{l} \frac{\partial I}{\partial y}+\dot{e} \quad$ on $z=-l$.

By vertically integrating the continuity Eq. (3) between $z=-I$ and $z=-B$ and applying 15 the boundary conditions Eqs. (12) and (29) we derive the following thickness evolution equation for the plume

$\frac{\partial D_{\mathrm{p}}}{\partial t}+\nabla \cdot\left(D_{\mathrm{p}} \bar{u}_{\mathrm{p}}\right)=\dot{e}$

\subsubsection{The ambient}

Let the vertically averaged velocity for the ambient, $\overline{\boldsymbol{u}}_{\mathrm{a}}$, be defined as

GMDD

4, 65-136, 2011

\section{A two-layer flow model to represent ice-ocean interactions}

V. Lee et al.

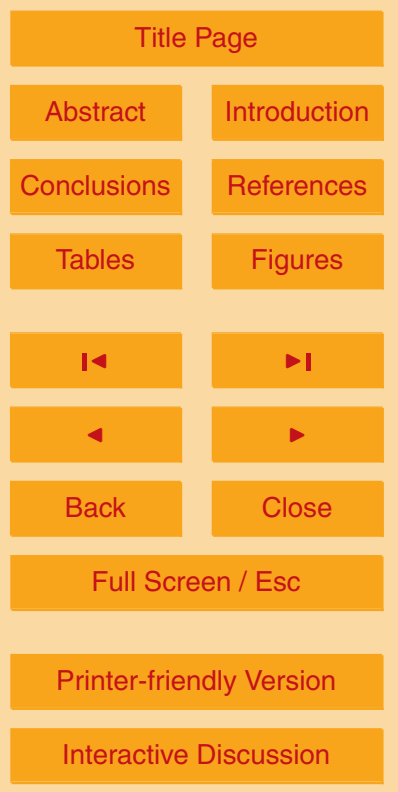


From the definitions of velocity averaged over various depths, the ambient velocity is

$\bar{u}_{\mathrm{a}}=\frac{1}{D_{\mathrm{a}}}\left(H \overline{\boldsymbol{u}}-D_{\mathrm{p}} \overline{\boldsymbol{u}}_{\mathrm{p}}\right)$,

GMDD

which is simply the residual flow once the cavity and plume flows have been found. Similarly, the thickness of the ambient is just

$5 \quad D_{\mathrm{a}}=H-D_{\mathrm{p}}$,

where the plume depth is found by solving Eq. (30).

\subsection{Two-layer scalar properties}

Let the vertically averaged scalar variables in the plume, $\chi_{\mathrm{p}}$, and in the ambient, $\chi_{\mathrm{a}}$, be defined as follows

$\chi_{\mathrm{p}}(x, y, t)=\frac{1}{D_{\mathrm{p}}} \int_{-1}^{-B} \chi(x, y, z, t) d z$

$\chi_{\mathrm{a}}(x, y, t)=\frac{1}{D_{\mathrm{a}}} \int_{-h}^{-l} \chi(x, y, z, t) d z$

where $\chi$ represents either potential temperature, $T$, or salinity, $S$.

The evolution equation for the scalar properties of the plume is found by taking the vertical average of Eqs. (4) and (5) between the base of the ice shelf and the interface

and applying boundary conditions Eqs. (12) and (29). This gives

$\frac{\partial \chi_{\mathrm{p}}}{\partial t}+\bar{u}_{\mathrm{p}} \cdot \nabla \chi_{\mathrm{p}}=K_{\mathrm{h} \chi} \nabla^{2} \chi_{\mathrm{p}}+\frac{\gamma_{\chi}\left|\bar{u}_{\mathrm{p}}\right|}{D_{\mathrm{p}}}\left(\chi_{\mathrm{B}}-\chi_{\mathrm{p}}\right)+\frac{\dot{e}}{D_{\mathrm{p}}}\left(\chi_{l}-\chi_{\mathrm{p}}\right)$,

\section{A two-layer flow model to represent ice-ocean interactions}

V. Lee et al.

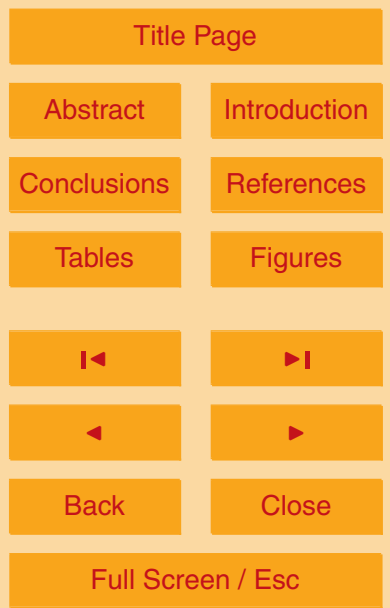

Printer-friendly Version 
where $\chi_{\mathrm{B}}$ and $\chi_{1}$ are the scalar values on the underside of the ice shelf and the interface, respectively. The second term on the right hand side of Eq. (36) represents the scalar fluxes into the ice shelf through the turbulent boundary layer adjacent to the shelf base where $\gamma_{\chi}$ is the turbulent exchange coefficient. The values of $\gamma_{\mathrm{T}}$ and $\gamma_{\mathrm{S}}$ are calculated 5 from Eqs. (15) and (16), respectively, in Holland and Feltham (2006). The entrainment of scalar properties across the plume-ambient interface is represented by the third term, while diffusion across the interface is neglected. The value of the scalar at the interface, $\chi_{l}$, is not known. It is modelled using a depth weighted average of the plume and ambient scalars,

$10 \quad \chi_{I}=\frac{1}{H}\left(D_{\mathrm{p}} \chi_{\mathrm{p}}+D_{\mathrm{a}} \chi_{\mathrm{a}}\right)$

instead.

The scalar equation for the ambient is found similarly by vertically averaging the Eqs. (4) and (5) between the bedrock and the interface and applying boundary conditions Eqs. (29) and (13). If we neglect the effects of geothermal heating then we 15 have

$\frac{\partial \chi_{\mathrm{a}}}{\partial t}+\overline{\boldsymbol{u}}_{\mathrm{a}} \cdot \nabla \chi_{\mathrm{a}}=K_{\mathrm{h} \chi} \nabla^{2} \chi_{\mathrm{a}}+\delta_{D_{\mathrm{p}}} \frac{\gamma_{\chi}\left|\overline{\boldsymbol{u}}_{\mathrm{a}}\right|}{D_{\mathrm{a}}}\left(\chi_{\mathrm{B}}-\chi_{\mathrm{a}}\right)-\frac{\dot{e}}{D_{\mathrm{a}}}\left(\chi_{I}-\chi_{\mathrm{a}}\right)$,

where $\delta_{D_{\mathrm{p}}}$ is defined as

$\delta_{D_{\mathrm{p}}}= \begin{cases}1 & \text { if } D_{\mathrm{p}}=0 \\ 0 & \text { otherwise },\end{cases}$

such that there is an exchange of scalar fluxes between the ambient and the underside of the ice shelf if there is no plume.

The values of the ambient scalar properties beneath the ice shelf front are set by vertically averaging the ocean properties at the opening of the cavity from the bedrock

GMDD

4, 65-136, 2011

\section{A two-layer flow model to represent ice-ocean interactions}

V. Lee et al.

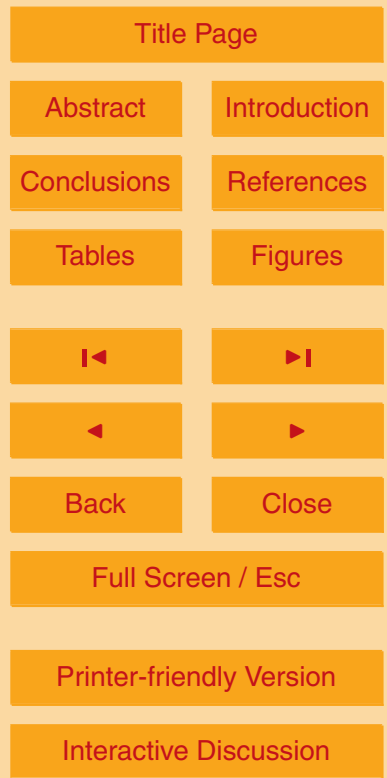


to the plume-ambient interface. The ocean properties could be supplied by an OGCM, but here we model them using mean background profiles given by

$\chi_{o}(z)= \begin{cases}\chi_{s}+\frac{\chi_{s}-\chi_{\mathrm{b}}}{d_{t}} z & \text { if }-d_{t}<z \leq 0 \\ \chi_{\mathrm{b}} & \text { else } z \leq-d_{t} .\end{cases}$

In other words, the properties vary linearly across the thermocline and halocline in the 5 upper $d_{t}$ m of ocean and then remain constant to the sea floor. The values of properties at the surface and bottom of the ocean are given by $\chi_{s}$ and $\chi_{\mathrm{b}}$, respectively.

\subsubsection{Entrainment}

We model the turbulent exchange of meltwater and ocean water across the interface by modifying the approach of Jungclaus and Backhaus (1994) to include detrainment. We assume simply that the faster layer entrains water from the slower one. Our characteristic velocity is the relative velocity of the two layers. The entrainment rate is calculated using Kochergin (1987)'s parametrization

$\dot{e}= \begin{cases}\frac{c_{1}^{2}}{S_{m}}\left(\left|\overline{\boldsymbol{u}}_{\mathrm{p}}-\overline{\boldsymbol{u}}_{\mathrm{a}}\right|^{2}+\frac{g\left(\rho_{\mathrm{a}}-\rho_{\mathrm{p}}\right) D_{\mathrm{p}}}{\rho_{0} S_{m}}\right)^{\frac{1}{2}} & \text { if } D_{\mathrm{p}}>D_{\min } \text { and }\left|\overline{\boldsymbol{u}}_{\mathrm{p}}\right|>\left|\overline{\boldsymbol{u}}_{\mathrm{a}}\right| \\ -\frac{c_{1}^{2}}{S_{m}}\left(\left|\overline{\boldsymbol{u}}_{\mathrm{p}}-\overline{\boldsymbol{u}}_{\mathrm{a}}\right|^{2}+\frac{g\left(\rho_{\mathrm{a}}-\rho_{\mathrm{p}}\right) D_{\mathrm{a}}}{\rho_{0} S_{m}}\right)^{\frac{1}{2}} & \text { if } D_{\mathrm{p}}>D_{\min } \text { and }\left|\overline{\boldsymbol{u}}_{\mathrm{p}}\right|<\left|\overline{\boldsymbol{u}}_{\mathrm{a}}\right| \\ 0 & \text { otherwise, }\end{cases}$

where $c_{1}$ is a constant of proportionality and $S_{m}$ is the turbulent Schmidt number. The

$S_{m}=\frac{R i}{0.725\left(R i+0.186-\sqrt{R i^{2}-0.316 R i+0.0346}\right)}$

where $R i$ is the Richardson number

$R i=\max \left(0.05, \frac{g\left(\rho_{\mathrm{a}}-\rho_{\mathrm{p}}\right) D_{\mathrm{p}}}{\rho_{0}\left|\overline{\boldsymbol{u}}_{\mathrm{p}}-\overline{\boldsymbol{u}}_{\mathrm{a}}\right|^{2}}\right)$

GMDD

4, 65-136, 2011

\section{A two-layer flow model to represent ice-ocean interactions}

V. Lee et al.

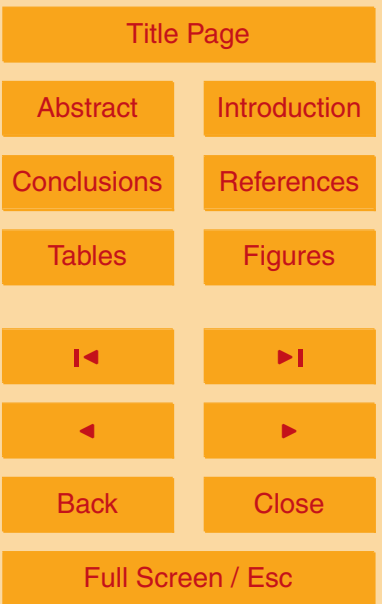

Printer-friendly Version

Interactive Discussion 


\subsubsection{Melting and freezing}

The scalar quantities, $T_{\mathrm{B}}$ and $S_{\mathrm{B}}$, on the underside of the ice shelf and the melt rate, $\dot{m}$, are calculated by solving the set of simultaneous equations from Jenkins and Bombosch (1995) representing the balance of salt and heat fluxes across the base of the ice shelf and the pressure freezing temperature as a linear function of salinity and depth

$\dot{m} S_{\mathrm{B}}=\gamma_{\mathrm{S}}\left|\bar{u}_{\mathrm{p}}\right|\left(S_{\mathrm{p}}-S_{\mathrm{B}}\right)$,

$\dot{m} L+c_{\mathrm{i}} \dot{m}\left(T_{\mathrm{B}}-T_{\mathrm{i}}\right)=c_{0} \gamma_{\mathrm{T}}\left|\overline{\boldsymbol{u}}_{\mathrm{p}}\right|\left(T_{\mathrm{p}}-T_{\mathrm{B}}\right)$,

$T_{\mathrm{B}}=a S_{\mathrm{B}}+b+c B$,

where $L$ is the latent heat of fusion of ice, $c_{\mathrm{i}}$ and $c_{0}$ are heat capacities of ice and 10 plume water, respectively, $T_{\mathrm{i}}$ is the core temperature of the ice shelf and $a, b$ and $c$ are constants.

\section{Numerical method}

To summarize, the vertically integrated cavity flow is described by Eqs. $(15,17,18$, and $24)$, the plume is described by Eqs. $(28,30$, and 36 ) and the ambient is described by 15 Eqs. (32, 33, and 38). We have chosen a numerical approach that is relatively simple to demonstrate that the model works rather than choose one that is highly efficient or of high order accuracy.

The numerical implementation of the our model is based on an earlier code by Holland and Feltham (2006) and Jungclaus and Backhaus (1994) for a transient twodimensional reduced-gravity model where only the plume is active. The main features of the code that are retained are the wetting and drying scheme, plume velocity correction and discretisation of the scalar equations, while we choose to put aside the frazil ice dynamics. The wetting and drying scheme determines the lateral extent of the plume by considering the slope of the plume-ambient interface. This allows plume to

\section{GMDD}

4, 65-136, 2011

\section{A two-layer flow model to represent ice-ocean interactions \\ V. Lee et al.}

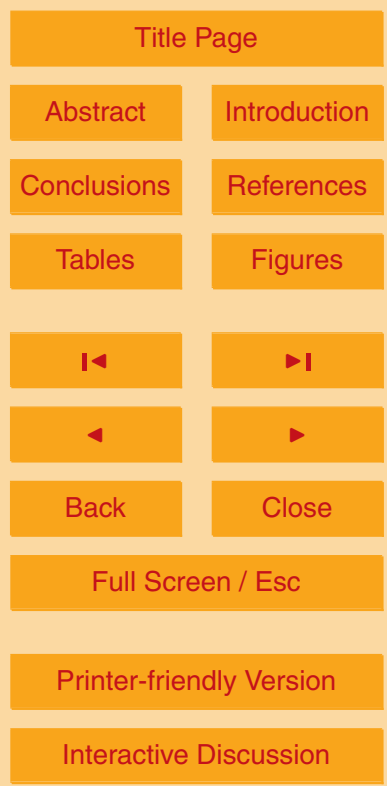


split or merge as it travels along the underside of the ice shelf. Also, the plume velocity need only be calculated in regions where the plume is active. From time to time the plume's flux needs to be corrected to prevent spurious negative plume thicknesses. It is not sufficient to simply reset negative values to zero because it does not prevent the 5 code from becoming unstable. The velocity must be corrected before the thickness equation is solved formally. This involves solving the thickness equation with no source terms and where negative values are detected adjacent velocity points are set to zero.

The main differences between our numerical model and the earlier one are the introduction of the rigid lid method for calculating cavity flow, the replacement of the full 10 momentum equation to calculate plume velocity by the diagnostic Eq. (28) and the introduction of ambient flow calculations. We also replace the first-order explicit timestepping scheme used to solve the plume's thickness equation with an implicit scheme and improve the handling of the open boundary conditions.

\subsection{Spatial discretisation}

15 The variables are arranged on the staggered C-grid (Mesinger and Arakawa, 1976) shown in Fig. 2. Streamfunction and vorticity are located in the centre of scalar cells as well as temperature, salinity and density. An advantage of C-grid is that first derivatives in the along stream direction can be discretised using a central difference one grid cell wide. The discrete form of the $x$ derivative of any scalar, $\phi$, which maps on to the centre of a $u$-cell is denoted as

$\partial_{x}\left(\phi_{i, k}\right)=\frac{\phi_{i+1, k}-\phi_{i, k}}{\Delta x}$,

while the form of the $x$ derivative of the $u$ component of velocity which maps to a scalar point is

$\partial_{x}\left(u_{i, k}\right)=\frac{u_{i, k}-u_{i-1, k}}{\Delta x}$.

25 The form of the $y$ derivatives follows similarly.
GMDD

4, 65-136, 2011

\section{A two-layer flow model to represent ice-ocean interactions}

V. Lee et al.

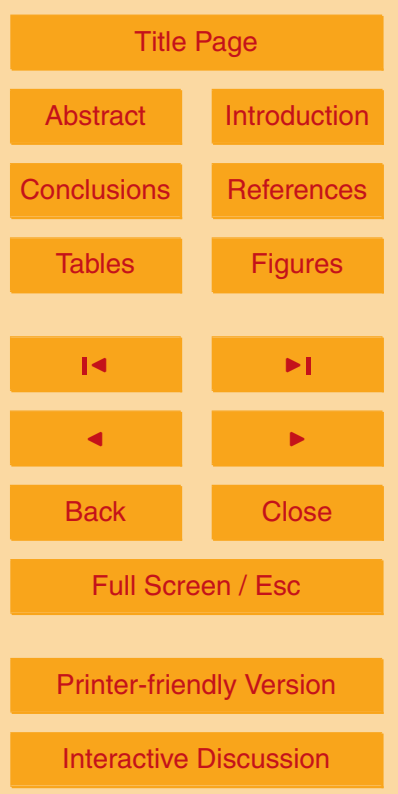


However, the cross stream derivative of a scalar used in the plume velocity Eq. (28) and the streamfunction is not so compact on the C-grid. The discrete form requires a larger stencil

${\overline{\partial_{2 x}\left(\phi_{i, k}\right)}}^{y}={\overline{\phi_{i+1, k}-\phi_{i-1, k}}}_{2 \Delta x}^{y}$,

5 where the mean value denoted by

${\overline{\phi_{i, k}}}^{y}=\frac{\phi_{i, k}+\phi_{i, k+1}}{2}$

is required to map the finite difference on to the $u$-cell. At the lateral boundaries the central difference is replaced by the second-order one-sided difference

$\partial_{2 x}\left(\phi_{L, k}\right)=\frac{-3 \phi_{L, k}+4 \phi_{L+1, k}-\phi_{L+2, k}}{2 \Delta x}$,

10 where $L$ represents the scalar cell adjacent to the lateral boundary. If there are insufficient ocean cells, which could be the case along sections of the grounding line for realistic geometries, to calculate the second-order one-side difference then the first-order one-sided difference is taken. In the case of the streamfunction we know its value on the boundary, $\psi_{g}$, so the first derivative can be approximated using a second-order 15 polynomial fit

$\partial_{2 x}\left(\psi_{L, k}\right)=\frac{-4 \psi_{g}+3 \psi_{L, k}+\psi_{L+1, k}}{3 \Delta x}$.

We also exploit the insulation condition to approximate the derivatives of density adjacent to the grounding line by linearly interpolating the known value of the normal gradient of density on the boundary, which is zero, and central difference across the opposite cell face to give

$\partial_{2 x}\left(\rho_{L, k}\right)=\frac{\rho_{L, k}-\rho_{L+1, k}}{2 \Delta x}$.

\section{GMDD}

4, 65-136, 2011

\section{A two-layer flow model to represent ice-ocean interactions}

V. Lee et al.

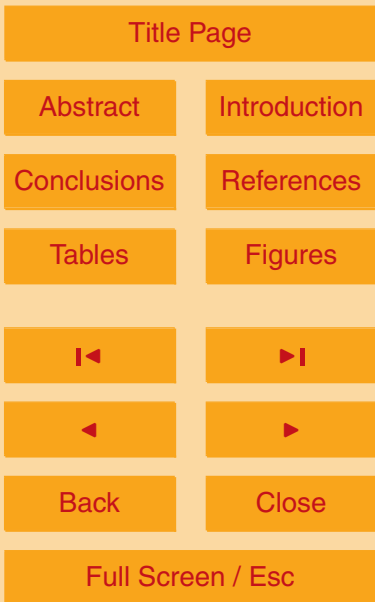

Printer-friendly Version

Interactive Discussion 


\subsection{Initial conditions}

The plume thickness is initialized using a constant value across the whole underside of the ice shelf. Potential temperature and salinity fields are initialized using the background ocean profiles, Eq. (40). In the plume, they are set to profile values at the

5 plume-ambient interface, while in the ambient they are set by vertically averaging the profiles across the layer. The flow field is evolved from rest.

\subsection{Timestepping}

The initialized fields are evolved by solving the discrete linear form of the coupled nonlinear governing equations. Figure 3 provides a brief outline of the numerical scheme 10 during one timestep. The equations for plume thickness and the scalar properties are the only prognostic equations in our model. We describe how these are solved along with the streamfunction calculation in more detail.

\subsubsection{Streamfunction}

We begin each timestep by constructing the baroclinic torque, Eq. (24), using the interface position and thickness and density fields from the previous timestep. The discrete form of Eq. (20) is

$\mathcal{J}\left(X_{i, k}, Y_{i, k}\right)=\partial_{2 x}\left(X_{i, k}\right) \partial_{2 y}\left(Y_{i, k}\right)-\partial_{2 y}\left(X_{i, k}\right) \partial_{2 x}\left(Y_{i, k}\right)$,

where the scalar fields $X$ and $Y$ are mapped on to a scalar cell. We then calculate the streamfunction using an iterative procedure rather than solve the streamfunction-

1. constructing an expression for the vorticity from Eq. (17) using cavity velocity from the previous inner iteration,

2. solving a linear system of equations for the streamfunction from the definition of vorticity in terms of the streamfunction, Eq. (18), 
3. calculating the new cavity velocity from the streamfunction definition, Eq. (15), and

4. testing for convergence using the cavity velocity.

4, 65-136, 2011

The advantages of this method are that the equations are relatively simple to discretise 5 and, as we see, only one matrix factorization need be carried out at the start of any run. The divergence of the cavity velocity in Eq. (17) is readily discretised on the C-grid as follows

$(\nabla \cdot \overline{\boldsymbol{u}})_{i, k}=\partial_{x}\left(\bar{u}_{i, k}\right)+\partial_{y}\left(\bar{v}_{i, k}\right)$.

No special handling of the no-normal flow condition along the rigid lateral boundaries 10 or grounding line is necessary. In the interior of the cavity the elliptical Eq. (18) is discretised using a standard 5-point stencil to give

$A_{E} \psi_{i+1, k}+A_{W} \psi_{i-1, k}+A_{N} \psi_{i, k+1}+A_{S} \psi_{i, k-1}-A_{P} \psi_{i, k}=\zeta_{i, k}$,

where the coefficients are

$A_{E}=\frac{1}{{\overline{H_{i, k}}}^{x} \Delta x^{2}}, \quad A_{W}=\frac{1}{{\overline{H_{i-1, k}}}^{x} \Delta x^{2}}$,

$15 \quad A_{N}=\frac{1}{{\overline{H_{i, k}}}^{y} \Delta y^{2}}, \quad A_{S}=\frac{1}{{\overline{H_{i, k-1}}}^{y} \Delta y^{2}}$,

$A_{P}=A_{E}+A_{W}+A_{N}+A_{S}$.

For cells adjacent to the rigid lateral boundary we apply the Dirichlet boundary condition Eq. (22). We choose to set $\psi_{g}=1$. If the boundary is to the right of a scalar cell, for example, then the stencil becomes

$A_{W} \psi_{i-1, k}+A_{N} \psi_{i, k+1}+A_{S} \psi_{i, k-1}-A_{P} \psi_{i, k}=\zeta_{i, k}-A_{E} \psi_{g}$

\section{A two-layer flow model to represent ice-ocean interactions}

V. Lee et al.

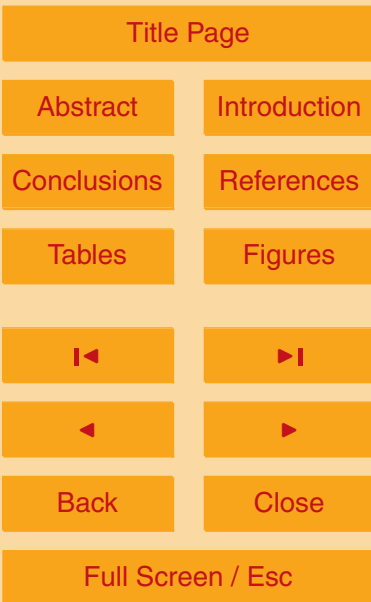

Printer-friendly Version

Interactive Discussion 
where

$A_{E}=\frac{2}{{\overline{H_{i, k}}}^{x} \Delta x^{2}}$

GMDD

4, 65-136, 2011

and ${\overline{H_{i, k}}}^{x} \approx\left(3 H_{i, k}-H_{i-1, k}\right) / 2$ is approximated with a linearly extrapolated value. It is important to note that we cannot treat the boundary as a true grounding line, i.e. $H=0$, 5 because the coefficients will be undefined. For the handling of the open boundary condition at the ice shelf front see Sect. 3.4. All the coefficients are clearly fixed in time, only the streamfunction and the vorticity evolve in time. Thus, in theory the inverse matrix of the coefficients can be calculated at the start of the run and the streamfunction subsequently calculated using matrix multiplication between the inverse and a vector containing the vorticity and fixed boundary values. In practice, we carry out a LU factorization on the first call, then perform forward and back substitutions given the known $\mathbf{L}$ and $\mathbf{U}$ matrices to solve for the streamfunction on subsequent calls. The cavity velocity is calculated from

$\bar{u}_{i, k}=-\frac{1}{{\overline{H_{i, k}}}^{x}}{\overline{\partial_{2 y}\left(\psi_{i, k}\right)}}^{x}, \quad \bar{v}_{i, k}=\frac{1}{{\overline{H_{i, k}}}^{y}}{\overline{\partial_{2 x}\left(\psi_{i, k}\right)}}^{y}$,

15 where one-side differencing is employed near the lateral boundaries. The boundary conditions on the grounding line are applied by imposed zero normal velocity and making use of the fixed streamfunction value to calculating the tangential velocity. The inner iterations are stopped when more than 5 iterations have been performed and when the maximum value of the absolute change in cavity velocity between iterations is less than $201.0 \times 10^{-11}$.

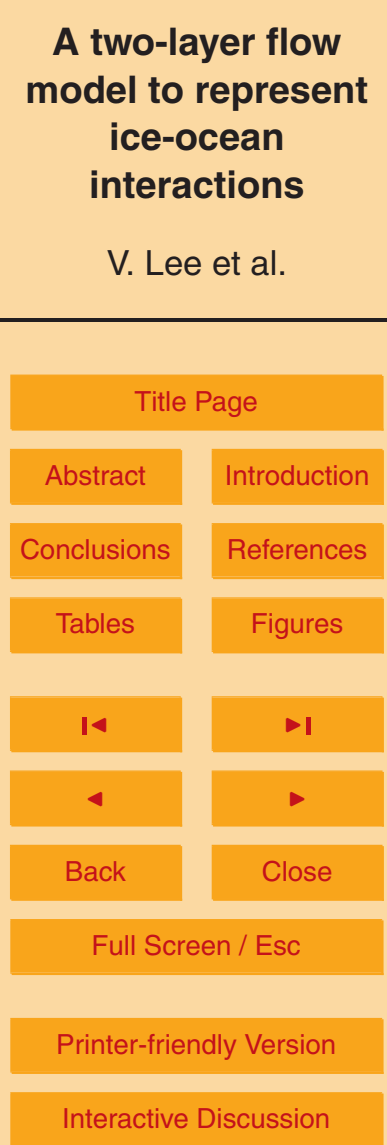




\subsubsection{Plume thickness}

The plume thickness Eq. (30) is evolved using the Crank-Nicolson method (Ferziger and Perić, 2002). The discretised form of the equation is given by

$$
C_{E} D_{\mathrm{p}_{i+1, k}}^{n+1}+C_{W} D_{\mathrm{p}_{i-1, k}}^{n+1}+C_{N} D_{\mathrm{p}_{i, k+1}^{n+1}}^{n+1}+C_{\mathrm{S}} D_{\mathrm{p}_{i, k-1}^{n+1}}^{n+1}+\left(1+C_{P}\right) D_{\mathrm{p}_{i, k}}^{n+1}
$$

$5=\dot{e}_{i, k} \Delta t-C_{E} D_{\mathrm{p}_{i+1, k}}^{n}-C_{W} D_{\mathrm{p}_{i-1, k}}^{n}-C_{N} D_{\mathrm{p}_{i, k+1}}^{n}-C_{\mathrm{S}} D_{\mathrm{p}_{i, k-1}}^{n}+\left(1-C_{P}\right) D_{\mathrm{p}_{i, k}}^{n}$,

where superscripts $n$ and $n+1$ represent the variable at times $t$ and $t+\Delta t$, respectively.

The coefficients are as follows

$C_{E}=\frac{\bar{u}_{\mathrm{p}_{i, k}} \Delta t}{4 \Delta x}, \quad C_{W}=\frac{\bar{u}_{\mathrm{p}_{i-1, k}} \Delta t}{4 \Delta x}$

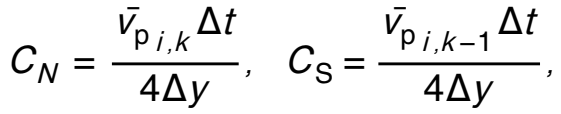

$C_{P}=C_{E}+C_{W}+C_{N}+C_{\mathrm{S}}$

No special treatment is required on the rigid lateral boundaries on the C-grid. See Sect. 3.4 for how the open boundary condition is handled at the ice shelf front. The rate of entrainment is calculated from Eq. (41) using velocities from the current timestep and thicknesses and densities from the previous one. It is worth noting that entrainment should simply be set to zero when the relative flow speed is small otherwise we obtain spurious thickness values which may cause the code to crash. The above linear system of equations is solved using the stabilized version of the bi-conjugate gradient squared method preconditioned with Gauss-Seidel successive over relaxation method from the PETSc package (Balay et al., 2009). Following Jungclaus and Backhaus (1994), the solution is used to calculate the plume-ambient interface rather than update plume thickness straight away. The interface position at the glacial inflow is set first. Then any spurious values, where the interface lies above the base of the ice shelf, are reset to values for the ice shelf base before the interface is used to update the plume thickness.

\section{A two-layer flow model to represent ice-ocean interactions}

V. Lee et al.

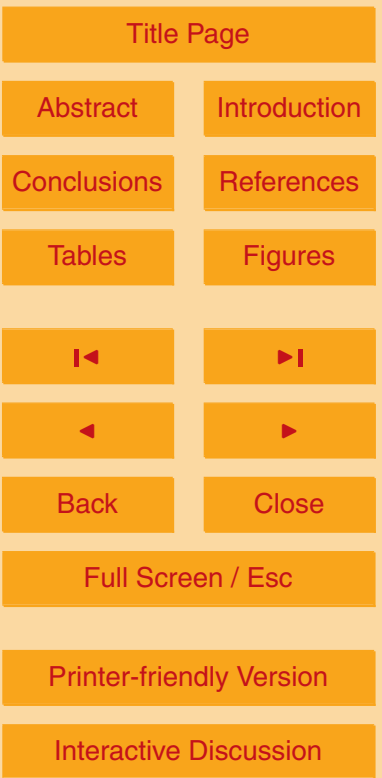


The plume velocity is also updated by recalculating it from the mass flux divided by the new thickness.

\subsubsection{Scalar properties}

The equations for the temperature and salinity for plume, Eq. (36), and ambient, 5 Eq. (38), are solved using the algorithm employed by Jungclaus and Backhaus (1994). The equations are evolved using a first-order explicit timestepping scheme and advection terms are calculated using a selective vector, first-order upwinding scheme. This means that the timestep of the numerical scheme is restricted by the Courant number. Diffusion terms are calculated using central differences. The values of temperature and salinity at the interface are obtained from Eq. (37) and entrainment is calculated again from Eq. (41) using the updated velocities and layer thicknesses. We found that if any spurious values of plume temperature and salinity were calculated they were often linked to a large entrainment term in Eq. (36). The temperature, salinity and melt rate at the base of the ice shelf are calculated by solving Eqs. (44)-(46) (Holland and

15 Feltham, 2006). As with entrainment, melt rate values should be set to zero when the flow speed is small to prevent calculating spurious temperature and salinity values.

The insulating boundary condition along the rigid lateral boundaries is readily imposed during the calculations of the advection and diffusion terms. Once the new temperature and salinity fields have been obtained we prescribe values along the glacial inflow. These inflow values are calculated at the start of a model run using a method by Holland and Feltham (2006). It combines meltwater, whose properties are calculated using a theory by Gade (1979), with a small portion of the background ocean at the depth of the inflow.

\subsection{Boundary conditions at the ice shelf front}

25 Beneath the ice shelf front we have an open boundary condition. Such conditions are notoriously difficult to implement numerically (Blayo and Debreu, 2005). The
GMDD

4, 65-136, 2011

\section{A two-layer flow model to represent ice-ocean interactions}

V. Lee et al.

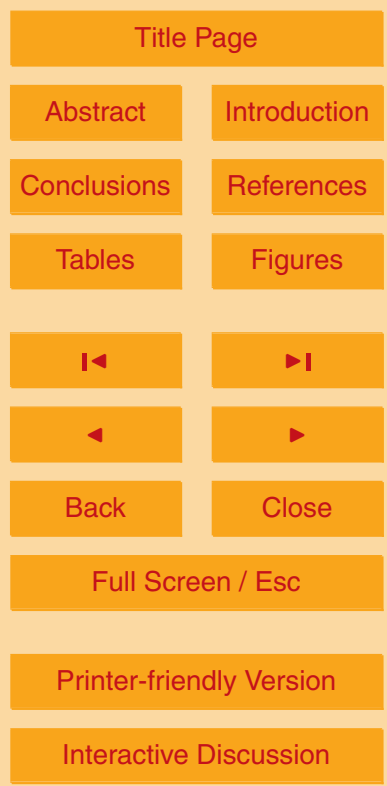


implementation needs to close the system of discrete equations while allowing flow to pass through the open boundary seemingly unhindered. A simple condition, used by Payne et al. (2007), is to impose no-normal gradient on the flow and scalar fields. We found that the plume did not pass out of the computational domain cleanly. In par5 ticular, thick plume flow moving along a rigid lateral boundary towards the ice shelf front only partly left the domain while the rest continued to flow along the open boundary as if it was solid. We have tried a different approach.

For simplified cavity shapes the open boundary is somewhat easier to handle because we can treat the plume as a pure outflow and the ambient as inflow. We treat 10 the outflow condition in similar manner to outflow in a supersonic, compressible simulation (Anderson, 1995) by extrapolating the variables in the interior of the domain to the open boundary. This allows information from the computational domain to determine the boundary values. While this approach is well-posed for supersonic flow where information travels in one direction it is only an approximation for our incompressible side the cavity by the nature of incompressibility. We set the plume velocity, thickness, temperature and salinity on the open boundary by linear extrapolating in the normal direction. On the staggered grid, we only need extrapolate the component of velocity that is tangential to the boundary, for example $\bar{v}_{\mathrm{p}}$ for $i=\max$. For the plume thickness, we introduce the extrapolation into the implicit scheme by altering the stencil near the boundary. If the open boundary is at $i=\max$, for example, then the Eq. (62) for the cell adjacent to the boundary becomes

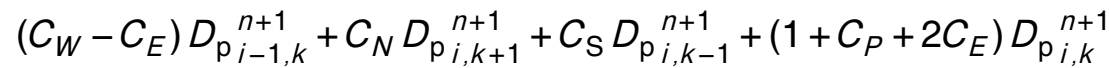

$$
\begin{aligned}
& =\dot{e}_{i, k} \Delta t-C_{E} D_{\mathrm{p}_{\text {max }, k}}^{n}-C_{W} D_{\mathrm{p}_{i-1, k}}^{n}-C_{N} D_{\mathrm{p}_{i, k+1}}^{n}-C_{\mathrm{S}} D_{\mathrm{p}_{i, k-1}}^{n}+\left(1-C_{P}\right) D_{\mathrm{p}_{i, k}}^{n} \text {, }
\end{aligned}
$$

25 where coefficients are unchanged.

For the streamfunction we impose a fixed value of $\psi_{g}$ on the open boundary. It implies that there is no vertically-averaged cavity flow across the boundary. We set the normal component of cavity velocity to zero on the boundary. Importantly, this does

\section{GMDD}

4, 65-136, 2011

\section{A two-layer flow model to represent ice-ocean interactions}

V. Lee et al.

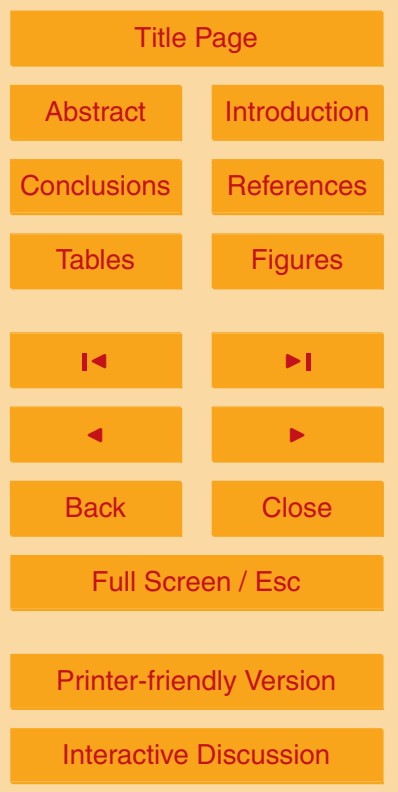

Interactive Discussion 
not mean that the plume cannot flow, it just means that the ambient must flow in the opposite direction to the plume.

We only need implement a condition on the temperature and salinity fields of the ambient at the open boundary, since velocity and thickness can be determined from

5 Eqs. (32) and (33) using the approximate cavity and plume boundary values. Here, we calculate their values by vertically averaging the background ocean profiles given by Eq. (40) between the bedrock at the plume-ambient interface. Note that these values vary in time as the interface position changes.

\section{Experimental set up}

10 We test the two-layer model using a computation domain for a simplified geometry, which loosely represents the cavity beneath Pine Island Ice Shelf. The domain shown in Fig. 4 has a rectangular plan view with horizontal dimensions of 60 by $70 \mathrm{~km}$ which is discretised using a grid of 64 by 72 cells with spacing of $1 \mathrm{~km}$ in both directions. Two cells along the edges of three sides of the domain are masked to represent solid 15 land boundaries. The grounding line is located at $y=0$. The inflow of meltwater from beneath Pine Island Glacier across the grounding line is located along a $40 \mathrm{~km}$ section cut out of the centre of the grounding line. The ice shelf front and open boundary is located at $y=70 \mathrm{~km}$. The underside of the ice shelf is represented by the function

$$
B=\frac{B_{\mathrm{g}}}{\left(1+\left[\left(B_{\mathrm{g}} / B_{\mathrm{f}}\right)^{\alpha}-1\right] y / L\right)^{1 / \alpha}}
$$

20 (Holland et al., 2008; van der Veen, 1999), where $L$ is the length of the cavity, $B_{\mathrm{g}}$ and $B_{\mathrm{f}}$ are the depths below sea level of the ice at the grounding line and the shelf front and are set to 900 and $300 \mathrm{~m}$, respectively. The constant $\alpha$ determines the curvature of the underside of the shelf and is set to 2 giving a steep slope near the grounding line that flattens near the front. The water column thickness at the grounding line is set to $300 \mathrm{~m}$ and the bedrock is flat with $h=1200 \mathrm{~m}$.
GMDD

4, 65-136, 2011

\section{A two-layer flow model to represent ice-ocean interactions}

V. Lee et al.

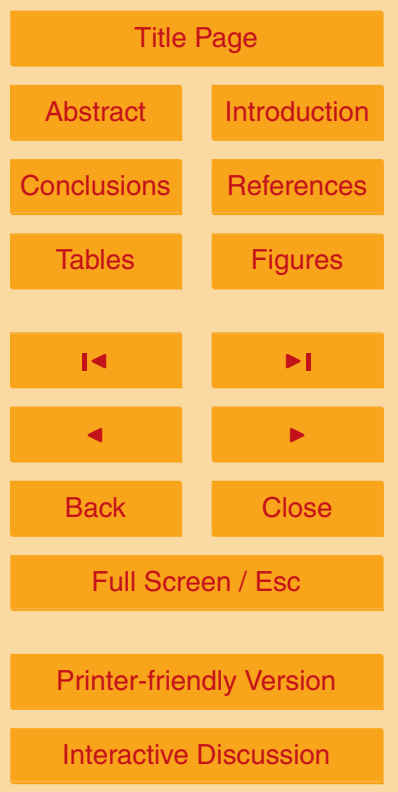


We set up a standard experiment to examine the behaviour of the model and then perform a sensitivity analysis to find its physical and numerical limits. The numerical and physical parameters of the standard experiment are given in Table 1. The parameter values have been taken from Payne et al. (2007) with the exception of the en5 trainment coefficient which is set to 0.02 to produce a lower mean melt rate. The fixed thickness, temperature and salinity at the glacial inflow are set to $1 \mathrm{~cm},-2.48^{\circ} \mathrm{C}$ and 33.42, respectively. The background ocean temperature and salinity profiles, Eq. (40), used to initialize and set the open boundary scalar properties are an approximation of measured profiles at Pine Island Ice Shelf front (Jacobs et al., 1996). The sur10 face values are set to $-1.9^{\circ} \mathrm{C}$ and 33.8 and bottom values to $1.0^{\circ} \mathrm{C}$ and 34.7 , with the thermocline and halocline depth set to $600 \mathrm{~m}$ (Payne et al., 2007). The standard experiment is evolved using a time step of $60 \mathrm{~s}$.

We investigate the effects of varying flow parameters on both the model behaviour and the stability of the code. We have chosen to vary drag coefficients for the cavity and the plume, entrainment coefficient and eddy diffusivity because their values are poorly constrained. They need to be tuned to provide melt rates, say, which are comparable with inferred observations because their values are simply unknown in real cavities. It would, therefore, be useful to have an idea of the range of values for which the code is stable. Initially, each parameter is varied individually while maintaining the others at their standard value to find its limits. Then any complex nonlinear interaction between the parameters is sought by varying all four parameters. The large parameter space is randomly sampled using a Latin hypercube to generate 50 experiments.

\section{Results}

\subsection{Standard experiment}

25 The motion within the cavity beneath the ice shelf adjusts to an equilibrium within 10 days. During the spin up the uniform plume is cooled and freshened at the glacial

\section{GMDD}

4, 65-136, 2011

\section{A two-layer flow model to represent ice-ocean interactions}

V. Lee et al.

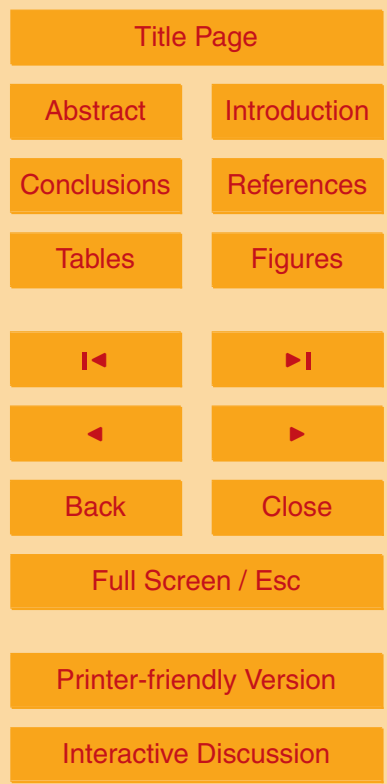

Interactive Discussion 
inflow, which induces buoyant flow along the underside of the ice shelf. The plume grows as it moves away from the inflow by entraining relatively warm, saline, ambient water. It is also cooled and freshened as the flow enhances basal melting of the shelf. When it is sufficiently thick to feel the effect of the Coriolis force the flow is di5 verted towards the left hand side wall (Southern Hemisphere). Once it has hit the solid boundary it remains in contact with the wall as it travels along the ice shelf to the front where it passes out of the cavity into the open ocean. We refer to this motion along the solid boundary as "wall-flow". After the initial spin up only minor adjustments occur to the flow so we take a time average of 30 days starting at day 20 and concentrate on 10 spatial patterns of the flow.

The time-averaged variable fields from the standard experiment are displayed in Fig. 5. The mean streamfunction (Fig. 5a) shows that the cavity circulation is dominated by two gyres; a stronger, narrower, clockwise (positive) one near the left hand wall and a counterclockwise one in the interior. Over time the clockwise gyre weakens 15 slightly while the other stengthens. There are also two small gyres around the corners of the glacial inflow as expected.

The buoyant plume continually moves from the grounding line to the ice shelf front and it exists everywhere beneath the shelf so the use of Jungclaus and Backhaus (1994)'s wetting and drying scheme is not required here. It has spatial means for speed, thickness and density of $18.9 \mathrm{~cm} \mathrm{~s}^{-1}, 8.1 \mathrm{~m}$ and $1029.39 \mathrm{~kg} \mathrm{~m}^{-3}$ (which can be broken down into a mean temperature of $-1.32^{\circ} \mathrm{C}$ and salinity of 33.79), respectively. The motion of the plume is far from uniform, however (see Figs. $5 b-d$ ). It can be separated into three regimes, which we call grounding line flow, wall-flow and interior flow. Grounding line flow occurs within the first $\sim 25 \mathrm{~km}$ of the domain where the underside of the ice shelf is steepest. The plume water is at its densest here with the maximum temperature of $-0.60^{\circ} \mathrm{C}$ and salinity of 34.07 . The plume begins flowing from all along the grounding line and not just from the glacial inflow. Within the first $\sim 20 \mathrm{~km}$ the plume is still thin but it is moving quickly away from the grounding line $\left(\bar{v}_{\mathrm{p}} \sim 25 \mathrm{~cm} \mathrm{~s}^{-1}\right)$. The $x$ component of the plume velocity is directed towards the left and its magnitude reaches
GMDD

4, 65-136, 2011

\section{A two-layer flow model to represent ice-ocean interactions}

V. Lee et al.

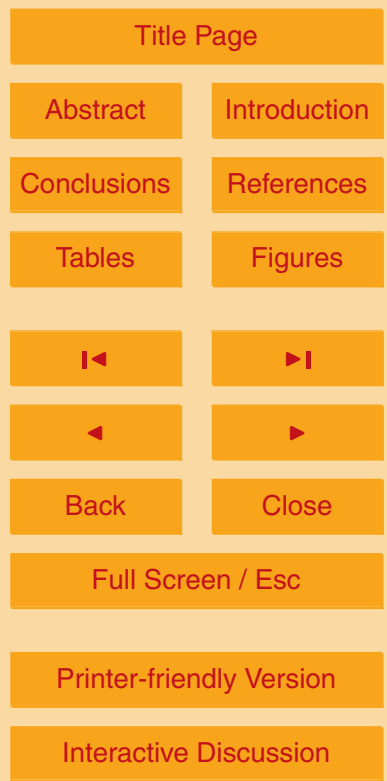


a maximum of $26 \mathrm{~cm} \mathrm{~s}^{-1}$ close to the wall flow and about $20 \mathrm{~km}$ from the grounding line. Wall-flow is the most active regime and where the plume is most concentrated. A maximum plume speed of $73.6 \mathrm{~cm} \mathrm{~s}^{-1}$ is achieved about half way along the side wall. The plume slows as the shelf flattens but continues to grow along the wall to reach its max5 imum thickness of $86 \mathrm{~m}$ at the open boundary. It is worth noting that there is enhanced spreading $\left(\bar{u}_{\mathrm{p}}=5 \mathrm{~cm} \mathrm{~s}^{-1}\right)$ of the wall-flow close to the open boundary. The temperature and salinity of the plume adjacent to the wall beneath the shelf front are $-1.34^{\circ} \mathrm{C}$ and 33.76, respectively. Interior flow refers to the motion of the plume where the underside of the shelf flattens and is the least dynamic of the three regimes. The plume continues to migrate towards the wall-flow while travelling towards the shelf front, but its speed decreases. Its density also decreases reaching a minimum beneath the front near the wall-flow where it is cooled and freshened to $-1.88^{\circ} \mathrm{C}$ and 33.57 , respectively.

The driving mechanisms of the plume have been determined by reconstructing the terms of the momentum Eq. (27) and considering their relative importance. Grounding 15 line and interior flows are driven by buoyancy across the interface between the two layers in the $y$-direction. To maintain steady state this is balanced by plume drag, alone, in the grounding line flow and a combination of Coriolis force and drag in the interior flow. In the $x$-direction, the Coriolis force and plume drag balance each other. Wall-flow is driven by buoyancy across the interface in the $x$-direction and balanced 20 by the Coriolis force. Forcing due to plume density gradient in the $x$-direction has only a small (an order of magnitude smaller than the driving force) balancing contribution in the wall-flow. While forcing due to lateral ambient density gradients are also small (again an order of magnitude smaller than the driving forces), they account for the enhanced spreading of the wall-flow at the open boundary noted earlier. Barotropic 25 forcing is mostly unimportant except in the $x$-direction around the the corners of the inflow where it is balanced by plume drag.

The ambient flow is weak (see Fig. 5e). Its speed has a mean value of $0.34 \mathrm{~cm} \mathrm{~s}^{-1}$ and reaches a maximum of just $6.58 \mathrm{~cm} \mathrm{~s}^{-1}$, which is between one and two orders of magnitude smaller than the plume speed. Ambient flow, while it is relatively

\section{GMDD}

4, 65-136, 2011

\section{A two-layer flow model to represent ice-ocean interactions}

V. Lee et al.

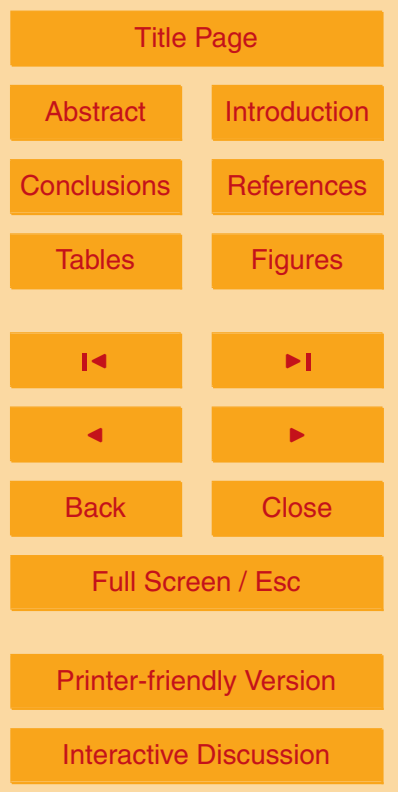

Interactive Discussion 
deep, will always be weaker than that of the plume by continuity. A characteristic ambient speed can be calculated using a rule-of-thumb approach to continuity where the ambient and plume fluxes are approximately equal. Using mean values of plume speed, thickness and ambient thickness, this characteristic ambient speed $5\left|\bar{u}_{\mathrm{a}}\right| \approx\left|\bar{u}_{\mathrm{p}}\right| D_{\mathrm{p}} / D_{\mathrm{a}}=18.9 \times 8.1 / 738.7=0.2 \mathrm{~cm} \mathrm{~s}^{-1}$, which is not dissimilar from the modelled mean value.

Ambient flow draws ocean water from the open boundary towards the grounding line beneath the wall-flow. It weakly spreads from beneath the wall-flow across the cavity. This spreading increases as it travels towards the grounding line. Beneath the ground10 ing line flow the ambient flow weakens as the plume thins. Instead, there is stronger circulation around the corners of the inflow. There is also a very weak anti-clockwise circulation, which is not visible in the figure, beneath the interior flow near the open boundary and right hand wall. The effects of the weak advection from the open boundary to the grounding line on mean ambient density field can be seen in Fig. 5f. However, 15 the lack of spatial variation where the ambient density is close to the reference value for seawater and has a small range of $0.04 \mathrm{~kg} \mathrm{~m}^{-3}$ indicates that diffusion is the dominant process. The ambient temperature has a range of $0.19^{\circ} \mathrm{C}$ around a mean value of $0.87^{\circ} \mathrm{C}$. Notice that ocean water entering the cavity beneath the wall-flow is denser than elsewhere along the open boundary and is the source of the relatively strong lateral ambient density gradients there. This is because the boundary temperature and salinity values, which are calculated by vertically averaging the background ocean profiles, are warmer and more saline beneath the wall-flow where the ambient-plume interface is deeper. If the boundary values were independent of depth then there would be no enhanced spreading of the plume.

The temporal mean rates of entrainment are shown in Fig. $5 \mathrm{~g}$. The entrainment field is non-negative which means that there is no detrainment of the plume into the ambient. This is unsurprising because we have established that the ambient speed is substantially less than the plume speed. The spatial mean value is $3.2 \mathrm{~m}$ day $^{-1}$, but entrainment varies in the different flow regimes. These variations can be explained in

\section{GMDD}

4, 65-136, 2011

\section{A two-layer flow model to represent ice-ocean interactions}

V. Lee et al.

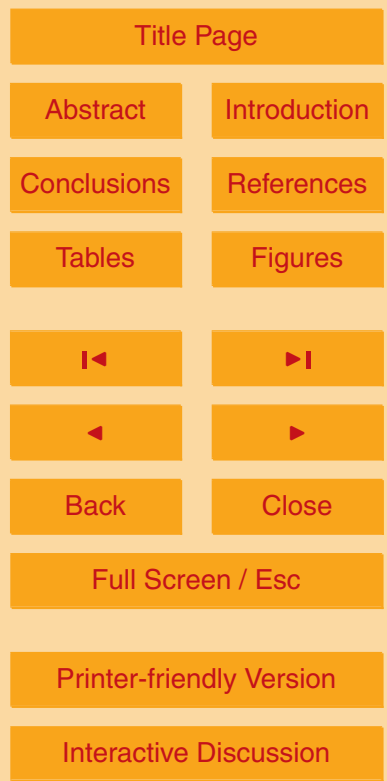


terms of the Richardson number, Eq. (43), which is a measure of the stabilising effects of buoyancy and the destabilising effects of a vertical shear flow. In the grounding line regime entrainment is high because the Richardson number, Eq. (43), is small. This is because the density difference between the plume and the ambient is at a minimum 5 and the plume is fast and thin. The glacial inflow appears to enhance entrainment slightly. Entrainment in the wall-flow reaches its maximum value of $14.1 \mathrm{~m} \mathrm{day}^{-1}$ because shear flow (or relative speed between the layers) across the interface is at its greatest. Its value falls towards the open boundary as the density difference increases and the Richardson number increases. In the interior the Richardson number is high so there is little entrainment.

Finally, the temporal mean melt rates are shown in Fig. 5h. The spatial mean value is $30.6 \mathrm{~m} \mathrm{yr}^{-1}$, but reaches a maximum of $121.0 \mathrm{~m} \mathrm{yr}^{-1}$ in the wall-flow where the plume speed is greatest. Melting in the grounding line regime is also high with values $\sim 75 \mathrm{~m} \mathrm{yr}^{-1}$. The plume is moving quickly here and it is relatively warm and saline 15 from entrainment of ambient water. Importantly, there is no freezing beneath the ice shelf.

\subsection{Comparison with one-layer models}

The two-layer cavity model differs from the one-layer reduced gravity plume model (Jungclaus and Backhaus, 1994; Holland and Feltham, 2006) used by 20 Payne et al. (2007) in using a simplified plume momentum equation and adding an active ambient layer. The effects of the former modification were determined by comparing the results from the original one-layer model which uses a fully nonlinear momentum equation (refered to as the nonlinear model) with those from the one-layer model with the simplified momentum balance (reduced model). The effects of the latter 25 were determined by comparing the results from the reduced model with those from the two-layer model.

The behaviour of the plume using the standard experimental set up (see Table 1) for both the one-layer models is similar to that of the two-layer model (Figs. 5b-d, g and $h$ ).
GMDD

4, 65-136, 2011

\section{A two-layer flow model to represent ice-ocean interactions}

V. Lee et al.

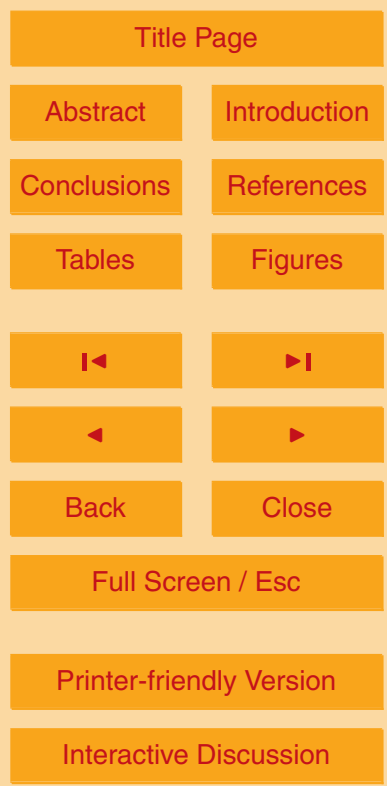

Interactive Discussion 
Simplifying the momentum causes the temporal-spatial mean melt rate to increase by $7.9 \%$ from $26.2 \mathrm{~m} \mathrm{yr}^{-1}$ for the nonlinear model to $28.3 \mathrm{~m} \mathrm{yr}^{-1}$ for the reduced model. It causes the plume to speed up by $7.3 \%$, but there is little, if any, change in the temperature and salinity mean values. The biggest changes are seen in the mean entrainment 5 rate which increases by $11.7 \%$ and the plume thickness which actually decreases by $12.2 \%$. Adding an active ambient layer leads to an increase in the mean melt rate by $8.1 \%$ from $28.3 \mathrm{~m} \mathrm{yr}^{-1}$ for the reduced model to $30.6 \mathrm{~m} \mathrm{yr}^{-1}$ for the two-layer model. The plume speeds up by $7.2 \%$, while its mean thickness decreases slightly by $6.5 \%$ and the mean entrainment rate increases slightly by $6.3 \%$. While the plume is warmer 10 by $12.5 \%$ (this is the percentage change of the mean deviation away from the reference temperature), it is the interface temperature and salinity that increase the most where their mean deviations increase by $27.1 \%$ and $525.6 \%$, respectively. These differences between the reduced and two-layer models are unlikely to be due to motion in the ambient since we have established that its circulation is very weak. They are more likely due to the differences in the scalar properties of the ambient. The interface and ambient scalar properties are determined differently in each model. In the one-layer models they are set directly to values from the background ocean profiles corresponding to the interface depth, whereas in the two-layer model they are calculated during the simulation from Eqs. (37) and (38). This results in a larger range of values $\left(\sim 1.4^{\circ} \mathrm{C}\right.$ and $\sim 0.45$ in salinity) between the grounding line, which is relatively warmer and saltier, and the ice shelf front for the one-layer models compared to the more homogeneous two-layer model (Fig. 5f).

Comparing the model results using single mean values does not provide information about the spatial variations. It is more useful to compare the behaviour in each of the three flow regimes as in Fig. 6 . The extent of the grounding line flow towards the ice shelf front is greater for the nonlinear model. Also, melting and entrainment, in particular, for the nonlinear model are concentrated in this regime. Their maximum rates of $76.8 \mathrm{~m} \mathrm{yr}^{-1}$ and $11.4 \mathrm{mday}^{-1}$, respectively, are located downstream of the glacial inflow. Simplifying momentum increases plume speed (Fig. 6b) and entrainment, though

\section{GMDD}

4, 65-136, 2011

\section{A two-layer flow model to represent ice-ocean interactions}

V. Lee et al.

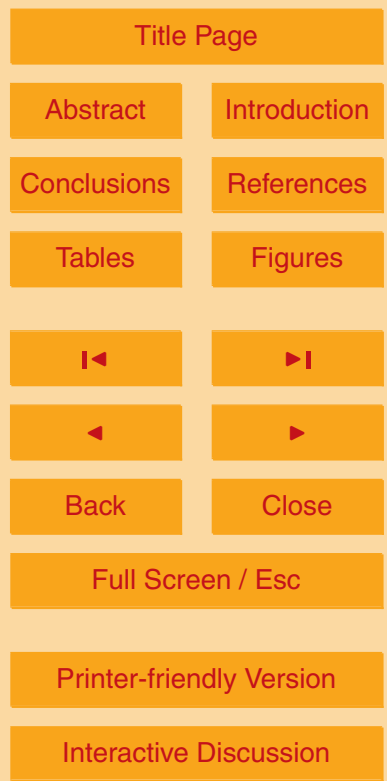


the location of new maximum rate of $13.6 \mathrm{~m} \mathrm{day}^{-1}$ has shifted to the left hand wall. Consequently, the plume is warmer and more saline, which in turn accounts for an increase in melting. The maximum melt rate is no longer in this regime; instead it has moved into the wall-flow.

5 The wall-flow for the reduced model differs from that of the nonlinear model significantly (Figs. 6a and b) as a result of removing the nonlinear advection terms from the momentum equation. The flow becomes more concentrated along the wall itself with the maximum speed of $62.6 \mathrm{~cm} \mathrm{~s}^{-1}$ located in a grid cell adjacent to the wall. The nonlinear wall-flow is only slightly thicker with a maximum thickness of $94.6 \mathrm{~m} \mathrm{com-}$ 10 pared with $92.0 \mathrm{~m}$ for the reduced model, but it is broader. Its maximum velocity of $38.5 \mathrm{~cm} \mathrm{~s}^{-1}$, located mid way across the flow, is much slower than that of the reduced model. The result of a more concentrated wall-flow for the reduced model is increased entrainment rates and a surge to a maximum of $111.1 \mathrm{~m} \mathrm{yr}^{-1}$ in melt rates adjacent to the wall.

15 In the interior flow both the models behave similarly. Near the right hand wall there is an indication that the plume is slightly denser and flow is slightly faster for the reduced model which is probably due to the removal of advection from the momentum equation. The most significant difference between the two models occurs beneath the ice shelf front (Figs. 6a and b). The nonlinear model uses a no-normal gradient open 20 boundary condition, which means that the flux leaving the domain is underestimated. Consequently, the nonlinear plume is artifically thicker at the front. Also, the velocity out of the domain is slower and the plume is lighter and fresher than the reduced model with an extrapolated open boundary.

The effects of adding the active ambient on the grounding line flow go against the 25 trends in the temporal-spatial mean values (Figs. 6c-f). Melting and entrainment in the two-layer model are slightly weaker compared to the reduced model. The plume becomes slightly fresher and cooler and the flow slower. These changes are probably due to the slightly lower interface temperature and salinity even though there is some evidence of ambient flow in the velocity field around the corners of the inflow.

\section{GMDD}

4, 65-136, 2011

\section{A two-layer flow model to represent ice-ocean interactions}

V. Lee et al.

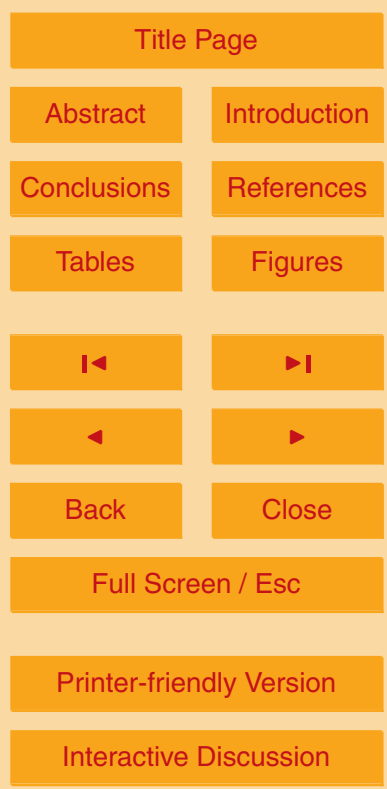


The interface temperature and salinity outside the grounding line regime are higher for the two-layer flow and the differences increase towards the ice shelf front (temperature is shown in Fig. $6 f$ and the salinity pattern is similar). The same trend is true of the ambient temperature and salinity. Consequently, the wall-flow is more dominant in 5 the two-layer model with greater melt and entrainment rates extending further along the wall towards the ice shelf front. The flow is faster yet the plume is thinner. The plume is warmer and saltier towards the front than the reduced model, which explains the extended melt rates. There is no enhanced spreading of the wall-flow at the front in the one-layer model since the density gradients in the ambient are neglected.

10 In the interior melting is greater in the two-layer model, which is due indirectly to the warmer and more saline interface. Entrainment is somewhat higher in the right hand corner of the interior at the edge of the grounding line flow but then the difference decreases sharply towards the front and the wall-flow. The interior flow is more rapid, but the plume thickness is similar. The differences in plume density flip about half way along the interior (Fig. 6e). At the edge of the grounding line regime the two-layer plume is denser because it is warmer and saltier, but then becomes fresher and hence lighter towards the ice shelf front. The plume is fresher, eventhough the ambient is saltier, because of the higher melt rates in the interior of the two-layer model. This freshening slows the plume and decreases melting such that the differences in speed and melt rate between the two models decrease near the front.

\subsection{Sensitivity to flow parameters}

The results of varying the tunable flow parameters, such as the effects on the melt rates shown in Fig. 7, are displayed using line plots of the temporal-spatial mean values against the parameter. The spatial variations of the time-averaged fields are represented by adding the fifth and ninety-fifth percentiles of its distribution to the plots along with its minimum and maximum values. A loose interpretation based on the standard experiment of this representation is that values between the fifth and ninety-fifth percentiles correspond to the grounding line regime and those lying significantly outside

\section{GMDD}

4, 65-136, 2011

\section{A two-layer flow model to represent ice-ocean interactions}

V. Lee et al.

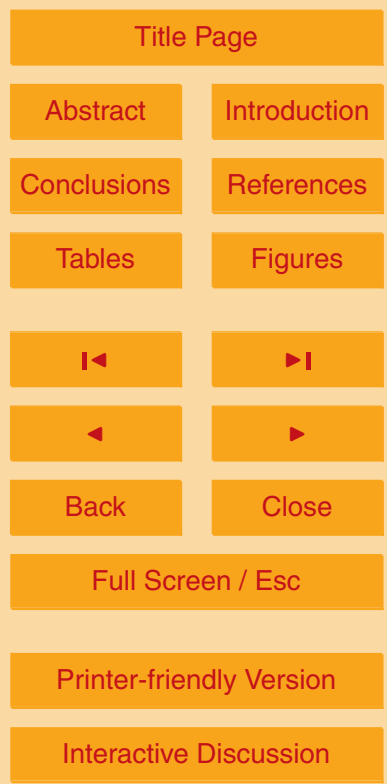


correspond to the wall-flow. Also, spurious extreme values such as temperatures exceeding maximum background ocean temperature in the absence of heat sources and excessive plume velocity indicate that the numerical scheme is struggling.

\subsubsection{Plume drag coefficient}

5 Decreasing the plume drag coefficient from $6.0 \times 10^{-3}$ to $0.5 \times 10^{-3}$ increases plume speed and the grounding line flow and wall-flow intensify, as one would expect. The extent of the grounding line flow towards the ice shelf front shrinks and entrainment rates increase. The wall-flow deepens while the horizontal spread from the wall as it travels towards the front decreases, as drag decreases, until it nears the front where it spreads to approximately the same width, irrespective of the drag, to leave the domain. Entrainment and melt rates also increase in the wall-flow as drag decreases. For higher plume drag coefficients the grounding line flow is the dominant regime, but as the coefficient decreases the dominance shifts to the wall-flow. In the interior the plume flow is more directed towards the wall-flow as the drag decreases. Also, its speed which means close to the right-hand wall velocity is necessarily directed towards the front to satisfy the no-normal velocity boundary condition. Consequently, the grounding line flow is drawn further into the interior near the right-hand wall as drag decreases.

These shifts in the flow pattern are only reflected in the changes to the extreme val20 ues of velocity and maximum values of plume thickness, melt and entrainment rates. Their mean values show only small changes because the portion of the domain that the active flow occupies also changes. For example, the maximum plume speed, thickness and entrainment rates increase significantly by $148.7 \mathrm{~cm} \mathrm{~s}^{-1}, 80.8 \mathrm{~m}$ and $88.9 \mathrm{~m} \mathrm{day}^{-1}$, respectively, as the plume drag coefficient decreases from $6.0 \times 10^{-3}$ to $0.5 \times 10^{-3}$, 25 whereas the mean values only increase by $5.4 \mathrm{~cm} \mathrm{~s}^{-1}, 2.1 \mathrm{~m}^{2}$ and $3.4 \mathrm{~m} \mathrm{day}^{-1}$, respectively. The mean plume speed actually decreases slightly for $c_{p}=0.5 \times 10^{-3}$ as the area of the high speed regimes decreases faster than the speed increases.

\section{GMDD}

$4,65-136,2011$

\section{A two-layer flow model to represent ice-ocean interactions}

V. Lee et al.

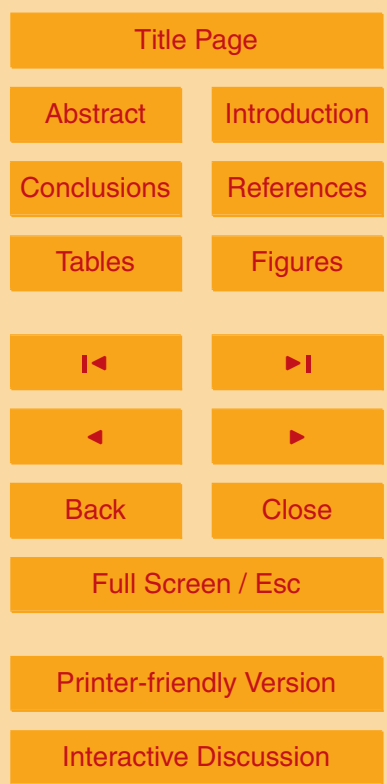


The effects of varying the plume drag coefficient on the melt rates are shown in Fig. 7a. The results from the experiment at $c_{\mathrm{p}}=0.1 \times 10^{-3}$ are included in the plot for completeness, but they are not physically meaningful and will not be discussed. The maximum values increase with decreasing drag as the wall-flow intensifies. The 5 mean spans a range of $10.7 \mathrm{~m} \mathrm{yr}^{-1}$, which is moderately large compared to other fields. However, both the mean and ninety-fifth percentile peak at $c_{\mathrm{p}}=0.2 \times 10^{-3}$ with values of 31.8 and $82.3 \mathrm{~m} \mathrm{yr}^{-1}$, respectively. The mean drops for low drag principally because the area of the active flow shrinks and in part because of numerical problems near the grounding line, which we discuss at the end of this section. Interestingly, the drop in the 10 ninety-fifth percentile for low drag reflects a slight drop in the melt rate in the grounding line flow. Why this should happen is unclear particularly as the plume becomes warmer and saltier here as drag decreases.

The variation of plume temperature with the plume drag coefficient is shown in Fig. $8 \mathrm{a}$. The minimum temperature corresponds to the fixed temperature at the glacial 15 inflow. The range of temperatures per experiment increases as the drag decreases but there is no concentration of extreme values into a particular flow regime. The mean increases significantly by $0.98^{\circ} \mathrm{C}$ as the drag decreases. The rise in spatial variation is caused by increased entrainment of warm ambient water in the grounding line and wall-flow regimes. For high drag coefficients the warmest waters are contained within 20 the grounding line flow, but as drag increases they spread into the interior flow and then migrate further up the right-hand wall towards the front. The variation of salinity is similar with the mean increasing by 0.39 across the drop in drag coefficients.

The speed of the ambient also increases in direct response to the increase in plume speed as the plume drag coefficient decreases. The ambient remains relatively inactive 25 as indicated by a mean speed that does not exceed $0.7 \mathrm{~cm} \mathrm{~s}^{-1}$ and even what seems a large increase in the maximum values of $21.1 \mathrm{~cm} \mathrm{~s}^{-1}$ is in fact small compared to that of the plume. The properties of the ambient are barely affected by the change in drag where the mean and range of temperatures changes only by $0.01^{\circ} \mathrm{C}$. There is a larger variation in temperature beneath the wall-flow at the open boundary in response to the

\section{GMDD}

4, 65-136, 2011

\section{A two-layer flow model to represent ice-ocean interactions}

V. Lee et al.

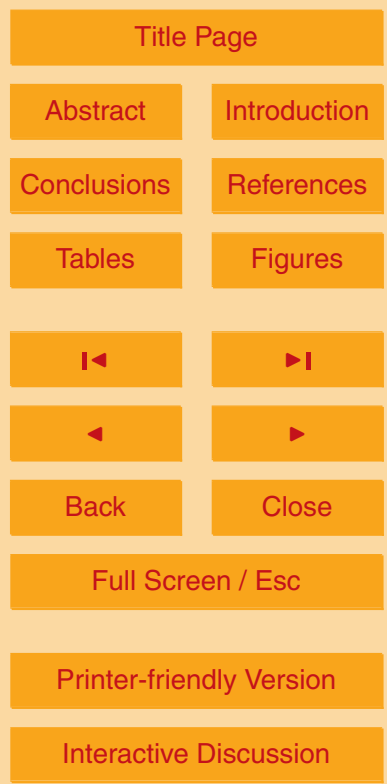


deepening wall-flow as drag decreases. Also, the warmer water at the open boundary is drawn further towards the grounding line.

A less obvious response of the model to a decrease in the plume drag coefficient is an increase in circulation of the whole cavity. This can clearly be seen in Fig. 8b 5 from the widening range of streamfunction values as drag decreases. The response is not obvious because the streamfunction-vorticity equation, Eq. (19), does not depend on plume velocity. It does however depend on plume density and interface gradients through the baroclinic torque, Eq. (24), both of which increase significantly as drag decreases. The mean streamfunction switches between negative and positive values 10 between drag coefficients of $3.0 \times 10^{-3}$ (standard experiment) and $3.5 \times 10^{-3}$, which indicates that the circulation pattern changes. For lower drag coefficients, the two main gyres observed in the standard experiment (Fig. 5a) strengthen as drag decreases. The counterclockwise gyre becomes significantly more dominant, where it spreads to fill the domain and squeezes the clockwise gyre against the left-hand wall. Evidence of 15 large weak anticlockwise circulation can be seen in the flow pattern of both the layers when the drag is very low. The plume is even drawn down from the beneath the ice shelf front towards the grounding line beside the wall-flow. For higher drag coefficients, a third clockwise gyre forms next to the right-hand wall towards the grounding line. As drag increases it grows and splits the fading counterclockwise gyre. When drag is high a small counterclockwise gyre forms in the left-hand corner by the grounding line. These changes mean that the plume spreads further towards the front before it migrates to the wall and ambient flow spreads across the width of the shelf before being drawn towards the glacial inflow.

\section{Numerical issues}

25 We found that experiments with a plume drag coefficient of $1.0 \times 10^{-3}$ or less developed a numerical oscillation along the left-hand boundary where the wall-flow was thickest (Fig. 9a). A possible explanation is that the Crank-Nicolson timestepping scheme can produce oscillatory solutions for large time steps even though it is unconditionally stable

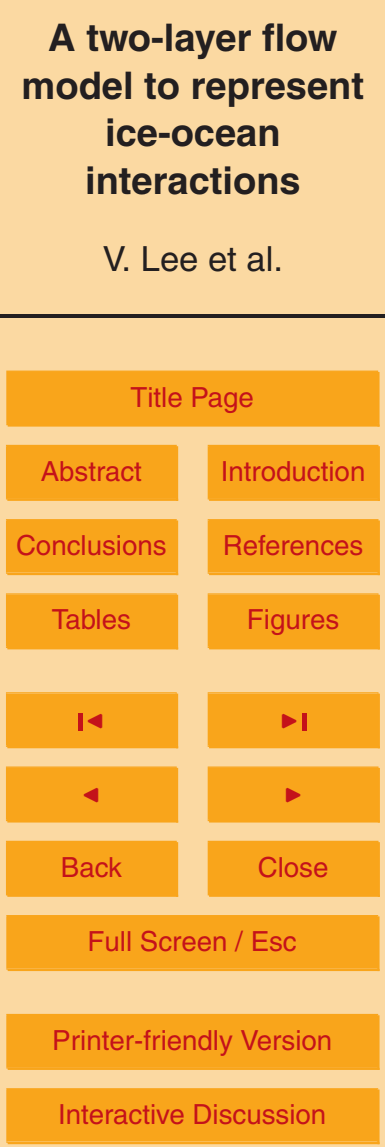


(Ferziger and Perić, 2002). While the oscillation disappears when the time step is reduced, it still occurs for other timestepping schemes. A more likely explanation is that the numerical scheme has difficulties imposing the no-normal boundary condition with the plume's momentum balance, Eq. (27), in these grid cells. Pure geostrophic 5 flow is not compatible with rigid boundaries, so frictional drag needs to be added to the momentum equation, as mentioned in Sect. 2.1. The quadratic drag term in our equation is an inverse function of plume thickness. This means that along the boundary where frictional drag is most required it is weak because the wall-flow is deep. We found that the oscillation did not necessarily become unstable unless the Courant condition, given by

$$
\Delta t<\frac{1}{\frac{2 K}{(\Delta x)^{2}}+\frac{|u|_{\max }}{\Delta x}+\frac{|v|_{\max }}{\Delta y}},
$$

was violated. Our code is subject to this condition because it uses an explicit timestepping scheme to solve the scalar Eqs. (36) and (38). The timestep for the standard experiment, $\Delta t=60 \mathrm{~s}$, easily satisfies the condition where the right-hand side is $827 \mathrm{~s}$.

15 The experiment for $c_{p}=0.5 \times 10^{-3}$ with the standard time step crashed shortly after the right-hand side reached $34.3 \mathrm{~s}$. The experiments with a plume drag coefficient of $1.0 \times 10^{-3}$ or less displayed in Figs. $7 \mathrm{a}$ and 8 use a smaller time step of $\Delta t=30 \mathrm{~s}$ and as such have no numerical oscillation in the wall-flow.

The experiment for the lowest plume drag coefficient, $c_{p}=0.1 \times 10^{-3}$, ran to completion but failed to produce physically meaningful results, even when the time step was halved. We observed erroneous vertical striping in the solution, which can clearly be seen in Fig. 9b. Also, velocity correction was used extensively within the plume to stabilize the code. A very small amount of striping is visible in the standard experiment at the edge of the grounding line flow near the start of the wall-flow (see Fig. $5 \mathrm{~g}$ ), which disappears for higher drag. Striping may result from trying to simulate an intensifying wall-flow as drag decreases, but it is not an artifact of the reduced momentum equation since the nonlinear model also produces some striping.

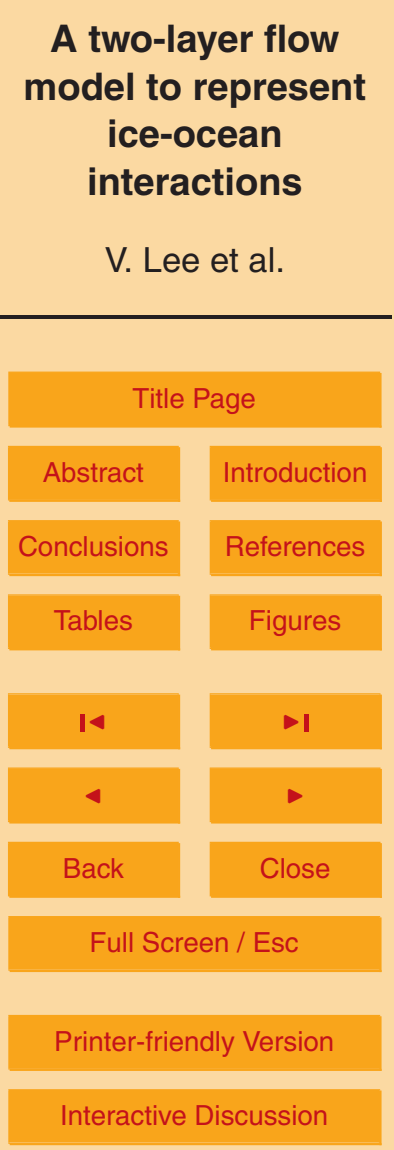


The flow in experiments with a plume drag coefficient of $1.5 \times 10^{-3}$ or less is only quasi steady, even when the numerical oscillation was removed. The velocity fields tend to be numerically noisy along the glacial inflow and the grounding line to the left of the inflow during spin up. The noise disappears before the flow reaches a steady 5 state. However, for low drag this noise persists and spreads to fill the grounding line flow as drag decreases. If a few spurious values are reasonably persistent then the extreme values of the time-averaged field are affected. The extremum are a good indication of struggling numerical code, for example the experiment with $c_{\mathrm{p}}=1.0 \times 10^{-3}$ has a minimum $x$-component of plume velocity almost twice the magnitude of the next min- imum. The streamfunction and the plume's density appear reasonably well-behaved, but their pattern becomes slightly distorted in front of the glacial inflow and close to the grounding line to the left of the inflow for low drag. The use of velocity correction also increases close to the grounding line as the grounding line flow intensifies. In the grid cells where the plume velocity is set to zero to stabilize the code corresponding melt rates, which are a function of plume velocity, is underestimated. This may partly account for the observed drop in mean melt rate and ninety-fifth percentile below $c_{\mathrm{p}}=2.0 \times 10^{-3}$ (Fig. 7a).

\subsubsection{Cavity drag coefficient}

Altering the cavity drag coefficient has barely any effect on the plume as demonstrated by the lack of variation in the melt rate in Fig. $7 \mathrm{~b}$. The mean melt rates drop by less than $0.1 \%$ as the cavity drag decreases from $6.0 \times 10^{-3}$ to $0.5 \times 10^{-3}$. The only noticeable effect is an increase of $2.0 \mathrm{~cm} \mathrm{~s}^{-1}$ in the $x$-component of the plume velocity in the wallflow near the ice shelf front.

The circulation of the whole cavity is most affected by changes in the cavity drag. The range of streamfunction values increases by an order of magnitude as the coefficient decreases from $6.0 \times 10^{-3}$ to $0.5 \times 10^{-3}$. The two main gyres (Fig. 5a) strengthen considerably, but the streamfunction's spatial pattern remains relatively unchanged. The
GMDD

4, 65-136, 2011

\section{A two-layer flow model to represent ice-ocean interactions}

V. Lee et al.

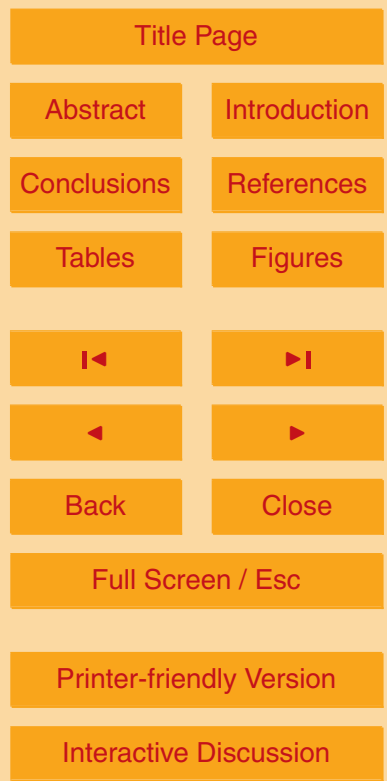


increase in circulation is translated into a modest increase in the mean ambient speed of $13.4 \%$. Again, the spatial pattern of the ambient flow does not alter significantly. Flow increases in the interior and around the corners of the glacial inflow, in particular. Interestingly, the ambient's flow beneath the wall-flow drops by $1.2 \mathrm{~cm} \mathrm{~s}^{-1}$ as the 5 drag decreases. This decrease in flow towards the grounding line is the result of the clockwise gyre near the left-hand wall strengthening. As a consequence, the relative speed across the plume-ambient interface beneath the wall-flow decreases and there is a slight drop in the maximum entrainment rates.

There were no particular numerical issues during the time-average period. The ex10 periments either ran to completion or the solution blew up around the corners of the glacial inflow within a few hours of simulated time for drag values $0.1 \times 10^{-3}, 0.05 \times 10^{-3}$ and $0.01 \times 10^{-3}$. It seems that while ambient flow increases by reducing the cavity drag coefficient, the code with a sufficiently small coefficient to potentially produce a significant increase would not be stable.

\section{$15 \quad$ 5.3.3 Entrainment coefficient}

Entrainment and plume thickness increase as the entrainment coefficient increases from 0.005 to 0.035 . The increase in entrainment is not simply a result of increasing the coefficient since the percentage increase in mean entrainment rate is 1.6 times greater than the increase that would occur if the cavity flow remained unaltered (remembering that the entrainment coefficient is squared in Eq. 41). The plume and ambient variable fields, excluding the ambient's scalar properties, also increase to enhance entrainment.

At the lowest entrainment coefficient, $c_{1}=0.005$, the three flow regimes, though weak, can still be distinguished along with heightened activity from the glacial inflow. The heightened flow from the glacial inflow appears to enhance entrainment of salt, but not 25 heat. The plume warms evenly towards the front but remains cooler than $-2.0^{\circ} \mathrm{C}$ as a result. The plume grows no thicker than $10 \mathrm{~m}$ and its mean thickness is less than its initial value of $1 \mathrm{~m}$. More importantly, ambient flow is extremely weak with a mean speed of $0.3 \mathrm{~mm} \mathrm{~s}^{-1}$ and is limited to circulation around corners of the glacial inflow.

\section{GMDD}

4, 65-136, 2011

\section{A two-layer flow model to represent ice-ocean interactions}

V. Lee et al.

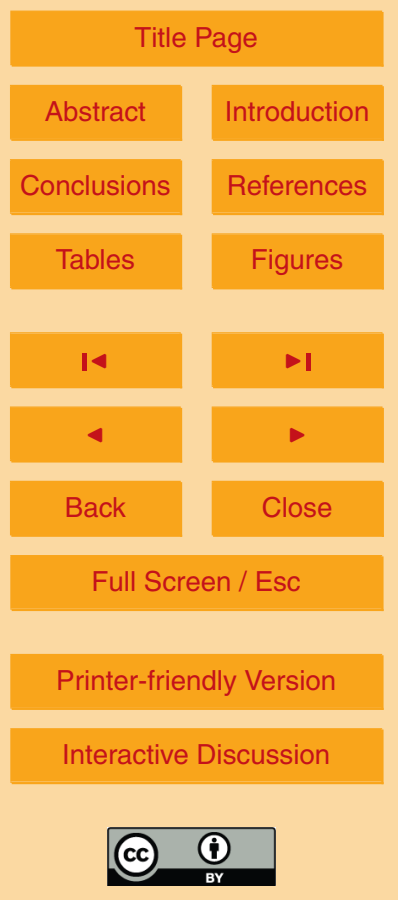


The general effects of increasing entrainment on the flow regimes are similar to those that occur when plume drag decreases (see Sect. 5.3.1). The main difference is that the wall-flow grows rather than intensifies. Firstly, this means that the horizontal spread from the wall increases slightly, rather than decreasing, as entrainment increases. Sec5 ondly, the spread across the open boundary increases, rather than remaining approximately constant. Finally, the wall-flow spreads more gradually to the open boundary for high entrainment coefficients.

The maximum values of plume speed, thickness and entrainment rates increase significantly by $88.7 \mathrm{~cm} \mathrm{~s}^{-1}, 174.1 \mathrm{~m}$ and $124.7 \mathrm{~m} \mathrm{day}^{-1}$, respectively, as the the wall-flow 10 grows and becomes dominant. All the corresponding ninety-fifth percentiles also increase as the entrainment coefficient increases from 0.005 to 0.035 . The mean values for plume thickness and entrainment rates increase significantly, unlike for the plume drag, by $16.4 \mathrm{~m}$ and $8.5 \mathrm{~m}$ day $^{-1}$, respectively. Increasing entrainment has a greater effect on the plume's thickness than on its speed. The mean plume speed, shown in Fig. 10a, increases through $10.9 \mathrm{~cm} \mathrm{~s}^{-1}$, but peaks at $c_{1}=0.025$ with a value of $19.5 \mathrm{~cm} \mathrm{~s}^{-1}$. It drops because the extent of grounding line flow shrinks and the attenuation of the velocity towards the ice shelf front in the interior increases. The plume thickness increases, however, in the corner of interior flow between wall-flow and grounding line regime, which accounts for the significant rise in its mean values.

Figure 7c shows the effect of varying the entrainment coefficient on the timeaveraged melt rates. The results from experiments with $c_{1}=0.04,0.05$ and 0.06 are included in this plot and in Fig. 10, but are not discussed for reasons that are be explained at the end of this section. The values of melt rates generated by the model for entrainment coefficients between 0.005 to 0.035 more than cover the range of melt rates that have been inferred from observations of Pine Island Bay. The mean and maximum values increase from as little as 1.4 and 4.5 to 48.6 and $293.5 \mathrm{~m} \mathrm{yr}^{-1}$ as the coefficient increases. However, the most interesting range is that of the ninety-fifth percentiles which increases from 4.1 to $124.8 \mathrm{~m} \mathrm{yr}^{-1}$, because they approximate the maximum value close to the grounding line.

GMDD

4, 65-136, 2011

\section{A two-layer flow model to represent ice-ocean interactions}

V. Lee et al.

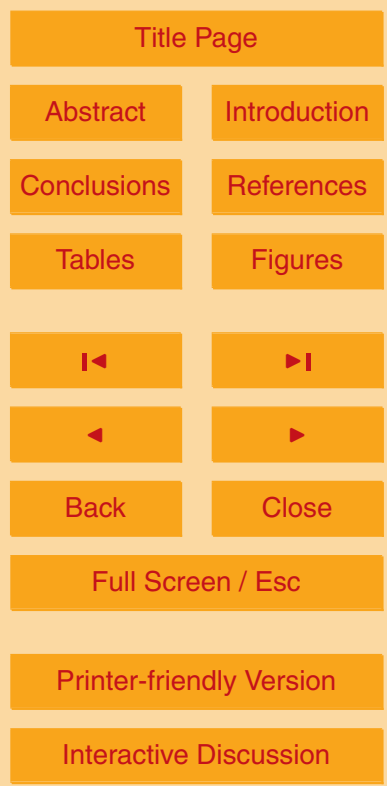

Interactive Discussion 
The scalar properties of the plume increase significantly with increasing entrainment. The mean values of temperature and salinity increase by $1.24^{\circ} \mathrm{C}$ and 0.48 , respectively. The spatial patterns of the scalars are affected by increasing entrainment in the same way as decreasing plume drag. The qualitative description given in Sect. 5.3.1 of 5 changes in the plume's temperature field applies equally well here.

The ambient remains relatively inactive despite the percentage increase in mean speed being considerably greater than that of the plume. The ambient's mean speed increases by just $1.0 \mathrm{~cm} \mathrm{~s}^{-1}$ and its maximum speed only reaches $22.9 \mathrm{~cm} \mathrm{~s}^{-1}$. The scalar properties of the ambient barely alter, where the range of ambient temperature only changes by $0.02{ }^{\circ} \mathrm{C}$. Isopycnals are approximately parallel to the $x$-axis, with the densest water at the grounding line, for the lowest entrainment coefficient and then become increasingly displaced as the coefficient increases. This is due to relatively warm saline water being drawn into the cavity beneath the growing wall-flow at the open boundary and spreading across the grounding line.

15 The pattern of the cavity's circulation completely changes as the entrainment coefficient increases. Figure $10 \mathrm{~b}$ shows that the range of streamfunction values decreases between the two lowest coefficients and then increases as entrainment increases. At $c_{1}=0.005$ there are two gyres which are focused on the corners of the glacial inflow and dissipate weakly towards the ice shelf front and the left-hand wall. The one on the left-hand corner is counterwise, whereas the other is clockwise and slightly more dominant. As entrainment increases, these two weaken and the two main gyres observed in the standard experiment (see Fig. 5a) gradually appear towards the front. The original gyres are replaced by small ones of opposite rotation. The distinctive spatial pattern of Fig. 5 is formed between $c_{1}=0.015$ and 0.02 (standard experiment) and is marked with a change of sign of the mean streamfunction. For higher coefficients, the two main gyres strengthen while the spatial pattern remains relatively unchanged. The clockwise gyre strengthens more rapidly than the clockwise one, as for low plume drag, but it does not expand or suppress the growth of the clockwise gyre nearly as much.

\section{GMDD}

4, 65-136, 2011

\section{A two-layer flow model to represent ice-ocean interactions}

V. Lee et al.

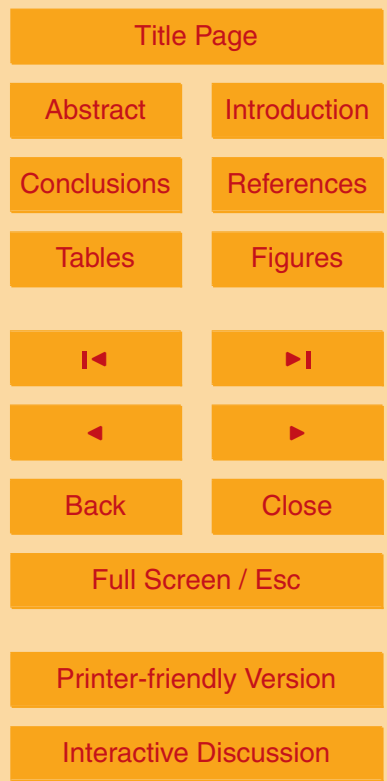




\section{Numerical issues}

The numerical oscillation encountered at low plume drag coefficients also developed along the thickest part of the wall-flow for $c_{1}=0.035$ and higher. It did not become unstable for our values of entrainment coefficient. The results displayed in Figs. 7c, 10 5 and 11 have no oscillation along the wall since it was readily removed by halving the size of the time step as before.

For $c_{1}=0.030$ and higher the flow is only quasi steady with numerical noise from the spin up persisting close to the grounding line to the left of the glacial inflow. However, as entrainment increases above $c_{1}=0.04$ numerical noise is replaced by dis$x$ wave motion across the glacial inflow. In Fig. 11a showing the instantaneous $x$-velocity field for $c_{1}=0.06$, four waves with a wavelength of $8-10 \mathrm{~km}$ are visible. We found that they were not affected by the change in time step, but the grounding line flow is poorly resolved. They may be artificial internal gravity waves resulting from baroclinic instability along the glacial inflow. The Rossby number remains small, i.e.

$15 R o=U / L f \approx 0.5 /\left(3000 \times 1.4 \times 10^{-4}\right)=1.2$, even though the grounding line flow all but disappears at very high coefficients. The forcing term in the momentum balance due to plume density gradient in the $x$-direction, Eq. (27), also increases along the glacial inflow by an order of magnitude compared to the maximum value in the standard experiment. This is not only because the plume density gradient increases, but also because the plume thickens rapidly, reaching $30 \mathrm{~m}$ within a few grid cells of the grounding line, as well.

The results from experiments with $c_{1}=0.04,0.05$ and 0.06 in Figs. $7 c$ and 10 have not been included in our discussion not because they contain artificial internal waves, but because their ambient temperature has become unphysical. From Figs. 11b we can see that the ambient temperature of these experiments exceeds $1^{\circ} \mathrm{C}$ in part of the domain. It is physically impossible for the temperature to exceed the maximum background ocean temperature, which is $1^{\circ} \mathrm{C}$, in the absence of any heat sources. This warm water is generated beneath the wall-flow where entrainment rates are high,
GMDD

4, 65-136, 2011

\section{A two-layer flow model to represent ice-ocean interactions}

V. Lee et al.

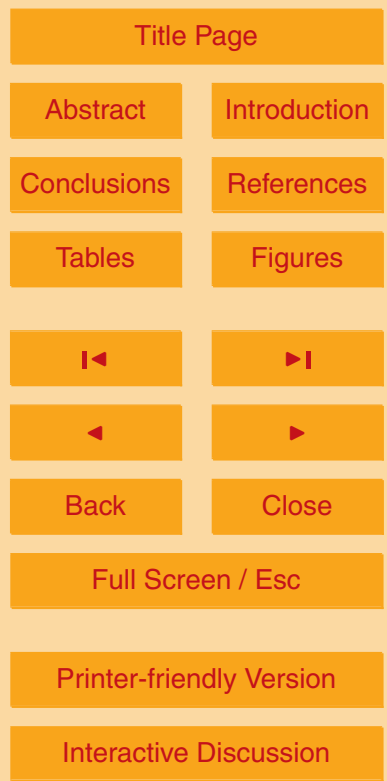


and sweeps across the grounding line. We have found that the scalar properties tend to become unphysical when the entrainment terms in their Eqs. (38) and (36) become large. This is particularly true of the plume in the original one-layer nonlinear model.

\subsubsection{Eddy diffusivity}

5 The range of scalar properties decreases as eddy diffusivity increases from 50 to $1000 \mathrm{~m}^{2} \mathrm{~s}^{-1}$, as one would expect. In the plume spatial patterns of the scalar properties become more fuzzy, while in the ambient advection of scalar properties beneath the wall-flow from the open boundary gives way to diffusive cooling and freshening of warm salty water from the grounding line. The effects of varying the eddy diffusivity are 10 small and mostly unsurprising as suggested by the variation of melt rates in Fig. $7 \mathrm{~d}$. The wall-flow weakens slightly as diffusivity increases where its thickness, speed and entrainment decreases while it spreads slightly further from the wall as it travels to the ice shelf front. The extent of the ground line flow also decreases slightly. However, plume speed increases here and in the interior as diffusivity increases and is marked by increasing values of the ninety-fifth percentile. Consequently, the mean values of plume speed, thickness and entrainment increase slightly as diffusivity increases.

The circulation in the whole cavity alters slightly where the two main gyres observed in Fig. 5a weaken as diffusivity increases and the gyres on the corners of the glacial inflow grow and merge with the others. The ambient flow slows slightly beneath the wall-flow, but increases towards the glacial inflow and, in particular, around the inflow's corners. Overall, the mean ambient speed increases as diffusivity increases. This increase in circulation around the inflow means that the plume flow from the glacial inflow becomes distinct from the rest of the surrounding grounding line flow for high eddy diffusivities. Plume velocity away from the inflow increases along with entrainment.

The variation of melt rates with eddy diffusivity are displayed in Fig. $7 \mathrm{~d}$. We found that the ambient temperature fields became unphysical for experiments with the smallest eddy diffusivities, 1.0 and $5.0 \mathrm{~m}^{2} \mathrm{~s}^{-1}$, and so their results are not discussed. Melt rates in the wall-flow are affected most with maximum values decreasing by $26.6 \mathrm{~m} \mathrm{yr}^{-1}$
GMDD

4, 65-136, 2011

\section{A two-layer flow model to represent ice-ocean interactions}

V. Lee et al.

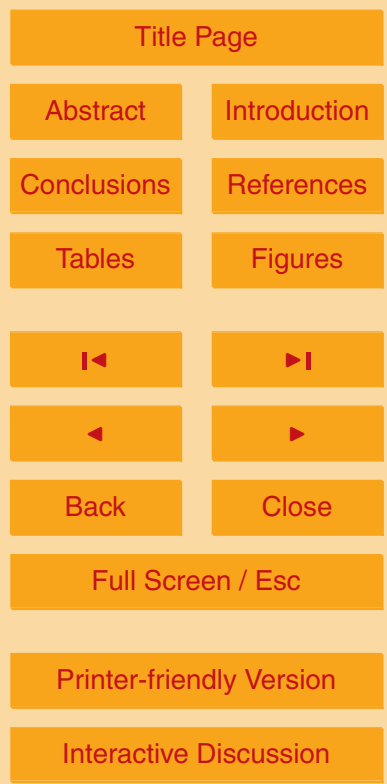

Interactive Discussion 
as eddy diffusivity increases from 50 to $1000 \mathrm{~m}^{2} \mathrm{~s}^{-1}$. They remain high towards the ice shelf front for low diffusivity, but then the maximum rates retreat towards the grounding line as the wall-flow weakens. Mean values decrease only slightly by $1.8 \mathrm{~m} \mathrm{yr}^{-1}$ because the spread of the wall-flow and the grounding line regimes increase. We 5 stated earlier that the grounding line flow speeds up as diffusivity increases, but this has not led to an increase in melt rates. Instead, the enhanced entrainment from the glacial inflow weakens the melt rates and the ninety-fifth percentile values decrease by $9.9 \mathrm{~m} \mathrm{yr}^{-1}$. This is because the plume is cooled and freshened by entraining ambient water that becomes cooler and fresher near the grounding line as diffusivity increases.

The cooling and freshening of the plume downstream of the glacial inflow corresponds to decreases in the ninety-fifth percentiles of the scalar properties, while the fifth percentiles increase simply by diffusion in the interior near the ice shelf front. This results in the range of the fifth and ninety-fifth percentiles for plume temperature and salinity decreasing by $0.22^{\circ} \mathrm{C}$ and 0.08 , respectively, as eddy diffusivity increases from 1550 to $1000 \mathrm{~m}^{2} \mathrm{~s}^{-1}$.

The range of ambient's scalar properties shown in Fig. 12a decreases by over a third from 0.17 to $0.05^{\circ} \mathrm{C}$. For low diffusivity water close to the grounding line remains relatively warm and there is distinct advection of heat from the open boundary below the wall-flow across the domain. Also, the effects of ambient advection can be seen in the 20 plume fields. For $K_{\mathrm{h}}=1000 \mathrm{~m}^{2} \mathrm{~s}^{-1}$ there is no visible advection and most of the variation is smoothed away. The values of the ambient temperature field lie between the extreme values at the open boundary which are 0.76 and $0.86^{\circ} \mathrm{C}$.

However, varying the eddy diffusivity does not only affect the spatial pattern of the ambient temperature, but also its temporal behaviour. Figure $12 \mathrm{~b}$ shows the evolution of the spatial mean ambient temperature. It is clear that it has not reached a steady state within the 50 day simulation and that the rate at which it tends to a steady state increases with diffusion. The ambient is obviously dominated by diffusion, even at low eddy diffusivity, and its scalar properties tend to values between the extreme values at the open boundary.

\section{GMDD}

4, 65-136, 2011

\section{A two-layer flow model to represent ice-ocean interactions}

V. Lee et al.

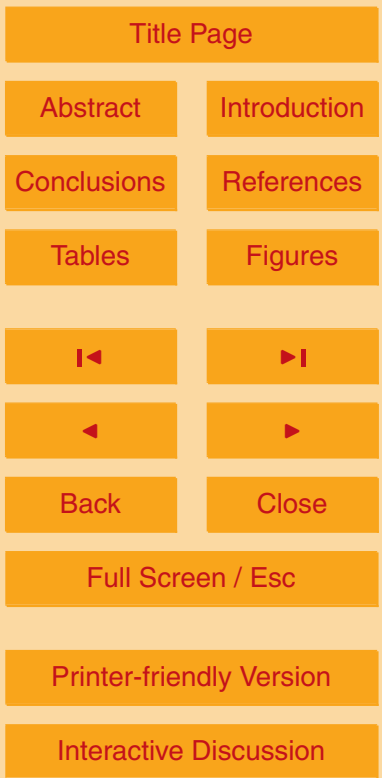




\subsection{Latin hypercube experiments}

The parameter space for all four flow parameters was randomly sampled using a Latin hypercube to generate 50 experiments. All the experiments completed the 50 day simulation, although seven experiments developed the numerical wall-flow oscillation and 5 one, with the lowest eddy diffusivity, exceeded the maximum background ocean temperature of $1^{\circ} \mathrm{C}$. The oscillation tended to occur in experiments with high entrainment coefficients and low plume drag coefficient and was characterized by values of both components of plume velocity lying outside $\pm 100.0 \mathrm{~cm} \mathrm{~s}^{-1}$. Simple linear regression analysis using the ordinary least squares method was performed on 42 experiments, 10 while the eight with unphysical results were treated as outliers and excluded from the regression.

Figure 13 shows the relationships of the individual flow parameters on the temporal and spatial mean melt rates. Clearly, the entrainment coefficient is the dominant parameter with a high R-squared value of 0.968 and an F-test $p$-value of less than

$151 \times 10^{-10}$, which indicates that the relationship is very unlikely due to chance, while the weakest bivariate correlation is with the plume drag coefficient. However, a multiple regression model with both entrainment and plume drag coefficients provides a better correlation with R-squared value of 0.991 and $p$-value of less than $1 \times 10^{-10}$.

The strongest relationship between one of the four parameters for each of the main variables are shown in Fig. 14. The entrainment coefficient accounts for most of the variation in the mean values with $\mathrm{R}$-squared value of over 0.8 for most variables except plume velocity, ambient scalar properties and the streamfunction. The ambient scalar properties vary strongly with eddy diffusivity instead. The description of the mean values can be improved by including more of the flow parameters in the regression model. 25 The results of multiple regression analysis are summarized in Table 2 . The plume drag coefficient appears unimportant when considered individually, but as part of a combination it can improve the model. Eddy diffusivity also improves the model for the $x$-component of velocity as well as the plume density and salinity (but not the plume

\section{GMDD}

4, 65-136, 2011

\section{A two-layer flow model to represent ice-ocean interactions}

V. Lee et al.

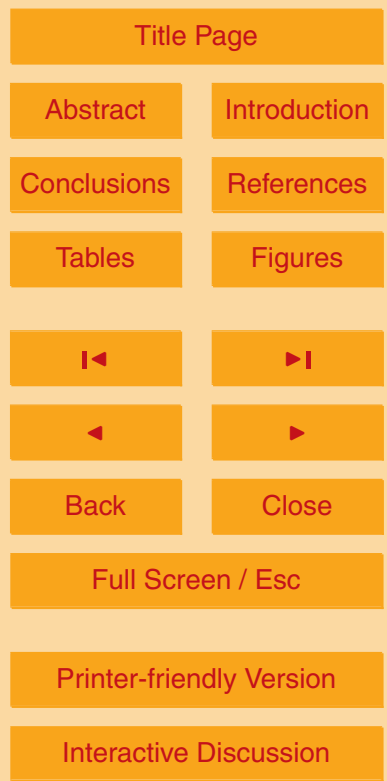


temperature). The R-squared values for the multiple regressions are all greater than 0.9 , except $y$-component of plume velocity and streamfunction. These two may be poorly correlated or may have nonlinear relationships to the flow parameters. Interestingly, the cavity drag coefficient appears to have no effect on the variables within our 5 linear analysis.

\section{Conclusions and future development}

The model was tested using an idealized sub-ice cavity geometry based on the dimensions of an ice shelf fed by Pine Island Glacier. The flow tends towards a geostrophic steady state where a dynamic meltwater plume exists everywhere beneath the shelf 10 and the ambient is almost static and homogeneous. The mean melt rate for the standard experiment is $30.6 \mathrm{~m} \mathrm{yr}^{1}$ with no basal freezing. The spatial pattern is highly localized with melt rates reaching about $75 \mathrm{~m} \mathrm{yr}^{1}$ within about $25 \mathrm{~km}$ of the grounding line where the slope of the underside of the shelf is greatest and a maximum rate of $121.0 \mathrm{~m} \mathrm{yr}^{1}$ close to the left-hand wall where the geostrophic plume flow converges.

15 These regions are characterized by high speed plume flow which results in high entrainment rates that warm and increase the salinity of the plume water. The spatial pattern is reasonably robust when the flow parameters are varied. For faster plume flows the highest melt rates are more concentrated in the wall-flow rather than close to the grounding line. Quantitatively, melt rates are far more variable. Mean values 20 anywhere between 1 and $50 \mathrm{~m} \mathrm{yr}^{1}$ could be obtained by varying a combination of the entrainment and plume drag coefficients.

The behaviour of our model appears plausible compared to that of the reduced gravity plume model (Holland and Feltham, 2006; Payne et al., 2007) using the same geometry and parameter values. However, we make no attempt to compare our model results with observations. This is because we use an idealized geometry and we have not tuned any of the parameters. When the reduced gravity plume model was run with realistic ice shelf topography, Payne et al. (2007) found that geostrophic flow
GMDD

4, 65-136, 2011

\section{A two-layer flow model to represent ice-ocean interactions}

V. Lee et al.

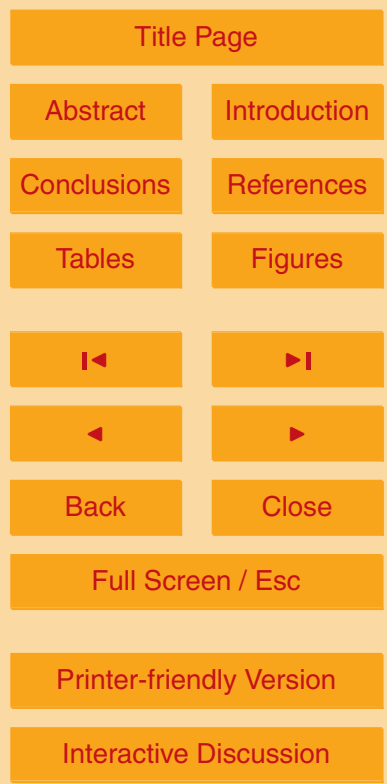

Interactive Discussion 
converged along channels in the underside of the shelf rather than along the lateral boundary. Also, there is little observational data with which to compare. Jenkins et al. (2010) have published the only direct observations which consist of bathymetry, topography of the underside of the shelf and water properties taken from six missions of an 5 autonomous underwater vehicle beneath the shelf made in January 2009. The only published oceanographic measurements (Jacobs et al., 1996) were taken from three sites within about $500 \mathrm{~m}$ of the ice shelf front in March 1994. Estimates of melt rates have been inferred from the ocean temperature and salinity profiles and glaciological observations from satellites. They range from $10-15 \mathrm{~m} \mathrm{yr}^{-1}$ (Jacobs et al., 1996; 10 Jenkins et al., 1997; Shepherd et al., 2004) to $26 \mathrm{~m} \mathrm{yr}^{-1}$ (Payne et al., 2007) and $24 \pm 4 \mathrm{~m} \mathrm{yr}^{-1}$ (Rignot, 1998). While the mean melt rate from our standard experiment is too high compared to these estimates, the results of the sensitivity study indicate that the flow parameter can be tuned to any of these values. Our spatial pattern cannot be confirmed with observations. However, Rignot (1998) and Payne et al. (2007) have 15 estimated that melt rates within about $20 \mathrm{~km}$ of the grounding line are enhanced with a local average of $50 \pm 10 \mathrm{~m} \mathrm{yr}^{-1}$ and maximum values over $100 \mathrm{~m} \mathrm{yr}^{-1}$, respectively.

In the modelled ambient, ocean properties from the shelf front are advected towards the grounding line beneath the plume's wall-flow. However, this flow is very weak. We find that even by varying the flow parameters valid values of the mean ambient speed do not exceed $1 \mathrm{~cm} \mathrm{~s}^{-1}$, compared to the mean plume speed which varies between 7 and $20 \mathrm{~cm} \mathrm{~s}^{-1}$. The weak ambient flow is consistent with mass conservation because the fast moving plume, with a mean thickness of less than $20 \mathrm{~m}$, occupies a small portion of the water column, which varies between 300 and $700 \mathrm{~m}$. The dominant process in the ambient is diffusion, which means that temperature and salinity tend towards values within the narrow range of the vertically averaged ocean properties directly beneath the shelf front. A lack of spatial variation in the water properties at depth beneath Pine Island Ice Shelf appears to be a feature of the first $20 \mathrm{~km}$ from the front (Jenkins et al., 2010). Further into the cavity comparisons end because there is a large rise in the bedrock, which is not present in our geometry.

\section{GMDD}

4, 65-136, 2011

\section{A two-layer flow model to represent ice-ocean interactions}

V. Lee et al.

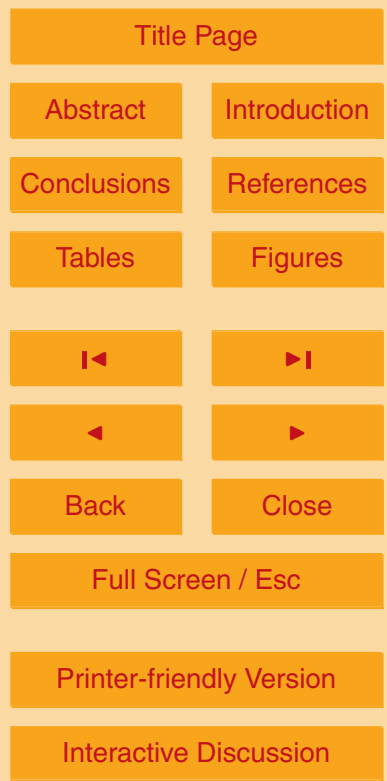


Varying poorly constrained flow parameters reveals that mean values of most of the model's variables are most strongly dependent on the entrainment coefficient. The main exceptions are the scalar properties of the ambient which strongly depended on the eddy diffusivity. These results confirm the importance of entrainment across the 5 plume-ambient interface and the dominance of diffusion in the ambient. Interestingly, most variable fields are also sensitive to the plume drag coefficient when it was varied individually, but linear regression of mean values from experiments where four flow parameters are randomly varied simultaneously shows only weak correlations with the coefficient. Whereas, results of multiple regression analysis reveal that strong corre10 lations with $R$-squared values of over 0.9 are obtained with linear combinations of the plume drag coefficient and the entrainment coefficient and/or eddy diffusivity. The only two exceptions are the streamfunction and $y$-component of plume velocity, which are either poorly correlated or have nonlinear relationships with the flow parameters. Importantly, the sensitivity study reveals that model output is insensitive to the cavity drag 5 coefficient. This suggests that our choice of linear drag law in the cavity's momentum equation does not interfere with our model results.

The model is well behaved for flow parameters that produced feasible mean melt rates. A numerical issue that may restrict the size of the timestep is the oscillation that develops along the thickest part of the wall-flow for low plume drag and high entrainment coefficients. We speculate that the oscillation is a consequence of the frictional geostrophic balance. It may occur because frictional drag, which is inversely proportional to plume thickness, decreases along the rigid boundary making the no normal flow boundary condition difficult to resolve. The oscillation introduces spurious plume velocity values that distort the melt rates, but the simulation only breaks down when the Courant condition is violated. The stability of the numerical code could be improved by replacing the explicit time stepping scheme used to evolve the equations for the scalar properties with an implicit scheme. The equations would take longer to solve at each timestep, but this could be mitigated somewhat by exploiting the fact that the matrix of coefficients would be the same for both temperature and salinity in each layer and

\section{GMDD}

4, 65-136, 2011

\section{A two-layer flow model to represent ice-ocean interactions}

V. Lee et al.

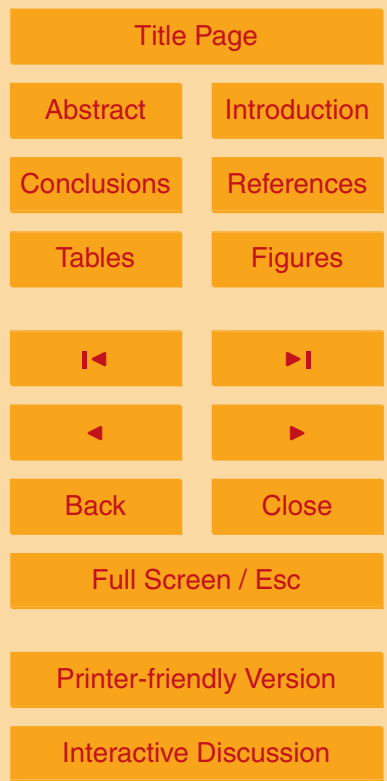


using a parallel linear solver. However, the implicit scheme will not stop the oscillation developing. Only reducing the size of the timestep will prevent its development.

We have established that our model can simulate strong spatial patterns of melt rates that can be tuned to observations, which makes it a good candidate for coupling 5 to ice sheet models. The coupling will involve passing time-averaged melt rates to the ice sheet model in exchange for the core ice temperature and topography of the underside of the ice shelf. How and when the fields will be passed depends on the grid and timestep size of each model. They will need to be interpolated between the two grids because it has been suggested that ice sheet models will require resolution of $10200-400 \mathrm{~m}$ to adequately capture grounding line motion (Gladstone et al., 2010). The timestep for the ice sheet model is determined by the Courant condition, so for typical ice stream velocities of a few hundred metres a year (Paterson, 1994) the timestep will be around one year. Even for Pine Island Glacier, where maximum velocities are around $2.5 \mathrm{~km} \mathrm{yr}^{-1}$ (Joughin et al., 2003), the timestep of around one month is large 5 compared to the timestep of $60 \mathrm{~s}$ used in our standard experiment. The difference in time scales will be handled by assuming that the plume flow will adjust quickly to changes in the overlying ice. Our model need only supply time-averaged melt rates from a steady state to the ice sheet model so that it can take a time step. When our model receives the new core ice temperature and shelf topography it will effectively restart. The cavity's land mask will be recalculated and the variables initialized with values from the end of the previous run. The new run will last long enough to adjust to a new equilibrium and to produce sufficient data to calculate the time-average melt rates. Initializing variables in the cavity model are straightforward unless changes in the ice shelf topography expand the lateral boundaries, such as for a retreating grounding line. In this case new ocean cells could be initialized by setting the velocities and plume thickness to zero and either extrapolating or averaging values from nearby old cells for the scalar properties in the ambient. The wetting and drying scheme (Jungclaus and Backhaus, 1994) should spread the plume to fill the new cells as our model runs.

\section{GMDD}

4, 65-136, 2011

\section{A two-layer flow model to represent ice-ocean interactions}

V. Lee et al.

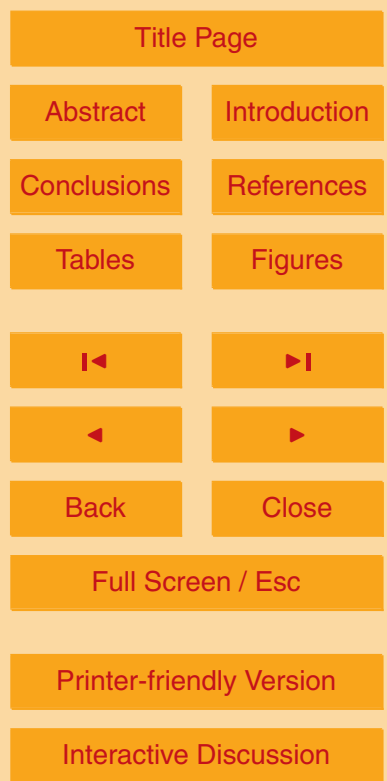


Further work and testing will need to be carried out on the two-layer flow model before a coupled model could be applied to the whole Antarctic Ice Sheet. We would need to demonstrate that the two-layer model could simulate basal freezing. In particular, we need to know what would happen if the plume loses buoyancy as freezing increases 5 salinity and it separates from the underside of the ice shelf. In order to simulate several sub-ice cavities at once, the run time of the two-layer model will be extremely important. Improvements in efficiency, such as using parallel solvers, could be made to the numerical scheme presented in this paper. If these did not sufficiently reduce run time, there is scope to simplify the model further. We find that the addition of the ambient 10 layer does not change the dynamics of the plume significantly and the assumption of stationary ambient made in the reduced-gravity model does not appear a bad approximation. We also find that the scalar properties of the ambient were driven by diffusion rather than advection, so we could replace the full prognostic scalar equation in the ambient with a diffusion equation. This would mean that the rigid lid streamfunction method could be dropped, which would save computational time significantly.

Acknowledgements. This work was supported by the UK Natural Enviroment Research Council through Theme 5 of the National Centre for Earth Observations. We would like to thank Paul Holland and Adrian Jenkins for their helpful criticism of the mathematical model.

\section{References}

Anderson, J. D.: Computational Fluid Dynamics: the Basics with Applications, McGraw-Hill Series in Mechanical Engineering, McGraw-Hill, Inc., New York, 1995. 90

Balay, S., Buschelman, K., Gropp, W. D., Kaushik, D., Knepley, M. G., Mclnnes, L. C., Smith, B. F., and Zhang, H.: PETSc Web page, http://www.mcs.anl.gov/petsc, last access: 12 January 2011, 2009. 88

25 Bamber, J. L., Riva, R. E. M., Vermeersen, B. L. A., and LeBrocq, A. M.: Reassessment of the potential sea-level rise from a collapse of the West Antarctic ice sheet, Science, 324, 901-903, doi:10.1126/science.1169335, 2009. 67

Beckmann, A. and Goosse, $\mathrm{H}$.: A parameterization of ice shelf-ocean interaction for climate models, Ocean Model., 5, 157-170, doi:10.1016/S1463-5003(02)00019-7, 2003. 68

\section{GMDD}

4, 65-136, 2011

\section{A two-layer flow model to represent ice-ocean interactions}

V. Lee et al.

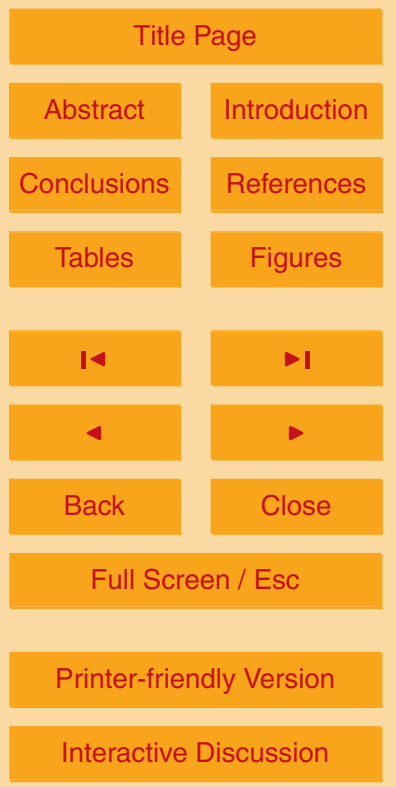

Interactive Discussion 
Blayo, E. and Debreu, L.: Revisiting open boundary conditions from the point of view of characteristic variables, Ocean Model., 9, 231-252, doi:10.1016/j.ocemod.2004.07.001, 2005. 89

Determann, J. and Gerdes, R.: Melting and freezing beneath ice shelves: implications from a three-dimensional ocean-circulation model, Ann. Glaciol., 20, 413-419, 1994. 68

Edwards, N., Willmott, A. J., and Killworth, P. D.: On the role of topography and wind stress on the stability of the thermohaline circulation, J. Phys. Oceanogr., 28, 756-778, doi:10.1175/1520-0485(1998)028<0756:OTROTA>2.0.CO;2, 1998. 72

Ferziger, J. H. and Perić, M.: Computational Methods for Fluid Dynamics, Springer-Verlag, Berlin Heidelberg New York, 3rd edn., 2002. 88, 103

Gade, H. G.: Melting of ice in sea water: a primitive model with application to the Antarctic ice shelf and icebergs, J. Phys. Oceanogr., 9, 189-198, doi:10.1175/15200485(1979)009<0189:MOIISW>2.0.CO;2, 1979. 89

Gerdes, R., Determann, J., and Grosfeld, K.: Ocean circulation beneath Filchner-Ronne Ice 15 Shelf from three-dimensional model results, J. Geophys. Res.-Oceans, 104, 15827-15842, doi:10.1029/1999JC900053, 1999. 68

Gille, S. T.: Warming of the Southern Ocean since the 1950s, Science, 295, 1275-1277, doi:10.1126/science.1065863, 2002. 68

Gladstone, R. M., Lee, V., Vieli, A., and Payne, A. J.: Grounding line migration in an adaptive mesh ice sheet model, J. Geophys. Res.-Earth, 115, F04014, doi:0.1029/2009JF001615, 2010. 115

Grosfeld, K. and Sandhäger, $H_{\text {.: }}$ The evolution of a coupled ice shelf-ocean system under different climate states, Global Planet. Change, 42, 107-132, doi:10.1016/j.gloplacha.2003.11.004, 2004. 68

Grosfeld, K., Gerdes, R., and Determann, J.: Thermohaline circulation and interaction between ice shelf cavities and the adjacent open ocean, J. Geophys. Res.-Oceans, 102, 1559515610, doi:10.1029/97JC00891, 1997. 68

Hattermann, T. and Levermann, A.: Response of Southern Ocean circulation to global warming may enhance basal ice shelf melting around Antarctica, Clim. Dynam., 35, 741-756, 30 doi:10.1007/s00382-009-0643-3, 2010. 68

Hellmer, H. H. and Olbers, D. J.: A two-dimensional model for the thermohaline circulation under an ice shelf, Antarct. Sci., 1, 325-336, doi:10.1017/S0954102089000490, 1989. 69

Holland, D. M. and Jenkins, A.: Adaptation of an isopycnic coordinate ocean model for the study
GMDD

4, 65-136, 2011

\section{A two-layer flow model to represent ice-ocean interactions}

V. Lee et al.

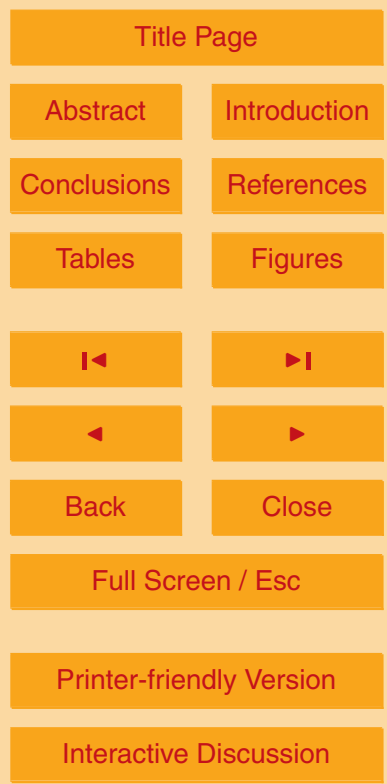


of circulation beneath ice shelves, Mon. Weather Rev., 129, 1905-1927, doi:10.1175/15200493(2001)129<1905:AOAICO>2.0.CO;2, 2001. 68

Holland, P. R. and Feltham, D. L.: The effects of rotation and ice shelf topography on frazil-laden ice shelf water plumes, J. Phys. Oceanogr., 36, 2312-2327, doi:10.1175/JPO2970.1, 2006. $5 \quad 69,80,82,89,96,112$

Holland, P. R., Jenkins, A., and Holland, D. M.: The response of ice shelf basal melting to variations in ocean temperature, J. Climate, 21, 2558-2572, doi:10.1175/2007JCLI1909.1, 2008. 68, 72, 91

Jacobs, S. S., Hellmer, H. H., and Jenkins, A.: Antarctic ice sheet melting in the Southeast Pacific, Geophys. Res. Lett., 23, 957-960, doi:10.1029/96GL00723, 1996. 92, 113

Jenkins, A. and Bombosch, A.: Modeling the effects of frazil ice crytals on the dynamics and thermodynamics of Ice Shelf Water plumes, J. Geophys. Res.-Oceans, 100, 6967-6981, doi:10.1029/94JC03227, 1995. 82

Jenkins, A., Vaughan, D. G., Jacobs, S. S., Hellmer, H. H., and Keys, J. R.: Glaciological and 15 oceanographic evidence of high melt rates beneath Pine island glacier, west Antarctica, J. Glaciol., 43, 114-121, 1997. 113

Jenkins, A., Dutrieux, P., Jacobs, S. S., McPhail, S. D., Perrett, J. R., Webb, A. T., and White, D.: Observations beneath Pine Island Glacier in West Antarctica and implications for its retreat, Nat. Geosci., 3, 468-472, doi:10.1038/ngeo890, 2010. 67, 113 recent accelerations of Pine Island Glacier, Antarctica, Geophys. Res. Lett., 30, 1706, doi:10.1029/2003GL017609, 2003. 66, 115

Jungclaus, J. H. and Backhaus, J. O.: Application of a transient reduced gravity plume model to the Denmark Strait Overflow, J. Geophys. Res., 99, 12375-12396, doi:10.1029/2006JG000274, 1994. 81, 82, 88, 89, 93, 96, 115

Kochergin, V. P.: Three-dimensional prognostic models, vol. 4 of Coastal and Estuarine Sciences, American Geophysical Union, pp. 201-208, American Geophysical Union, Washington, D. C., 1987. 81

Lange, M. A., Blindow, N., Breuer, B., Grosfeld, K., Kleiner, T., Mohrholz, C. O., Nico30 laus, M., Oelke, C., Sandhager, H., and Thoma, M.: Numerical model studies of Antarctic ice-sheet-ice-shelf-ocean systems and ice caps, Ann. Glaciol., 41, 111-120, doi:10.3189/172756405781813186, 2005. 68

Little, C. M., Gnanadesikan, A., and Oppenheimer, M.: How ice shelf morphology controls basal

GMDD

$4,65-136,2011$

\section{A two-layer flow model to represent ice-ocean interactions}

V. Lee et al.

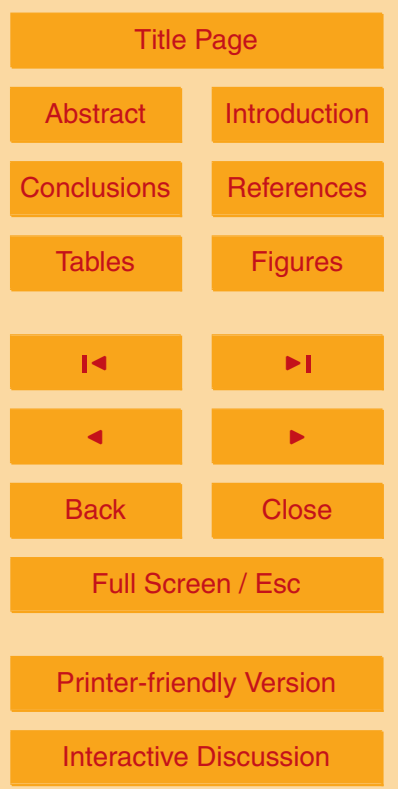


melting, J. Geophys. Res.-Oceans, 114, C12 007, doi:10.1029/2008JC005197, 2009. 68

Losch, M.: Modeling ice shelf cavities in a $\mathrm{z}$ coordinate ocean general circulation model, $\mathrm{J}$. Geophys. Res.-Oceans, 113, C08043, doi:10.1029/2007JC004368, 2008. 68

Mellor, G. L. and Durbin, P. A.: The structure and dynamics of the ocean surface mixed layer, J.

$5 \quad$ Phys. Oceanogr., 5, 718-728, doi:10.1175/1520-0485(1975)005<0718:TSADOT>2.0.CO;2, 1975. 81

Mercer, J. H.: West Antarctis ice sheet and $\mathrm{CO}_{2}$ greenhouse effect: threat of disaster, Nature, 271, 321-325, doi:10.1038/271321a0, 1978. 67

Mesinger, F. and Arakawa, A.: Numerical Methods Used in Atmospheric Models, vol. 1 of GARP Publications Series No. 17, WMO-ICSU Joint Organizing Committee, Geneva, 1976. 83

Olbers, D. and Hellmer, H.: A box model of circulation and melting in ice shelf caverns, Ocean Dynam., 60, 141-153, doi:10.1007/s10236-009-0252-z, 2010. 68

Paterson, W. S. B.: The Physics of Glaciers, Butterworth-Heinemann, Oxford, 3rd edn., 1994. 115

Payne, A. J., Vieli, A., Shepherd, A. P., Wingham, D. J., and Rignot, E.: Recent dramatic thinning of largest West Antarctic ice stream triggered by oceans, Geophys. Res. Lett., 31, L23401, doi:10.1029/2004GL021284, 2004. 67

Payne, A. J., Holland, P. R., Shepherd, A. P., Rutt, I. C., Jenkins, A., and Joughin, I.: Numerical modeling of ocean-ice interactions under Pine Island Bay's ice shelf, J. Geophys. Res.-Oceans, 112, C10019, doi:10.1029/2006JC003733, 2007. 69, 72, 73, 90, 92, 96, 112, 113

Pritchard, H. D., Arthern, R. J., Vaughan, D. G., and Edwards, L. A.: Extensive dynamic thinning on the margins of the Greenland and Antarctic ice sheets, Nature, 461, 971-975, doi:10.1038/nature08471, 2009. 67

Rignot, E. J.: Fast recession of a West Antarctic glacier, Science, 281, 549-551, doi:10.1126/science.281.5376.549, 1998. 67, 69, 113

Rignot, E., Vaughan, D. G., Schmeltz, M., Dupont, T., and MacAyeal, D.: Acceleration of Pine Island and Thwaites Glaciers, West Antarctica, Ann. Glaciol., 34, 189-194, doi:10.3189/172756402781817950, 2002. 67

30 Salmon, R.: Lectures on Geophysical Fluid Dynamics, Oxford University Press, New York, 1998. 72

Samelson, R. M. and Vallis, G. K.: A simple friction and diffusion scheme for planetary geostrophic basin models, J. Phys. Oceanogr., 27, 186-194, doi:10.1175/1520-
GMDD

4, 65-136, 2011

\section{A two-layer flow model to represent ice-ocean interactions}

V. Lee et al.

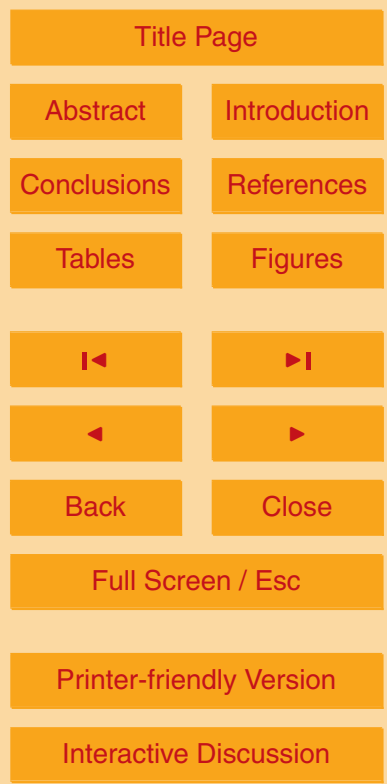

Interactive Discussion 
0485(1997)027<0186:ASFADS>2.0.CO;2, 1997. 72

Schoof, C.: Ice sheet grounding line dynamics: steady states, stability, and hysteresis, J. Geophys. Res.-Earth, 112, F03S28, doi:10.1029/2006JF000664, 2007. 67

Scott, J. B. T., Gudmundsson, G. H., Smith, A. M., Bingham, R. G., Pritchard, H. D., and 5 Vaughan, D. G.: Increased rate of acceleration on Pine Island Glacier strongly coupled to changes in gravitational driving stress, The Cryosphere, 3, 125-131, doi:10.5194/tc-3-1252009, 2009. 67

Shepherd, A., Wingham, D. J., and Mansley, J. A. D.: Inland thinning of the Amundsen Sea sector, West Antarctica, Geophys. Res. Lett., 29, 10, doi:10.1029/2001GL014183, 2002. 66

Shepherd, A., Wingham, D., and Rignot, E.: Warm ocean is eroding West Antarctic Ice Sheet, Geophys. Res. Lett., 31, L23402, doi:10.1029/2004GL021106, 2004. 66, 113

Thoma, M., Jenkins, A., Holland, D., and Jacobs, S.: Modelling circumpolar deep water intrusions on the Amundsen Sea continental shelf, Antarctica, Geophys. Res. Lett., 35, L18602, doi:10.1029/2008GL034939, 2008. 68

van der Veen, C. J.: Fundamentals of Glacier Dynamics, A. A. Balkema, Rotterdam, 1999. 91

Walker, R. T. and Holland, D. M.: A two-dimensional coupled model for ice shelf-ocean interaction, Ocean Model., 17, 123-139, doi:10.1016/j.ocemod.2007.01.001, 2007. 69

Weertman, J.: Stability of the junction of an ice sheet and an ice shelf, J. Glaciol., 13, 3-11, 1974. 67

Williams, M. J. M., Warner, R. C., and Budd, W. F.: The effects of ocean warming on melting and ocean circulation uner the Amery Ice Shelf, East Antarctica, Ann. Glaciol., 27, 75-80, 1998. 68

Williams, M. J. M., Grosfeld, K., Warner, R. C., Gerdes, R., and Determann, J.: Ocean circulation and ice-ocean interaction beneath the Amery Ice Shelf, Antarctica, J. Geophys. Res.-Oceans, 106, 22383-22399, doi:10.1029/2000JC000236, 2001. 68

Wingham, D. J., Wallis, D. W., and Shepherd, A.: Spatial and temporal evolution of Pine Island Glacier thinning, 1995-2006, Geophys. Res. Lett., 36, L17501, doi:10.1029/2009GL039126, 2009. 67

Zwally, H. J., Giovinetto, M. B., Li, J., Cornejo, H. G., Beckley, M. A., Brenner, A. C., 30 Saba, J. L., and Yi, D. H.: Mass changes of the Greenland and Antarctic ice sheets and shelves and contributions to sea-level rise: 1992-2002, J. Glaciol., 51, 509-527, doi:10.3189/172756505781829007, 2005. 66
GMDD

4, 65-136, 2011

\section{A two-layer flow model to represent ice-ocean interactions}

V. Lee et al.

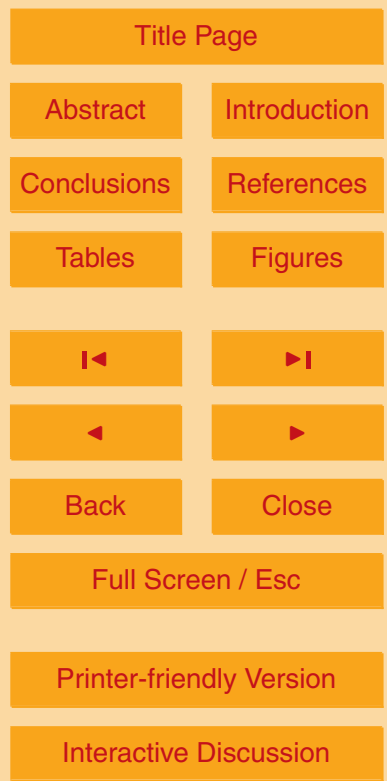


Table 1. Parameters used in the standard experiment. Starred values are varied in the sensitivity analysis.

\section{GMDD}

4, 65-136, 2011

\begin{tabular}{|c|c|c|}
\hline Symbol & Description & Value \\
\hline 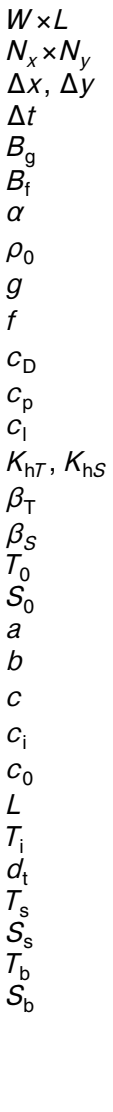 & $\begin{array}{l}\text { width and length of the cavity } \\
\text { number of computational cells } \\
\text { grid spacing } \\
\text { time step } \\
\text { depth of ice at grounding line } \\
\text { depth of ice at shelf front } \\
\text { curvature constant } \\
\text { reference density of seawater } \\
\text { gravity } \\
\text { Coriolis parameter } \\
\text { bulk cavity drag coefficient } \\
\text { plume drag coefficient } \\
\text { entrainment coefficient } \\
\text { horizontal eddy diffusivities } \\
\text { coefficient of thermal expansion } \\
\text { coefficient of haline contraction } \\
\text { reference temperature } \\
\text { reference salinity } \\
\text { constant in freezing point relation } \\
\text { constant in freezing point relation } \\
\text { constant in freezing point relation } \\
\text { heat capacity of ice } \\
\text { heat capacity of plume } \\
\text { latent heat of fusion of ice } \\
\text { core temperature of ice shelf } \\
\text { depth of thermocline and halocline } \\
\text { surface mean ocean temperature } \\
\text { surface mean ocean salinity } \\
\text { bottom mean ocean temperature } \\
\text { bottom mean ocean salinity } \\
\text { glacial inflow thickness } \\
\text { glacial inflow temperature } \\
\text { glacial inflow salinity }\end{array}$ & $\begin{array}{c}60 \times 70 \mathrm{~km} \\
64 \times 72 \\
1000 \mathrm{~m} \\
60 \mathrm{~s} \\
900 \mathrm{~m} \\
300 \mathrm{~m} \\
2 \\
1030.0 \mathrm{~kg} \mathrm{~m}^{-3} \\
9.81 \mathrm{~m} \mathrm{~s}^{-1} \\
-1.415 \times 10^{-4} \mathrm{~s}^{-1} \\
3.0 \times 10^{-3 *} \mathrm{~s}^{-1} \\
3.0 \times 10^{-3 \star} \\
0.02^{*} \\
100^{*} \mathrm{~m}^{2} \mathrm{~s}^{-1} \\
3.87 \times 10^{-5}{ }^{\circ} \mathrm{C}^{-1} \\
7.86 \times 10^{-4} \\
-2.0^{\circ} \mathrm{C} \\
34.5 \\
-0.0573^{\circ} \mathrm{C} \\
-0.0832^{\circ} \mathrm{C} \\
-7.61 \times 10^{-4}{ }^{\circ} \mathrm{C} \mathrm{m}^{-1} \\
2009 \mathrm{~J} \mathrm{~kg}{ }^{-1}{ }^{\circ} \mathrm{C}^{-1} \\
3974 \mathrm{Jg}^{-1} \mathrm{C}^{-1} \\
3.35 \times 10^{5} \mathrm{~J} \mathrm{~kg}^{-1} \\
-15.0^{\circ} \mathrm{C}^{-1.9} \\
600 \mathrm{~m} \\
-1.9^{\circ} \mathrm{C} \\
33.8 \\
1.0^{\circ} \mathrm{C} \\
34.7 \\
1 \mathrm{~cm}^{\circ} \\
-2.48^{\circ} \mathrm{C} \\
33.8\end{array}$ \\
\hline
\end{tabular}

\section{A two-layer flow model to represent ice-ocean interactions}

V. Lee et al.

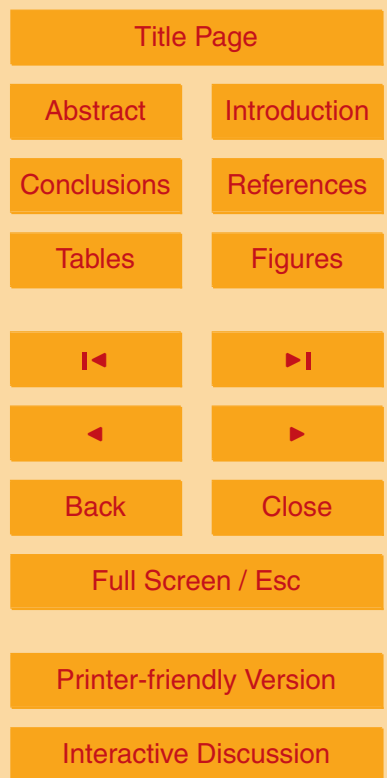


Table 2. Multiple regression of temporal and spatial mean values from the Latin hypercube experiments. Independent parameters are plume drag coefficient, $c_{\mathrm{p}}$, cavity drag coefficient, $c_{\mathrm{D}}$, entrainment coefficient, $c_{1}$, and eddy diffusivity, $K_{\mathrm{h}}$. P-values of less than $1 \times 10^{-10}$ are labelled small.

\begin{tabular}{llcc}
\hline Dependent variable & $\begin{array}{l}\text { Independent parameters } \\
\text { used in linear model }\end{array}$ & $R^{2}$ & p-value \\
\hline melt rate & $c_{\mathrm{p}}, c_{\mathrm{l}}$ & 0.991 & small \\
entrainment rate & $c_{\mathrm{p}}, c_{\mathrm{l}}$ & 0.969 & small \\
plume thickness & $c_{\mathrm{p}}, c_{\mathrm{l}}$ & 0.995 & small \\
plume velocity, $x$-component & $c_{\mathrm{p}}, c_{1}, K_{\mathrm{h}}$ & 0.918 & $\mathrm{small}$ \\
plume velocity, $y$-component & $c_{\mathrm{p}}, c_{\mathrm{D}}, c_{1}, K_{\mathrm{h}}$ & 0.435 & $2.3 \times 10^{-4}$ \\
plume density & $c_{\mathrm{p}}, c_{\mathrm{l}}, K_{\mathrm{h}}$ & 0.981 & $\mathrm{small}$ \\
plume temperature & $c_{\mathrm{p}}, c_{\mathrm{l}}$ & 0.979 & $\mathrm{small}$ \\
plume salinity & $c_{\mathrm{p}}, c_{\mathrm{l}}, K_{\mathrm{h}}$ & 0.986 & $\mathrm{small}$ \\
ambient velocity, $x$-component & $c_{\mathrm{p}}, c_{\mathrm{l}}$ & 0.956 & $\mathrm{small}$ \\
ambient velocity, $y$-component & $c_{\mathrm{p}}, c_{\mathrm{l}}$ & 0.967 & $\mathrm{small}$ \\
ambient density & $c_{\mathrm{l}}, K_{\mathrm{h}}$ & 0.964 & $\mathrm{small}$ \\
streamfunction & $c_{\mathrm{p}}, c_{\mathrm{D}}, c_{1}, K_{\mathrm{h}}$ & 0.507 & $2.1 \times 10^{-5}$ \\
\hline
\end{tabular}

\section{A two-layer flow model to represent ice-ocean interactions}

V. Lee et al.

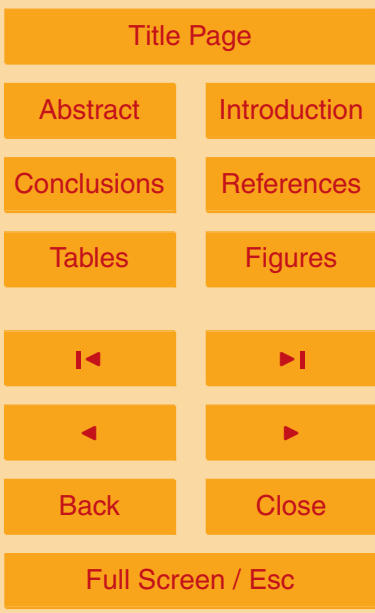

Printer-friendly Version

Interactive Discussion 


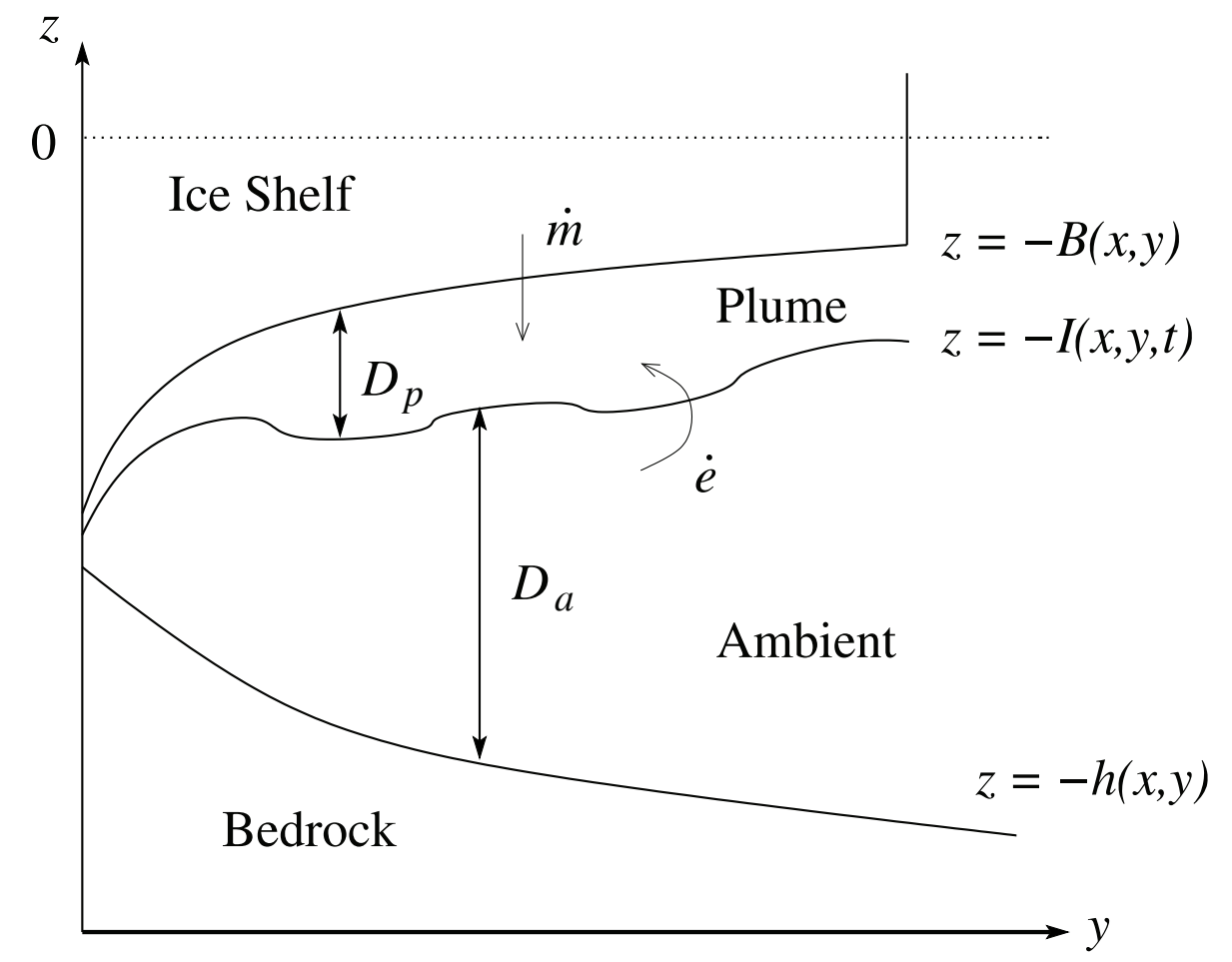

Fig. 1. Schematic of two-layer cavity model.

\section{GMDD}

4, 65-136, 2011

\section{A two-layer flow model to represent ice-ocean interactions}

V. Lee et al.

Title Page

Abstract

Introduction

Conclusions

References

Tables

Figures

14

4

Back

Full Screen / Esc

Printer-friendly Version

Interactive Discussion 

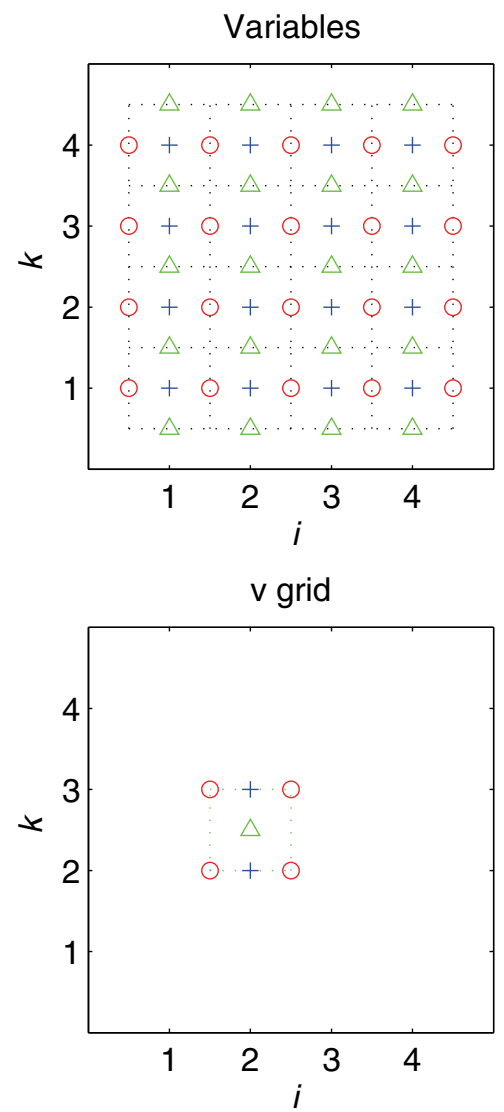
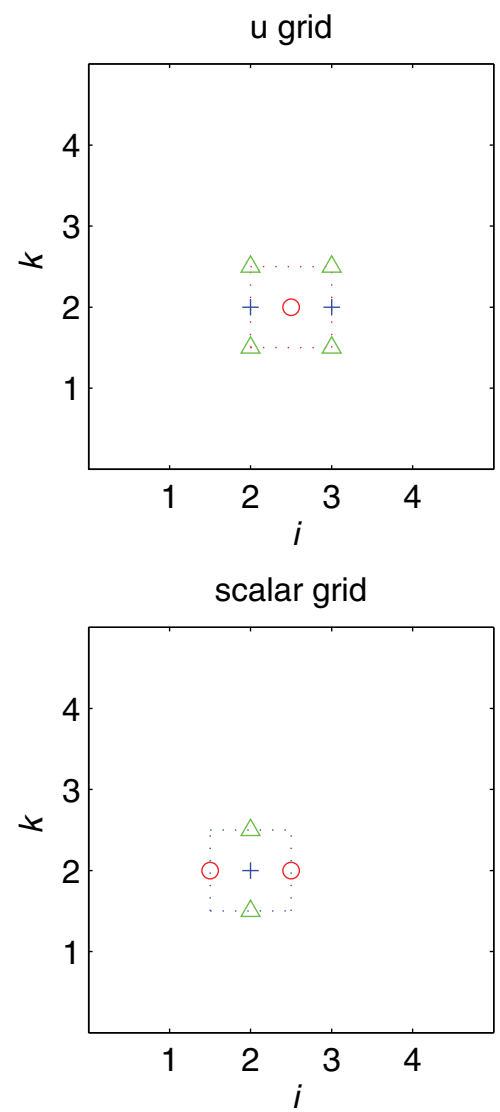

Fig. 2. Arrangements of scalars $(+), u(0)$ and $v(\triangle)$ on a C-grid. Top right panel shows arrangement on a $u$-cell with indices $(i, k)$ (cell edges marked by red dotted lines), bottom left shows a $v$-cell at $(i, k)$ (green dotted lines) and bottom right shows a scalar cell at $(i, k)$ (blue dotted lines).

\section{GMDD}

4, 65-136, 2011

\section{A two-layer flow model to represent ice-ocean interactions}

V. Lee et al.

\section{Title Page}

\section{Abstract}

Introduction

Conclusions

References

Tables

Figures

14

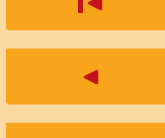

$\rightarrow$

Back

Close

\section{Full Screen / Esc}

Printer-friendly Version

Interactive Discussion 


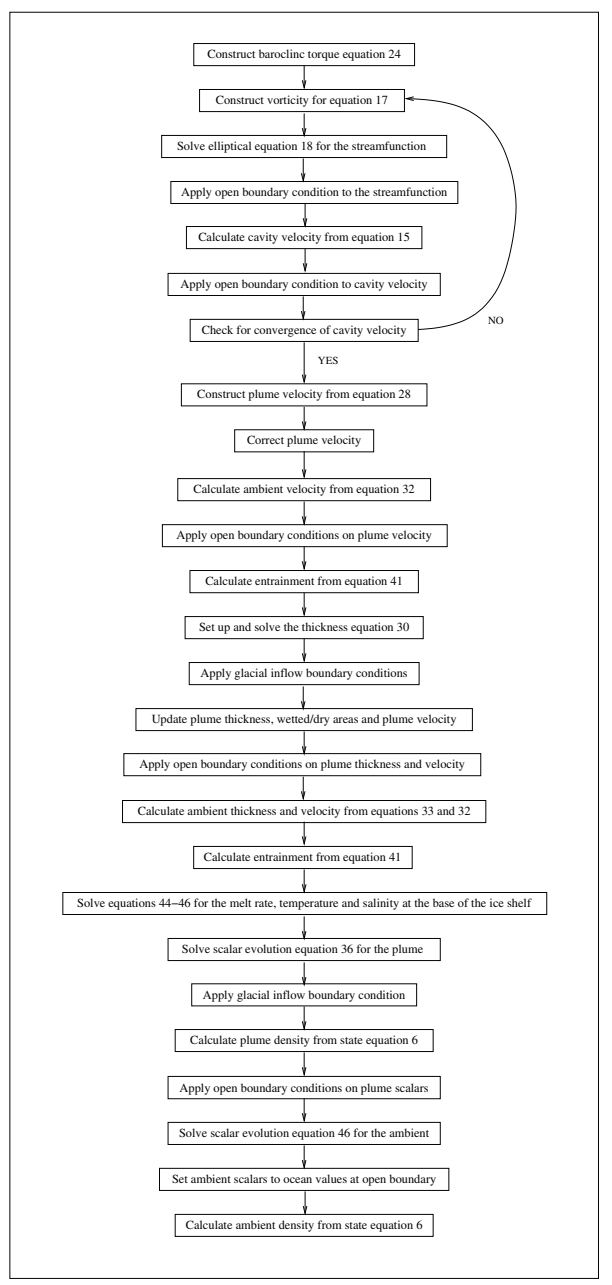

\section{GMDD}

4, 65-136, 2011

\section{A two-layer flow model to represent ice-ocean interactions}

V. Lee et al.

Title Page

Abstract

Conclusions

\section{Tables}

14

4

Back
Introduction

References

Figures

$\rightarrow$

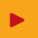

Close

Full Screen / Esc

Printer-friendly Version

Interactive Discussion

Fig. 3. Outline of the numerical scheme during one timestep. 


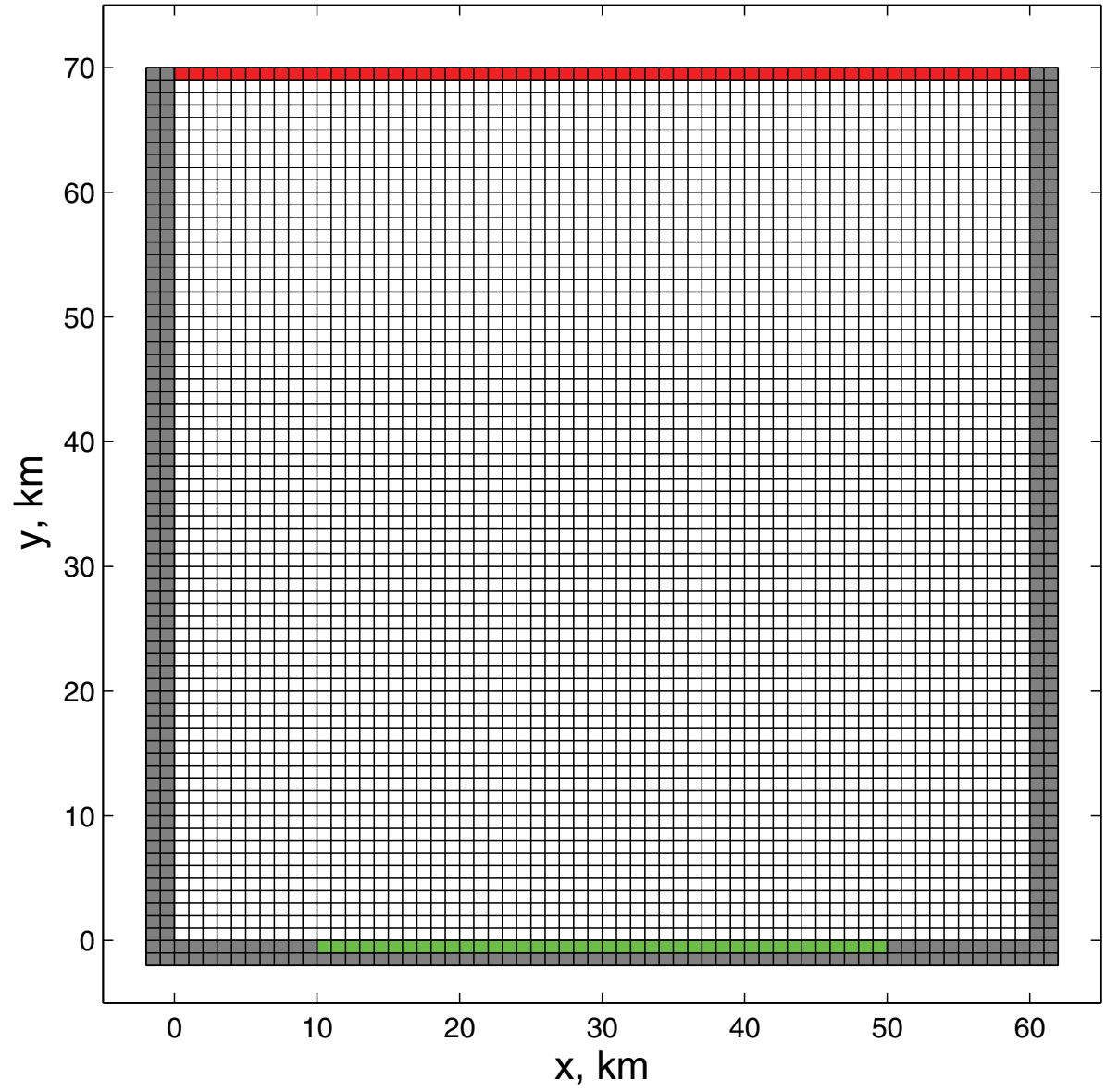

GMDD

4, 65-136, 2011

\section{A two-layer flow model to represent ice-ocean interactions}

V. Lee et al.

Title Page

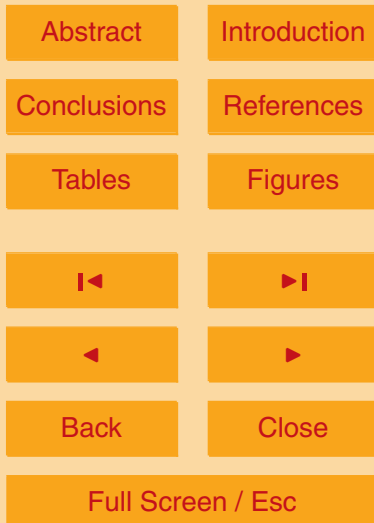

Fig. 4. Computational domain for an idealized cavity beneath Pine Island Ice Shelf. The cells representing the glacial inflow are shaded in dark green, those representing the rigid lateral boundaries are grey and those representing the open boundary are red. 

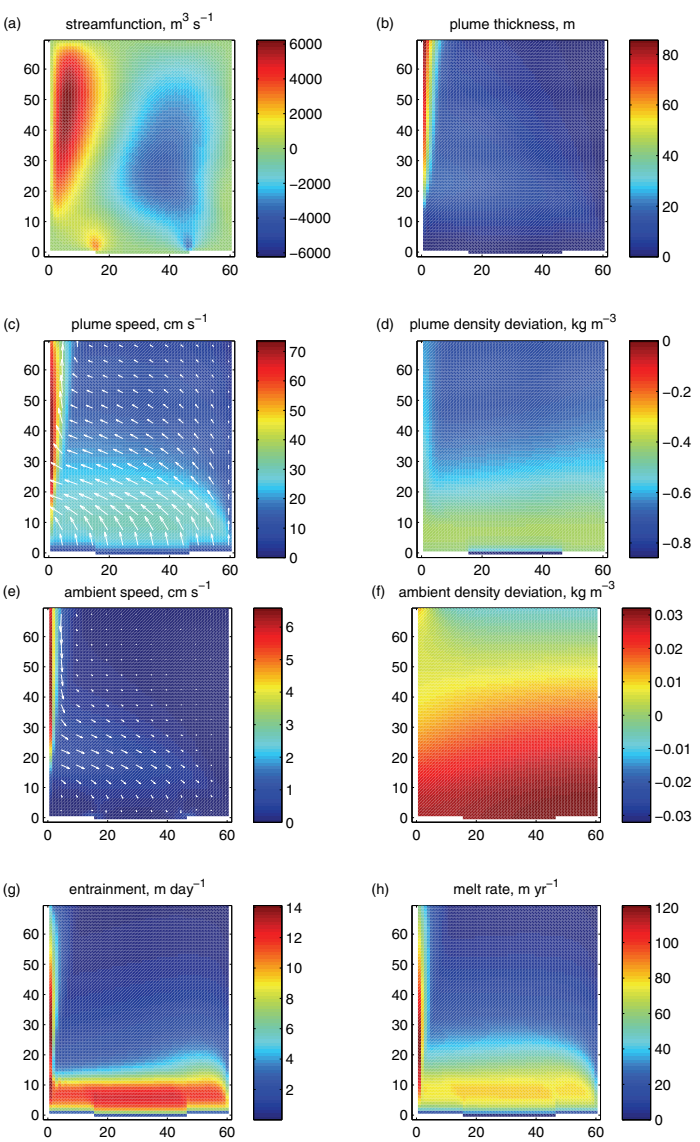

Fig. 5. Temporal mean variable fields for the standard experiment. In (c) and (d) the contours of speed are overlain with velocity direction. Density in panels (d) and (f) is presented as the deviation away from the reference density for seawater, $\rho_{0}$.

\section{GMDD}

4, 65-136, 2011

\section{A two-layer flow model to represent ice-ocean interactions}

V. Lee et al.

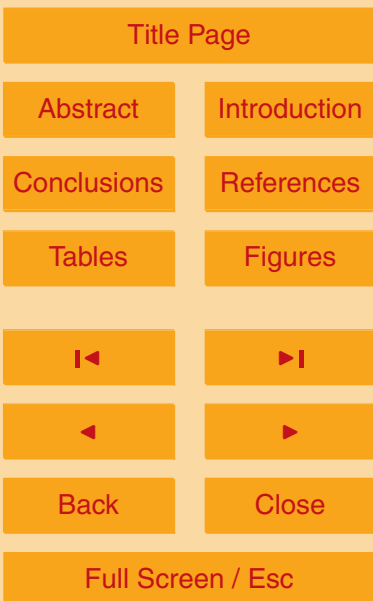

Printer-friendly Version

Interactive Discussion 

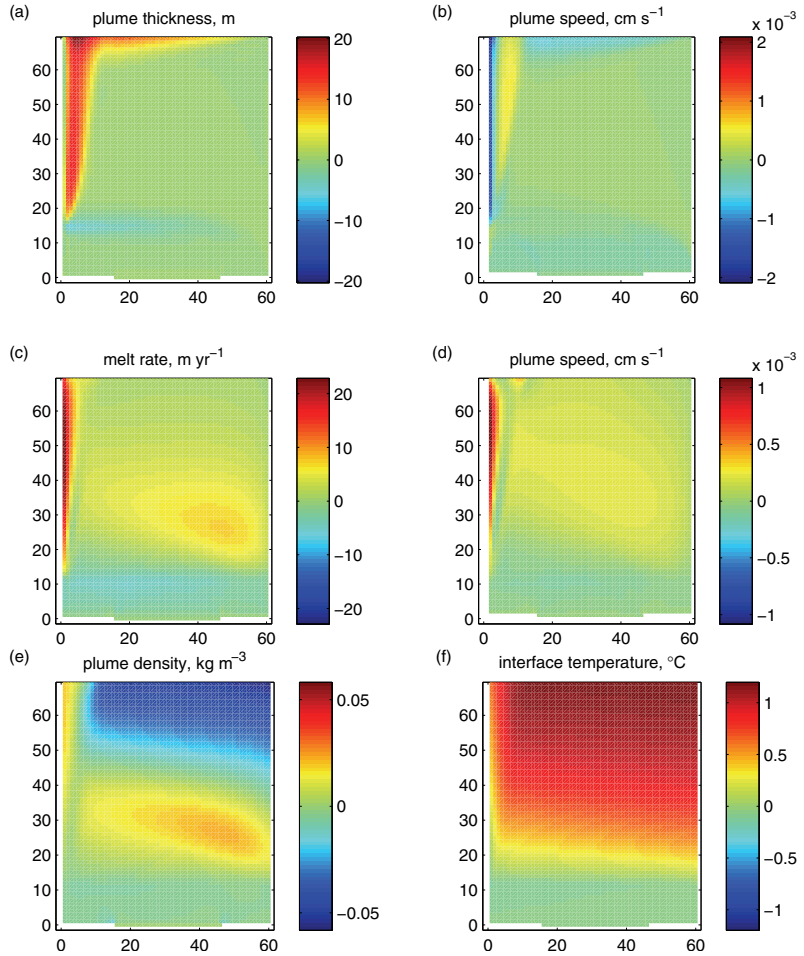

Fig. 6. Comparison of the different models. (a) and (b) show differences between the nonlinear and reduced models in the temporal mean for plume thickness and speed, respectively. (c-f) show differences between the two-layer and reduced models in the temporal mean for melt rates, plume speed and density and interface temperature, respectively.

\section{GMDD}

4, 65-136, 2011

\section{A two-layer flow model to represent ice-ocean interactions}

V. Lee et al.

\section{Abstract}

Title Pag

Introduction

Conclusions

References

\section{Tables}

Figures

14

4

Back

\section{Full Screen / Esc}

Printer-friendly Version

Interactive Discussion 


\section{GMDD}

4, 65-136, 2011
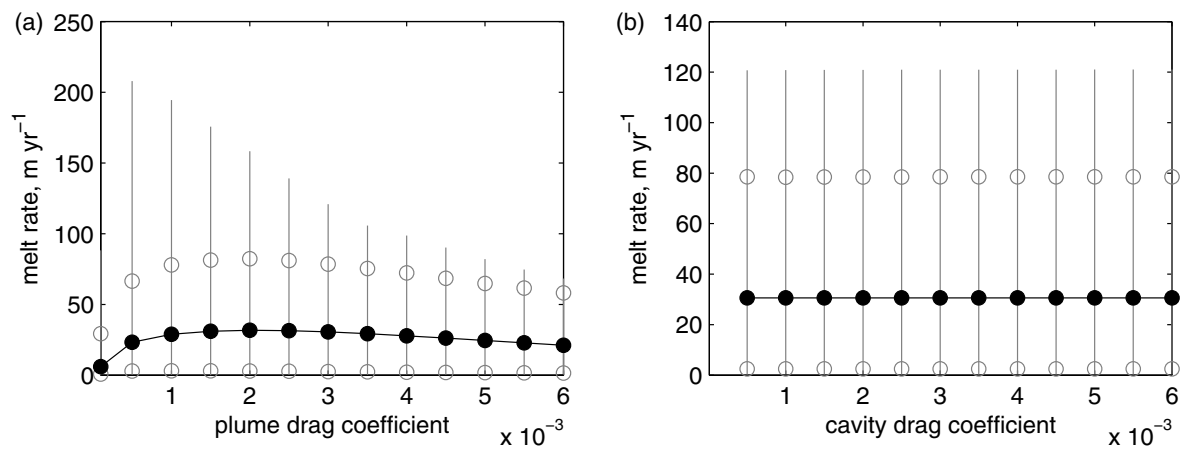

\section{A two-layer flow model to represent ice-ocean interactions}

V. Lee et al.
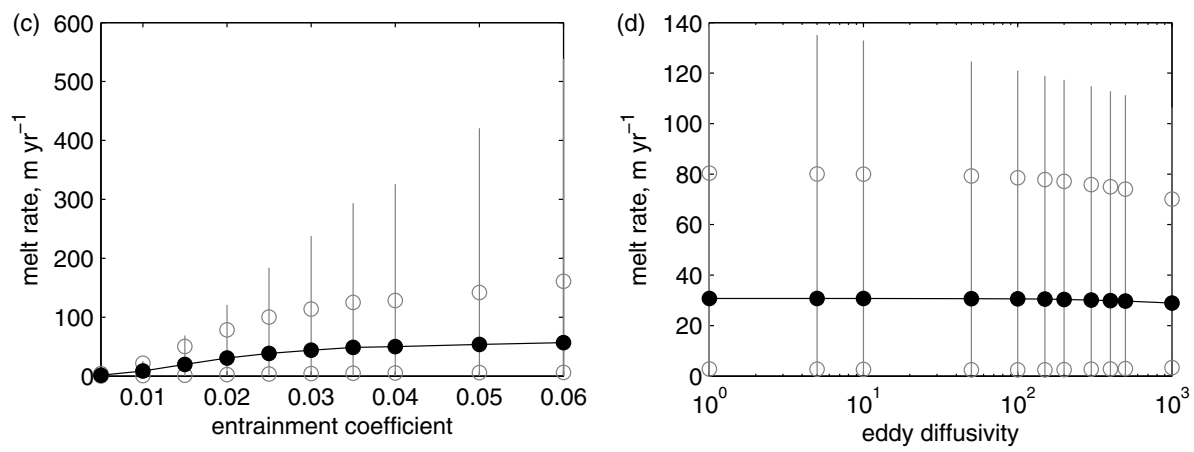

Fig. 7. Melt rates against various flow parameters. Solid circles represent the mean value, open circles the 5th and 95th percentiles. The vertical lines span the full range of the data.

Title Page

\section{Abstract}

Conclusions

\section{Tables}

14

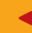

Back

Full Screen / Esc

Printer-friendly Version 


\section{GMDD}

4, 65-136, 2011

\section{A two-layer flow model to represent ice-ocean \\ interactions}
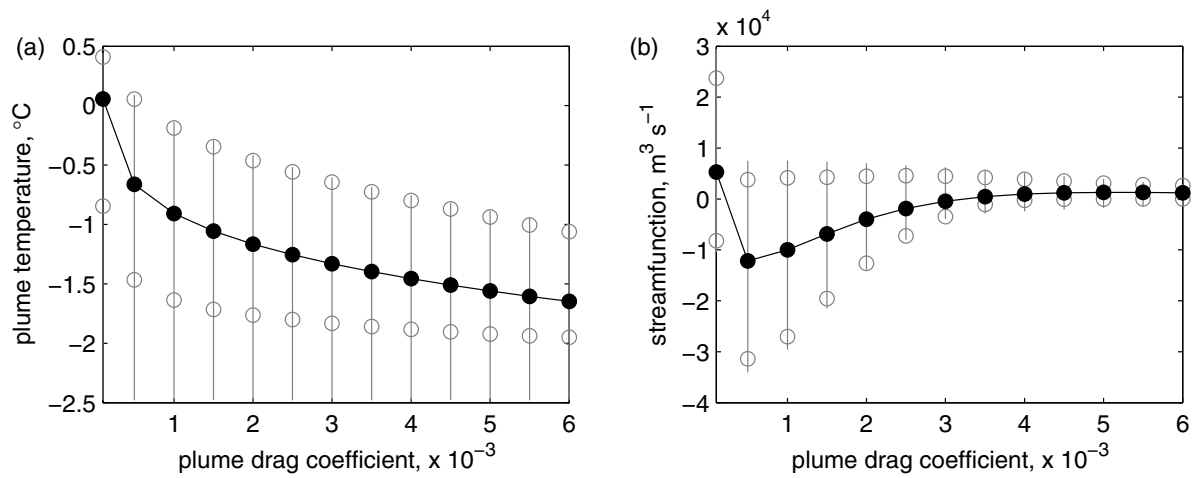

V. Lee et al.

Fig. 8. Plume temperature (a) and streamfunction (b) against plume drag coefficient. Solid circles represent the mean value, open circles the 5th and 95th percentiles. The vertical lines span the full range of the data.

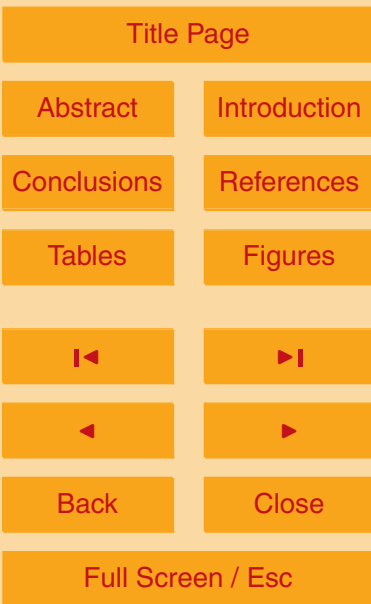

Printer-friendly Version 


\section{GMDD}

4, 65-136, 2011

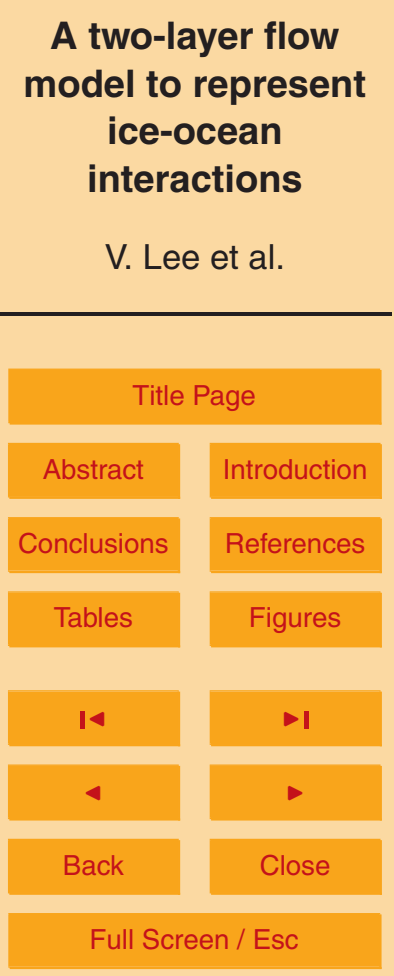

Printer-friendly Version

Interactive Discussion

V. Lee et al.

Full Screen / Esc
Fig. 9. Instantaneous velocity (a) and plume thickness (b) fields at day 50 illustrating numerical problems. (a) Numerical oscillation with $c_{\mathrm{p}}=1.0 \times 10^{-3}$ and $\Delta t=60 \mathrm{~s}$. (b) Vertical striping with $c_{\mathrm{p}}=0.1 \times 10^{-3}$ with $\Delta t=30 \mathrm{~s}$. (a) velocity in y-direction, $\mathrm{cm} \mathrm{s}^{-1}$

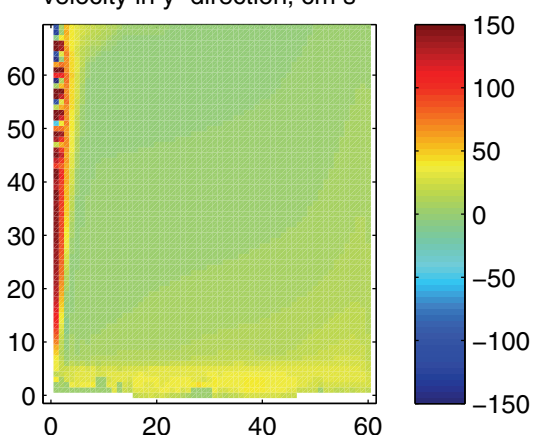

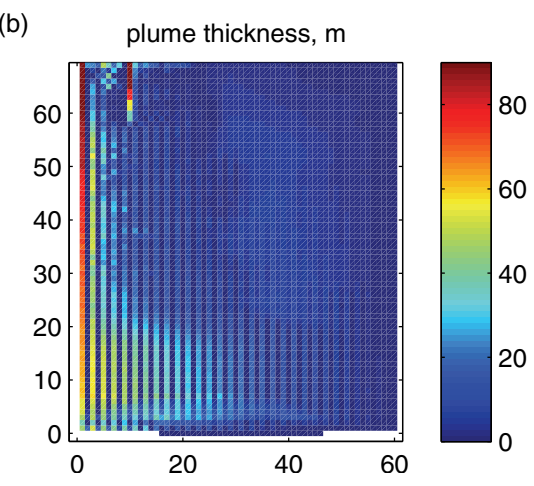

(b) 


\section{GMDD}

4, 65-136, 2011

\section{A two-layer flow model to represent ice-ocean interactions}
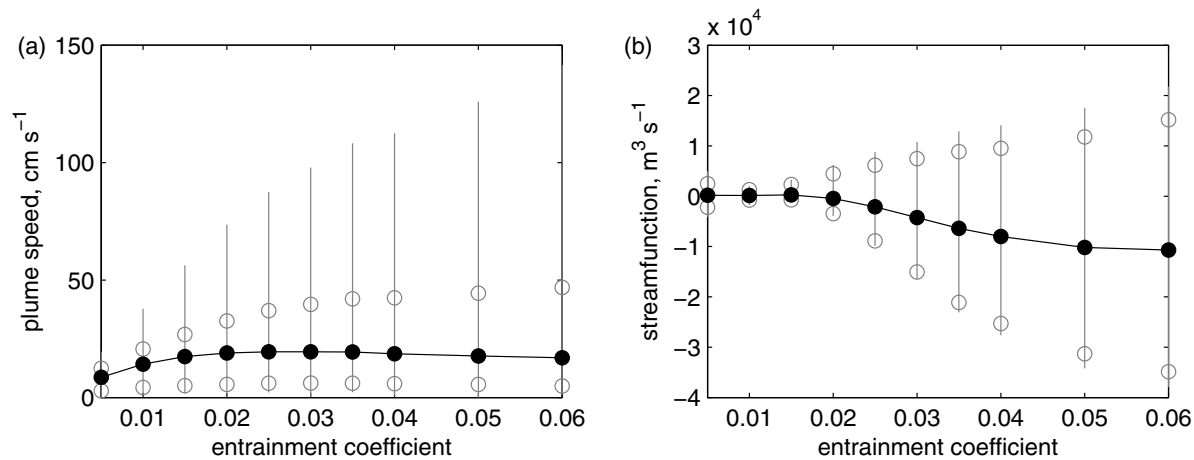

V. Lee et al.

Fig. 10. Plume speed (a) and streamfunction (b) against entrainment coefficient. Solid circles represent the mean value, open circles the 5 th and 95 th percentiles. The vertical lines span the full range of the data. 


\section{GMDD}

4, 65-136, 2011

\section{A two-layer flow model to represent ice-ocean \\ interactions}

(a) velocity in $\mathrm{x}$-direction, $\mathrm{cm} \mathrm{s}^{-1}$

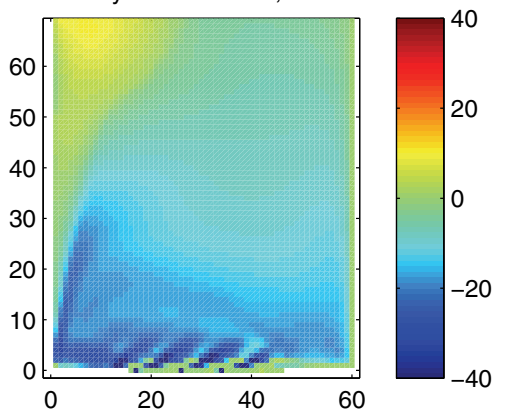

(b)

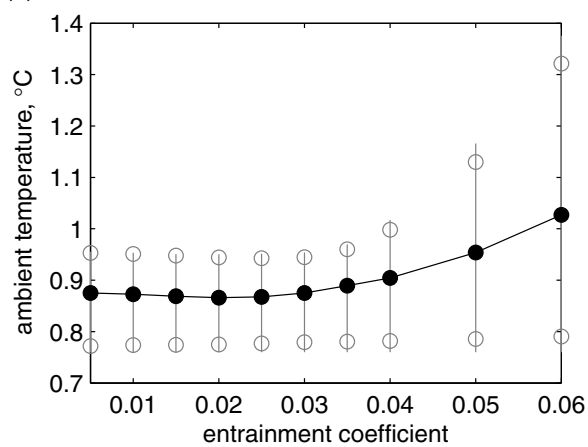

V. Lee et al.

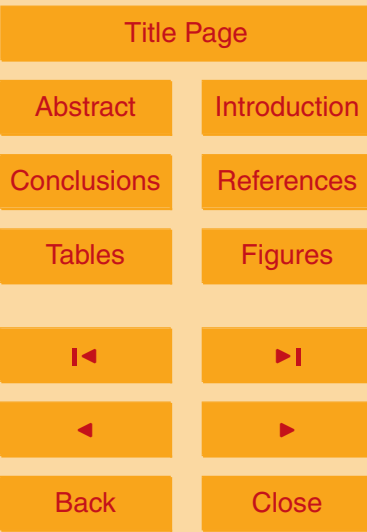

Full Screen / Esc

Printer-friendly Version

Interactive Discussion 


\section{GMDD}

$4,65-136,2011$
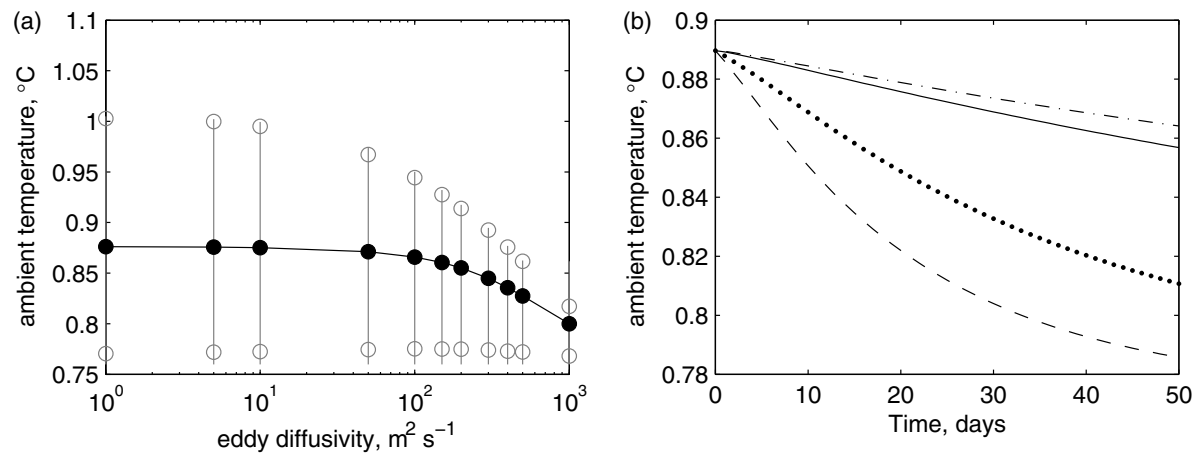

Fig. 12. (a) Time-averaged ambient temperature against eddy diffusivity. Solid circles represent the mean value, open circles the 5th and 95th percentiles. The vertical lines span the full range of the data. (b) Evolution of spatial mean ambient temperature for $K_{\mathrm{h}}=50$ (dash dot), 100 (base value, solid), 500 (dotted) and 1000 (dashed) $\mathrm{m}^{2} \mathrm{~s}^{-1}$.

\section{A two-layer flow model to represent ice-ocean interactions}

V. Lee et al.

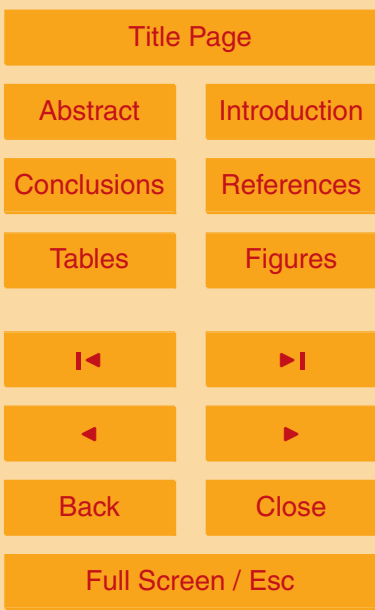

Printer-friendly Version

Interactive Discussion 

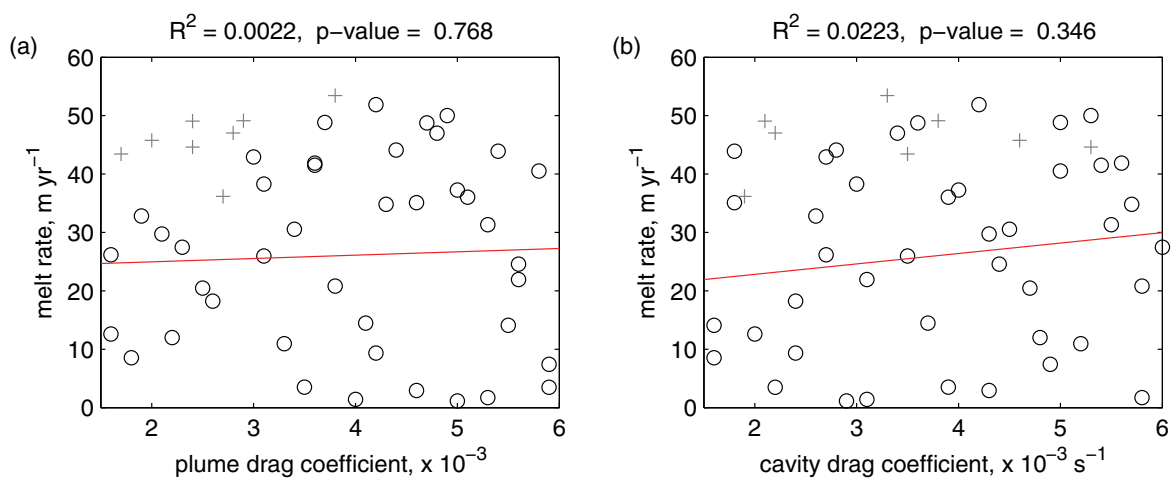

\section{GMDD}

4, 65-136, 2011
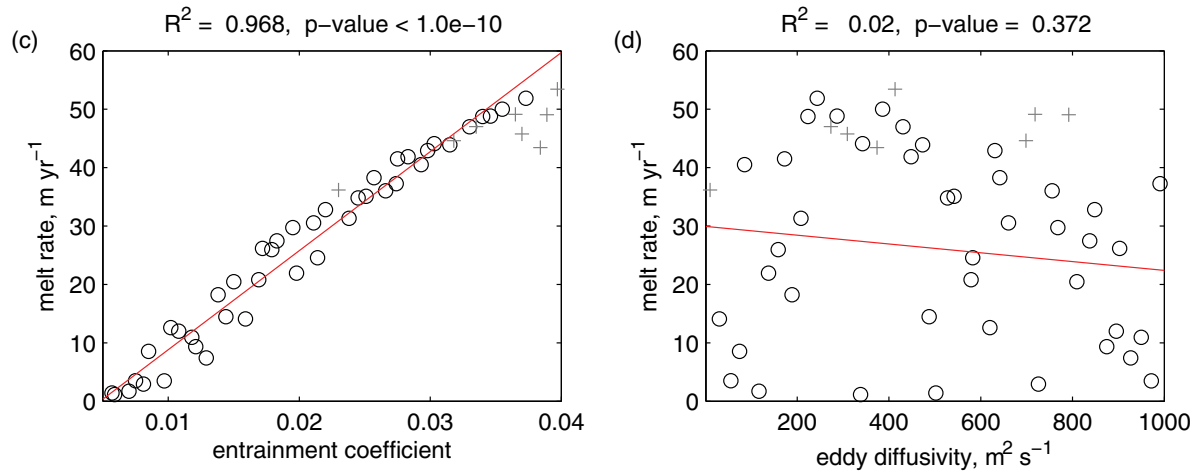

Fig. 13. Latin hypercube experiments for melt rate showing the relationships with (a) plume drag coefficient, (b) cavity drag coefficient, (c) entrainment coefficient and (d) eddy diffusivity. Temporal and spatial mean values marked with a black open circle. The best fit line (red) is calculated using ordinary least squares regression excluding experiments with unphysical results (gray plus).

\section{A two-layer flow model to represent ice-ocean interactions}

V. Lee et al.

\section{Title Page}

\section{Abstract}

Introduction

Conclusions

References

\section{Tables}

Figures

14

4

Back

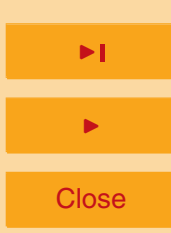

Full Screen / Esc

Printer-friendly Version

Interactive Discussion 

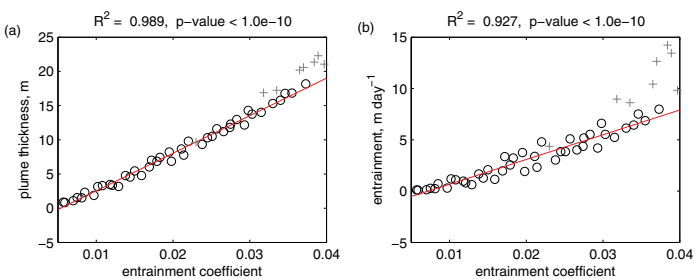

GMDD
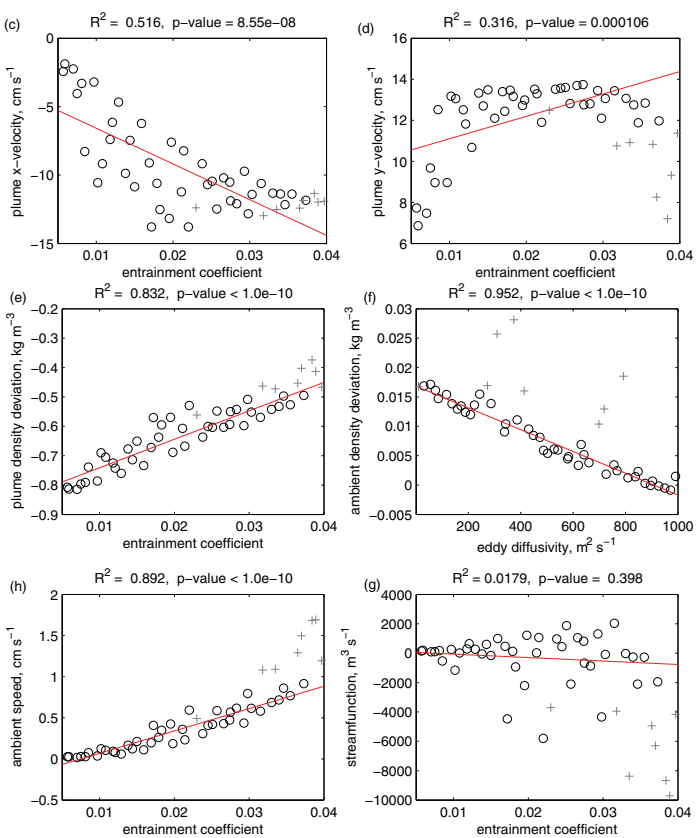

Fig. 14. Linear regression of temporal and spatial mean values with the dominant parameter. (a) Plume thickness, (b) entrainment, (c) and (d) components of plume velocity, (e) plume density deviation, (f) ambient speed and (g) streamfunction are against entrainment coefficient while (g) ambient density deviation is against eddy diffusivity. The best fit line (red) excludes experiments with unphysical results (gray plus).

\section{A two-layer flow model to represent ice-ocean interactions}

V. Lee et al.

\section{Title Page}

\section{Abstract}

Introduction

Conclusions

References

Tables

Figures

14

4

Back

Close

Full Screen / Esc

Printer-friendly Version

Interactive Discussion 